\title{
State-of-the-Art Diffusion Studies in the High Entropy Alloys
}

\author{
Juliusz Dąbrowa * and Marek Danielewski * \\ Faculty of Materials Science and Ceramics, AGH University of Science and Technology, al. Mickiewicza 30, \\ 30-059 Kraków, Poland \\ * Correspondence: dabrowa@agh.edu.pl (J.D.); daniel@agh.edu.pl (M.D.); Tel.: +48-126174013 (J.D.); \\ +48-126173296 (M.D.)
}

Received: 29 December 2019; Accepted: 19 February 2020; Published: 6 March 2020

\begin{abstract}
The development of the high entropy alloys (HEAs) is amongst the most important topics in the field of materials science during the last two decades. The concept of multicomponent, near-equimolar systems has been already applied to the number of other systems, including oxides, carbides, diborides, silicides, and it can be expected that other groups of materials will follow. One of the main driving forces for the development of HEAs is the so-called "four core effects": high entropy effects, severe lattice distortion, cocktail effect, and sluggish diffusion effect. Their existence and extent has been a subject of heated discussion. Probably the least studied of them is the sluggish diffusion effect, which is of the, especially, high importance from the point of view of the most possible applications of HEAs—as high-temperature materials. Its alleged existence carries a promise of obtaining materials with superior mechanical properties, higher creep resistance, and less susceptibility to high-temperature corrosion. In the current review, the state-of-the-art of diffusion studies in HEAs was presented, as well as the resulting conclusions concerning the existence of the sluggish diffusion effect. Based on the literature analysis, it can be stated that there is no experimental evidence, which would support the existence of the sluggish diffusion in HEAs on the level of tracer and self-diffusivities. Nevertheless, it can be pointed out that our current state of knowledge on the diffusion in HEAs is still far from complete; therefore, further directions of studies are proposed.
\end{abstract}

Keywords: high entropy alloys; sluggish diffusion; interdiffusion

\section{Introduction}

During the last decade, the high entropy alloys (HEAs) have become one of the most coveted topics in materials science. The history of their development started in 2004, with simultaneous reports by groups of Cantor et al. [1] and Yeh et al. [2]. In their study, the group of Cantor investigated the possibility of casting a 20-component equimolar alloy (sic!). While the results were far from being successful, with the obtained alloy being multiphase and extremely brittle, they were able to distinguish the formation of the continuous, single-phase matrix based on $\mathrm{Co}, \mathrm{Cr}, \mathrm{Fe}, \mathrm{Mn}$, and Ni. After casting an equimolar alloy based on these elements (commonly known as "Cantor alloy"), they obtained a single-phase solid solution, characterized by FCC (face-centered cubic) structure. Yeh et al. [2] approached the topic of multicomponent alloys in a bit more conservative manner, synthesizing a number of different multicomponent alloys from the Al-Co-Cr-Cu-Fe-Mo-Ni-V-Zr system and its subsystems. The obtained alloys were characterized by surprisingly simple structures, with the number of phases varying from one to four. In most cases, a prominent content of FCC and BCC (body-centered cubic) solid solution phases was observed. What is more, the mechanical properties of these alloys turned out to be very promising, with high hardness, good ductility, and high-temperature strength. As a result of these findings, a vast compositional space of multicomponent, near equimolar 
compositions, previously often considered to be useless, was opened for exploration in search of new metallic materials.

The most common definition of high entropy alloys [3] states that they are alloys based on five or more principal elements (the upper limit is sometimes arbitrarily set at 13), with the concentration of each of them varying between 5 to 35 at.\%. The configurational entropy of such a system reaches a maximum for a disordered solid solution phase, stabilizing, at least in theory, a simple crystal structure. Nowadays, this definition is becoming a bit less strict, with the 4-component, near-equimolar alloys also being commonly included in the high entropy family [4]. Such an approach to the alloys' design drastically differs from the conventional one, in which the alloy is based on one or two principal elements, which impose the main properties of the whole material.

From the very beginning, the high entropy alloys were believed to possess a number of extraordinary properties, distinguishing them from conventional systems. These properties were summarized in 2006 by Yeh [5] into the so-called "four core effects":

- high entropy effects-high configurational entropy tends to stabilize solid solution phases;

- severe lattice distortion-random distribution of atoms in the crystal lattice leads to its distortion and affects mechanical, transport, and thermal properties of the material;

- cocktail effect-synergistic effects, resulting from mutual interactions among composing elements occur, bringing excess quantities to the average values, simply predicted by the mixture rule;

- sluggish diffusion - kinetics of diffusion is hindered in comparison to pure metals and conventional alloys, resulting in smaller values of diffusion coefficients.

The postulate of the core effects existence can be considered a main driving force of HEAs development as it carries the promise of obtaining materials superior to the current ones. What is more, the concept of core effects has been already extended to other groups of high entropy materials, e.g., oxides [6]. However, today the influence or even very existence of these effects is being put in question $[4,7]$. There is a lot of evidence that the stabilizing effect of configurational entropy may have been overstated in the past [8-11]. A similar tendency for overstatement is reported for the lattice distortion in HEAs [12,13], in which case the results do not support the view that it exceeds the values observed in conventional systems. The cocktail effect, defined as a result of synergistic effects, cannot be really treated as specific to HEAs only, as, in fact, it has been used for centuries in conventional alloys, standing behind the concept of alloying additions [4]. As a result, the sluggish diffusion effect remains the core effect, on which we are the farthest from the consensus on the matter of its existence.

\section{Studies of Sluggish Diffusion Studies in High Entropy Alloys}

The "sluggish diffusion effect" has been a vital part of the high entropy alloys theory from the very beginning of their development [5]. Initially proposed back in 2006, it was used to describe the occurrence of nano-precipitates in the casted alloys, which were attributed to the limited effective diffusion transport $[2,14,15]$. In the opinion of these authors, the distorted lattice of HEAs hindered atomic movement, resulting in sluggish transport properties and formation of precipitates of nanometric size due to reduced rates of nucleation and growth. This view was later adopted by several authors to explain their own results, as well as to explain other phenomena, such as, e.g., slow kinetic of oxidation or high creep resistance [16-27]. However, despite the frequent usage of the sluggish diffusion argument, the first direct diffusion studies, performed using the diffusion couple approach, were published by Tsai et al. in 2013 [28], nine years after the first reports concerning the sluggish diffusion phenomenon.

In general, the diffusion studies in HEAs can be grouped into three categories: interdiffusion studies, tracer studies, and theoretical considerations. The summary of the published articles is presented in Table 1. 
Table 1. Summary of the published articles on the subject of diffusion in high entropy alloys.

\begin{tabular}{|c|c|c|c|c|c|}
\hline \multicolumn{6}{|c|}{ Experimental Studies } \\
\hline Studied Systems & Structure & Method & Diffusivities & Notes & Ref. \\
\hline Co-Cr-Fe-Mn-Ni & FCC & $\begin{array}{l}\text { Diffusion } \\
\text { couples/analytical } \\
\text { method }\end{array}$ & $\begin{array}{c}\text { Tracer } \\
\text { diffusivities }\end{array}$ & $\begin{array}{l}\mathrm{CoCrFeMn} \\
\text { composition. Slugerage } \\
\text { diffusion observed in the } \\
\text { temperature scale } \\
\text { normalized with respect to } \\
\text { the melting point. }\end{array}$ & {$[28]$} \\
\hline Co-Cr-Fe-Ni & FCC & $\begin{array}{c}\text { Diffusion } \\
\text { couples/analytical } \\
\text { method }\end{array}$ & Interdiffusivities & $\begin{array}{c}\text { Sluggish behavior reported } \\
\text { in absolute temperature } \\
\text { scale. }\end{array}$ & [29] \\
\hline $\begin{array}{l}\text { Al-Co-Cr-Fe-Ni, } \\
\text { Co-Cr-Fe-Mn-Ni } \\
\text { (reevaluated [28]) }\end{array}$ & FCC & $\begin{array}{l}\text { Diffusion } \\
\text { couples/numerical } \\
\text { method }\end{array}$ & $\begin{array}{c}\text { Tracer } \\
\text { diffusivities }\end{array}$ & $\begin{array}{l}\text { Only absolute temperature } \\
\text { scale considered, } \\
\text { comparable values of } \\
\text { diffusivities for both } \\
\text { systems. }\end{array}$ & {$[30]$} \\
\hline $\begin{array}{l}\text { Co-Cr-Fe-Mn-Ni, } \\
\text { Co-Cr-Fe-Ni }\end{array}$ & FCC & Tracer experiments & $\begin{array}{c}\text { Tracer } \\
\text { diffusivities }\end{array}$ & $\begin{array}{l}\text { Only diffusion of Ni studied, } \\
\text { not necessarily sluggish } \\
\text { diffusion behavior. }\end{array}$ & [31] \\
\hline $\begin{array}{l}\text { Co-Cr-Fe-Mn-Ni, } \\
\text { Co-Cr-Fe-Ni }\end{array}$ & FCC & Tracer experiments & $\begin{array}{c}\text { Tracer } \\
\text { diffusivities }\end{array}$ & $\begin{array}{l}\text { Grain boundary diffusion, } \\
\text { no signs of diffusion } \\
\text { retardation. }\end{array}$ & [32] \\
\hline Co-Cr-Fe-Mn-Ni & FCC & $\begin{array}{l}\text { Diffusion } \\
\text { couples/analytical } \\
\text { method }\end{array}$ & Interdiffusivities & $\begin{array}{l}\text { Good correlation of the } \\
\text { results with assumed } \\
\text { thermodynamics of the } \\
\text { system. }\end{array}$ & {$[33]$} \\
\hline $\begin{array}{l}\text { Co-Cr-Fe-Mn-Ni } \\
\text { and its subsystems }\end{array}$ & FCC & $\begin{array}{c}\text { Diffusion } \\
\text { couples/extrapolation } \\
\text { based on CALPHAD }\end{array}$ & $\begin{array}{c}\text { Tracer } \\
\text { diffusivities }\end{array}$ & $\begin{array}{l}\text { Lack of clearly abnormal } \\
\text { diffusion behavior of 4- and } \\
\text { 5-component systems. }\end{array}$ & {$[34]$} \\
\hline $\mathrm{Co}-\mathrm{Cr}-\mathrm{Fe}-\mathrm{Mn}-\mathrm{Ni}$ & FCC & $\begin{array}{c}\text { Diffusion } \\
\text { multiples/numerical } \\
\text { method }\end{array}$ & $\begin{array}{c}\text { Tracer } \\
\text { diffusivities } \\
\text { Interdiffusivities } \\
\end{array}$ & $\begin{array}{l}\text { Sluggishness of diffusion } \\
\text { visible mainly for the } \\
\text { interdiffusion coefficients. }\end{array}$ & [35] \\
\hline Al-Co-Cr-Fe-Ni & FCC & $\begin{array}{c}\text { Diffusion } \\
\text { multiples/numerical } \\
\text { method }\end{array}$ & $\begin{array}{c}\text { Tracer } \\
\text { diffusivities } \\
\text { Interdiffusivities } \\
\end{array}$ & $\begin{array}{l}\text { Sluggishness of diffusion } \\
\text { visible mainly for the } \\
\text { interdiffusion coefficients. }\end{array}$ & [36] \\
\hline $\mathrm{Co}-\mathrm{Cr}-\mathrm{Cu}-\mathrm{Fe}-\mathrm{Ni}$ & FCC & $\begin{array}{l}\text { Diffusion } \\
\text { multiples/numerical } \\
\text { method }\end{array}$ & $\begin{array}{c}\text { Tracer } \\
\text { diffusivities } \\
\text { Interdiffusivities } \\
\end{array}$ & $\begin{array}{l}\text { Sluggishness of diffusion } \\
\text { visible mainly for the } \\
\text { interdiffusion coefficients. }\end{array}$ & [37] \\
\hline $\mathrm{Al}-\mathrm{Co}-\mathrm{Cr}-\mathrm{Fe}-\mathrm{Ti}-\mathrm{Ni}$ & FCC & $\begin{array}{c}\text { Diffusion } \\
\text { multiples/numerical } \\
\text { method }\end{array}$ & $\begin{array}{c}\text { Tracer } \\
\text { diffusivities } \\
\text { Interdiffusivities } \\
\end{array}$ & $\begin{array}{l}\text { Sluggishness of diffusion } \\
\text { visible mainly for the } \\
\text { interdiffusion coefficients. }\end{array}$ & {$[38]$} \\
\hline $\begin{array}{l}\text { Co-Cr-Fe-Mn-Ni, } \\
\text { Co-Cr-Fe-Ni }\end{array}$ & FCC & Tracer experiments & $\begin{array}{c}\text { Tracer } \\
\text { diffusivities }\end{array}$ & $\begin{array}{l}\text { Continuation of [31] with } \\
\mathrm{Co}, \mathrm{Cr}, \mathrm{Mn} \text {, and } \mathrm{Mn} \text { isotopes. } \\
\text { Lack of proof for existence of } \\
\text { sluggish diffusion. }\end{array}$ & [39] \\
\hline $\begin{array}{l}\text { Co-Cr-Fe-Mn-Ni, } \\
\text { Co-Cr-Fe-Ni }\end{array}$ & FCC & Tracer experiments & $\begin{array}{c}\text { Tracer } \\
\text { diffusivities }\end{array}$ & $\begin{array}{l}\text { Monocrystalline samples, } \\
\text { Co, Cr, Mn, and Mn isotopes. } \\
\text { Good consistency with [39]. }\end{array}$ & {$[40]$} \\
\hline Co-Cr-Fe-Mn-Ni & FCC & Tracer experiments & $\begin{array}{c}\text { Tracer } \\
\text { diffusivities }\end{array}$ & $\begin{array}{c}\mathrm{Co}_{20} \mathrm{Cr}_{20} \mathrm{Fe}_{20} \mathrm{Mn}_{20} \mathrm{Ni}_{20}, \\
\mathrm{Co}_{10} \mathrm{Cr}_{10} \mathrm{Fe}_{10} \mathrm{Mn}_{10} \mathrm{Ni}_{60} \text {, and } \\
\mathrm{Co}_{2} \mathrm{Cr}_{2} \mathrm{Fe}_{2} \mathrm{Mn}_{2} \mathrm{Ni}_{92} \text { alloys, } \\
\text { too small differences to } \\
\text { justify presence of sluggish } \\
\text { diffusion. }\end{array}$ & {$[41]$} \\
\hline $\begin{array}{l}\mathrm{Co}-\mathrm{Cr}-\mathrm{Fe}-\mathrm{Mn}, \mathrm{Ni}, \\
\mathrm{Co}-\mathrm{Cr}-\mathrm{Fe}-\mathrm{Ni}\end{array}$ & FCC & $\begin{array}{c}\text { Diffusion } \\
\text { couples/analytical } \\
\text { method }\end{array}$ & Interdiffusivities & $\begin{array}{c}\text { Determination of } \\
\text { thermodynamic factors, } \\
\text { Co-Cr-Fe-Mn-Ni } \\
\text { significantly deviates from } \\
\text { ideal behavior. }\end{array}$ & {$[42]$} \\
\hline
\end{tabular}


Table 1. Cont.

\begin{tabular}{|c|c|c|c|c|c|}
\hline \multicolumn{6}{|c|}{ Experimental Studies } \\
\hline Studied Systems & Structure & Method & Diffusivities & Notes & Ref. \\
\hline $\mathrm{Co}-\mathrm{Cr}-\mathrm{Fe}-\mathrm{Mn}-\mathrm{Ni}$ & FCC & $\begin{array}{l}\text { Combined diffusion } \\
\text { couple and tracer } \\
\text { experiments }\end{array}$ & $\begin{array}{l}\text { Composition } \\
\text { dependent } \\
\text { atomic } \\
\text { mobilities }\end{array}$ & $\begin{array}{l}\text { Verification of the available } \\
\text { mobility databases, diffusion } \\
\text { behavior typical for the FCC } \\
\text { alloys. }\end{array}$ & {$[43]$} \\
\hline $\begin{array}{c}\text { Co-Cr-Fe-Mn-Ni, } \\
\text { Co-Cr-Fe-Ni, } \\
\text { Co-Fe-Mn-Ni }\end{array}$ & FCC & $\begin{array}{l}\text { Diffusion } \\
\text { couples/numerical } \\
\text { method }\end{array}$ & $\begin{array}{c}\text { Tracer } \\
\text { diffusivities }\end{array}$ & $\begin{array}{l}\text { The same matrix of tracer } \\
\text { diffusivities was used to all } \\
\text { three systems } \\
\text { simultaneously, lack of } \\
\text { difference between } 4 \text { - and } \\
\text { 5-component systems. }\end{array}$ & {$[44]$} \\
\hline $\begin{array}{c}\text { Co-Cr-Fe-Mn-Ni, } \\
\text { Co-Cr-Fe-Ni, } \\
\text { Co-Fe-Mn-Ni, } \\
\text { Co-Cr-Mn-Ni, } \\
\text { Al-Co-Cr-Fe-Ni } \\
\text { (reevaluated [30]) }\end{array}$ & FCC & $\begin{array}{l}\text { Diffusion } \\
\text { couples/numerical } \\
\text { method }\end{array}$ & $\begin{array}{c}\text { Tracer } \\
\text { diffusivities }\end{array}$ & $\begin{array}{l}\text { Analysis of both absolute } \\
\text { and normalized temperature } \\
\text { scales, sluggishness in the } \\
\text { latter observed only for } \\
\text { systems with Mn. }\end{array}$ & {$[45]$} \\
\hline \multicolumn{6}{|c|}{ Theoretical studies } \\
\hline $\begin{array}{l}\text { Co-Cr-Fe-Mn-Ni } \\
\text { (data from [28]) }\end{array}$ & FCC & $\begin{array}{l}\text { Quasi-binary } \\
\text { approach }\end{array}$ & - & $\begin{array}{l}\text { Critique of the approach } \\
\text { applied by Tsai et al. in [28]. }\end{array}$ & [46] \\
\hline $\begin{array}{l}\text { Co-Cr-Fe-Mn-Ni } \\
\text { (data from [28]) }\end{array}$ & FCC & $\begin{array}{l}\text { Quasi-binary } \\
\text { approach }\end{array}$ & - & Replay to [46]. & {$[47]$} \\
\hline $\begin{array}{l}\text { Co-Cr-Fe-Mn-Ni } \\
\text { (data from [28]) }\end{array}$ & FCC & Data analysis & - & $\begin{array}{l}\text { Analysis of the results from } \\
\text { [28] in comparison to other } \\
\text { FCC systems, confirmation } \\
\text { of the diffusion } \\
\text { sluggishness. }\end{array}$ & {$[48]$} \\
\hline - & - & $\begin{array}{l}\text { Moleko-Alnatt-Allnatt } \\
\text { (MAA) formalism }\end{array}$ & - & $\begin{array}{l}\text { Development of the } \\
\text { MAA-light approach for } \\
\text { evaluation of diffusion data } \\
\text { in HEAs. }\end{array}$ & [49] \\
\hline $\begin{array}{l}\text { Co-Cr-Fe-Mn-Ni } \\
\text { (data from [28]) }\end{array}$ & FCC & $\begin{array}{l}\text { Data analysis with } \\
\text { use of Darken, } \\
\text { Manning-Holdsworth-E } \\
\text { and MAA-light } \\
\text { approaches }\end{array}$ & $\begin{array}{l}\text { Self-diffusion } \\
\text { lliot } 6 \text { efficients }\end{array}$ & $\begin{array}{l}\text { Evaluation of the data from } \\
\text { [28] with use of different } \\
\text { methodologies. }\end{array}$ & {$[50]$} \\
\hline- & - & Review article & - & - & [51] \\
\hline
\end{tabular}

Still, at the current stage of studies, all subsequent studies benefit from all previous ones, without looking at this classification. Therefore, especially for the experimental studies, the most convincing way to present the state-of-the-art seems to be chronological order. Also, several groups became specialized in the topic of diffusion in HEAs; therefore, whenever possible, studies authored by the same teams were grouped together, allowing following the advancements made by each of them. It is also worth to point out that in all currently published studies, it is assumed that the diffusion in high entropy alloys occurs via the vacancy mechanism, which is further supported by the recent results of positron and neutron diffraction measurements performed by Huang et al. [52]. Based on these results, obtained for the CoCrFeNi and CoCrFeMnNi equimolar alloys, it can be said that the enthalpy of vacancy formation in high entropy alloys is lower than in pure, FCC-structured elements (Cu was used as a reference). However, it was also shown that the formation energy of the vacancy could strongly depend on the elements in the system, as, e.g., the presence of the $\mathrm{Mn}$ in $\mathrm{CoCrFeMnNi}$ significantly lowered this value, which was already suggested based on the diffusion behavior by Vaidya et al. [39] and further supported by Dabrowa et al. [45]. Therefore, it is always important to distinguish between 
features characteristic for the whole family of high entropy alloys and features resulting from the element-dependent effects, which may lead to incorrect conclusions and generalizations.

\subsection{State-of-the-Art of the Experimental Studies}

As already mentioned, the first article, which focused strictly on the diffusion in high entropy alloys, was published by Tsai et al. in 2013 [28]. Being the first one, it deserves special attention, as the published results shaped the following diffusion studies in HEAs. For the experimental part of the study, the Co-Cr-Fe-Mn-Ni metallic system was selected by the authors. At the time, this system was viewed as an extremely stable one (what is still true, although its stability is limited to the high-temperature region $[53,54]$ ). Another advantage of such choice was the relatively low chemical interactions between the elements (see Table 2), which, in the opinion of the authors, justified the application of the ideal solution assumption.

Table 2. Selected values of interaction parameters calculated by Miedema's scheme within the framework of the sub-regular solution model [55]. Only the zero-order coefficients $\Omega_{0}$ are presented.

\begin{tabular}{ccccccc}
\hline & Al & Co & Cr & Fe & Mn & Ni \\
\hline Al & - & -18.8 & -9.9 & -11.1 & -19.1 & -22.3 \\
Co & -18.8 & - & -4.5 & -0.6 & -5.2 & -0.2 \\
Cr & -9.9 & -4.5 & - & -1.5 & 2.1 & -6.7 \\
$\mathbf{F e}$ & -11.1 & -0.6 & -1.5 & - & 0.2 & -1.6 \\
$\mathbf{M n}$ & -19.1 & -5.2 & 2.1 & 0.2 & - & -8.2 \\
$\mathbf{N i}$ & -22.3 & -0.2 & -6.7 & -1.6 & -8.2 & - \\
\hline
\end{tabular}

The experimental part of the study was carried out with the use of diffusion couples technique. In this technique, typical for interdiffusion studies, two different alloys (end members) are put together and annealed, in order to obtain a diffusion joint. The authors incorporated the quasi-binary approach [56], meaning that in each diffusion couple, only two out of five elements exhibited a concentration gradient, with other components being kept on a constant level. Three different types of couples were prepared; the summary of their compositions is presented in Table 3.

Table 3. Composition of the end members in diffusion couples used by Tsai et al. [28].

\begin{tabular}{cccccc}
\hline \multirow{2}{*}{ Couple } & \multicolumn{5}{c}{ Composition (at.\%) } \\
\cline { 2 - 6 } & Co & Cr & Fe & Mn & Ni \\
\hline \multirow{2}{*}{ Cr-Mn } & 22 & 29 & 22 & 5 & 22 \\
& 22 & 17 & 22 & 17 & 22 \\
\hline \multirow{2}{*}{ Fe-Co } & 33 & 23 & 11 & 11 & 22 \\
& 11 & 23 & 33 & 11 & 22 \\
\hline \multirow{2}{*}{ Fe-Ni } & 23 & 24 & 30 & 11 & 12 \\
& 23 & 24 & 12 & 11 & 30 \\
\hline
\end{tabular}

The couples were annealed at four different temperatures: 1173, 1223, 1273, and $1323 \mathrm{~K}$. The quasi-binary approach was essential from the data analysis point of view. The authors started from the Fick's 2nd law for the interdiffusion, written for the $r-1$ independent components in the system:

$$
\frac{\partial c_{i}}{\partial t}=\sum_{j=1}^{r-1} \frac{\partial}{\partial x}\left(\tilde{D}_{i j}^{r} \frac{\partial c_{j}}{\partial x}\right)(i=1,2, \ldots, r-1),
$$

where $\tilde{D}_{i j}^{r}$ is an interdiffusion coefficient with the $r$-th component, treated as a reference one, and $c_{i}$ is a molar concentration of the $i$-th component. Determination of the diffusivities values in such 
case is possible, e.g., with the use of the extension of the Boltzmann-Matano method, proposed by Kirkaldy [56]:

$$
\int_{c_{i}^{+\infty}}^{c_{i}}\left(x-x_{0}\right) d c_{i}=-2 t \sum_{j=1}^{r-1} \tilde{D}_{i j}^{r} \frac{\partial c_{j}}{\partial x}(i=1,2, \ldots, r-1) .
$$

However, it requires $r-1$ independent couples with a common composition on their diffusion path, which is almost impossible to achieve in systems with more than three components. The use of the quasi-binary approach allowed simplifying the problem to the equation for the binary system:

$$
\int_{c_{i}^{+\infty}}^{c_{i}}\left(x^{*}-x_{0}\right) d c_{1}=-2 t \cdot \tilde{D}_{11}^{2} \frac{\partial c_{1}}{\partial x}
$$

where superscript * refers to the considered position within the sample. To eliminate the errors connected with the determination of the Matano plane position, the final equation used by Tsai et al. in order to obtain the values of diffusion coefficients was Equation (3) modified with the use of Sauer-Fraise method:

$$
\tilde{D}\left(c^{*}\right)=\frac{1}{2 t(d c / d x)_{x *}}\left[(1-Y) \int_{-\infty}^{x^{*}}\left(c^{*}-c^{-}\right) d x+Y \int_{x^{*}}^{\infty}\left(c^{+}-c^{*}\right) d x\right],
$$

where:

$$
Y=\frac{c^{*}-c^{-}}{c^{+}-c^{*}}
$$

The use of such an approach allows obtaining one interdiffusion coefficient, a characteristic for a given couple and common for both elements (the ones with gradients of concentration). However, in the opinion of the Tsai et al., it is possible to obtain two interdiffusion coefficients as a result of separate analysis of profiles for both component 1 and component 2 . While in a conventional, binary system, such an approach will make no difference, as the sum of molar fractions $n_{1}+n_{2}=1$, in a quasi-binary system, presence of, e.g., uphill effects on elements 3, 4, and 5 indeed differentiate the profiles for elements 1 and $2\left(n_{1}+n_{2} \neq\right.$ const). Still, the claim that it is possible to obtain two different interdiffusion coefficients from the singular diffusion couple is very controversial and even became a subject of heated discussion, which has been described later on. Further assumptions by a group of Tsai et al. included:

- $\quad$ since the movement of markers was negligible (very small Kirkendall effect, positions of Kirkendall and Matano planes were nearly the same), the interdiffusion coefficients were treated as intrinsic ones,

- the vacancies were assumed to be in equilibrium, and contributions of vacancy wind and correlation factors were deemed negligible; therefore, the non-diagonal elements in the matrix of Onsager's phenomenon diffusion coefficients $L_{i j}$ were eliminated,

- the system was treated as an ideal one; therefore, the activity coefficients were equal to 1 , and intrinsic diffusion coefficients were treated as indifferent from tracer ones.

In Figure 1, the obtained tracer values of diffusion coefficients are presented with the use of the Arrhenius plot. The determined sequence of decreasing diffusion rate was as follows: $D_{\mathrm{Mn}}^{*}>D_{\mathrm{Cr}}^{*}>$ $D_{\mathrm{Fe}}^{*}>D_{\mathrm{Co}}^{*}>D_{\mathrm{Ni}^{\prime}}^{*}$ similar to the one observed in conventional alloys [28]. 


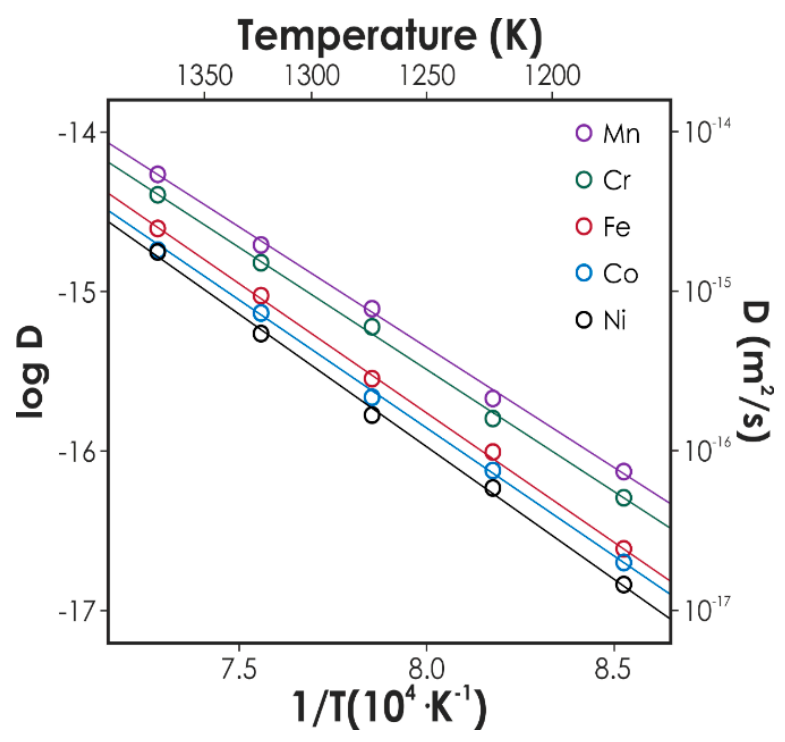

Figure 1. Temperature dependence of the tracer diffusion coefficients for all components in the Co-Cr-Fe-Mn-Ni system (after [28]). Reprinted from Acta Materialia 61 (2013), Sluggish diffusion in Co-Cr-Fe-Mn-Ni high-entropy alloys, 4887-4897 Copyright 2013, with permission from Elsevier.

Based on the Arrhenius plots, the authors managed to determine the activation energies of diffusion, according to the Arrhenius relation (for a given element):

$$
D^{*}=D_{0} \exp \left(-\frac{E_{a}}{R T}\right)
$$

where $E_{a}$ is the activation energy of the $i$-th component, and $D_{0}$ is the pre-exponential factor for the $i$-th component. Summary of the values of tracer diffusivities and energies of activation is presented in Table 4 , together with values for some of the conventional systems.

Table 4. Diffusion parameters for $\mathrm{Cr}, \mathrm{Mn}, \mathrm{Fe}, \mathrm{Co}$, and Ni in different matrices $[28,57,58]$.

\begin{tabular}{|c|c|c|c|c|c|c|}
\hline Solute & System & $D_{0}\left(10^{-4} \mathrm{~m}^{2} \cdot \mathrm{s}^{-1}\right)$ & $E_{a}\left(\mathrm{~kJ} \cdot \mathrm{mol}^{-1}\right)$ & $T_{m}(\mathrm{~K})$ & $E_{a} / T_{m}$ & $D_{T m}^{*}\left(10^{-13} \mathrm{~m}^{2} \cdot \mathrm{s}^{-1}\right)$ \\
\hline \multirow{8}{*}{$\mathrm{Cr}$} & CoCrFeMnNi & 5.59 & 292.9 & 1607 & 0.1823 & 1.69 \\
\hline & $\mathrm{Fe}(\mathrm{FCC})$ & 10.8 & 291.8 & 1812 & 0.1610 & 41.9 \\
\hline & Co & 0.084 & 253.7 & 1768 & 0.1435 & 2.69 \\
\hline & $\mathrm{Ni}$ & 5.2 & 289 & 1728 & 0.1673 & 9.55 \\
\hline & $\mathrm{Fe}-15 \mathrm{Cr}-20$ & 8.3 & 309 & 1731 & 0.1785 & 3.94 \\
\hline & $\mathrm{Fe}-15 \mathrm{Cr}-45 \mathrm{Ni}$ & 4 & 293 & 1697 & 0.1727 & 3.83 \\
\hline & $\mathrm{Fe}-22 \mathrm{Cr}-45 \mathrm{Ni}$ & 4.1 & 295 & 1688 & 0.1748 & 3.05 \\
\hline & $\mathrm{Fe}-15 \mathrm{Cr}-20 \mathrm{Ni}-\mathrm{Si}$ & 7.1 & 303 & 1705 & 0.1777 & 3.70 \\
\hline \multirow{4}{*}{$\mathrm{Mn}$} & CoCrFeMnNi & 5.01 & 288.4 & 1607 & 0.1794 & 2.12 \\
\hline & $\mathrm{Fe}(\mathrm{FCC})$ & 0.019 & 240.8 & 1812 & 0.1329 & 2.17 \\
\hline & $\mathrm{Co}$ & 0.093 & 243.7 & 1768 & 0.1378 & 5.87 \\
\hline & $\mathrm{Ni}$ & 7.5 & 280.9 & 1728 & 0.1626 & 24.2 \\
\hline \multirow{8}{*}{$\mathrm{Fe}$} & CoCrFeMnNi & 15.1 & 309.6 & 1607 & 0.1927 & 1.30 \\
\hline & $\mathrm{Fe}(\mathrm{FCC})$ & 0.46 & 284.1 & 1812 & 0.1568 & 2.97 \\
\hline & Co & 0.21 & 262.5 & 1768 & 0.1485 & 3.69 \\
\hline & $\mathrm{Ni}$ & 1 & 269.4 & 1728 & 0.1559 & 7.19 \\
\hline & Fe-15Cr-20 & 5.3 & 308 & 1731 & 0.1779 & 2.69 \\
\hline & $\mathrm{Fe}-15 \mathrm{Cr}-45 \mathrm{Ni}$ & 2.1 & 288 & 1697 & 0.1697 & 2.87 \\
\hline & $\mathrm{Fe}-22 \mathrm{Cr}-45 \mathrm{Ni}$ & 1.5 & 286 & 1688 & 0.1694 & 2.12 \\
\hline & Fe-15Cr-20Ni-Si & 5.1 & 303 & 1705 & 0.1777 & 2.66 \\
\hline
\end{tabular}


Table 4. Cont.

\begin{tabular}{|c|c|c|c|c|c|c|}
\hline Solute & System & $D_{0}\left(10^{-4} \mathrm{~m}^{2} \cdot \mathrm{s}^{-1}\right)$ & $E_{a}\left(\mathrm{~kJ} \cdot \mathrm{mol}^{-1}\right)$ & $T_{m}(\mathrm{~K})$ & $E_{a} / T_{m}$ & $D_{T m}^{*}\left(10^{-13} \mathrm{~m}^{2} \cdot \mathrm{s}^{-1}\right)$ \\
\hline \multirow{4}{*}{ Co } & $\mathrm{CoCrFeMnNi}$ & 9.26 & 306.9 & 1607 & 0.1910 & 0.98 \\
\hline & $\mathrm{Fe}(\mathrm{FCC})$ & 1.12 & 301.9 & 1812 & 0.1666 & 2.22 \\
\hline & Co & 0.55 & 288.7 & 1768 & 0.1633 & 1.63 \\
\hline & $\mathrm{Ni}$ & 2.26 & 283.6 & 1728 & 0.1641 & 6.05 \\
\hline \multirow{8}{*}{$\mathrm{Ni}$} & CoCrFeMnNi & 19.7 & 317.5 & 1607 & 0.1975 & 0.95 \\
\hline & $\mathrm{Fe}(\mathrm{FCC})$ & 3 & 314 & 1812 & 0.1733 & 2.66 \\
\hline & $\mathrm{Co}$ & 0.43 & 282.2 & 1768 & 0.1596 & 1.98 \\
\hline & $\mathrm{Ni}$ & 1.77 & 285.3 & 1728 & 0.1651 & 4.21 \\
\hline & $\mathrm{Fe}-15 \mathrm{Cr}-20$ & 1.5 & 300 & 1731 & 0.1733 & 1.33 \\
\hline & $\mathrm{Fe}-15 \mathrm{Cr}-45 \mathrm{Ni}$ & 1.8 & 293 & 1697 & 0.1727 & 1.73 \\
\hline & $\mathrm{Fe}-22 \mathrm{Cr}-45 \mathrm{Ni}$ & 1.1 & 291 & 1688 & 0.1724 & 1.09 \\
\hline & Fe-15Cr-20Ni-Si & 4.8 & 310 & 1705 & 0.1818 & 1.53 \\
\hline
\end{tabular}

$D_{0}$-preexponential factor, $E_{a}$-energy of activation, $T_{m}$-melting point, $D_{T m}^{*}$-diffusion coefficient at melting temperature.

The obtained values of energies of activation were relatively high in comparison to the conventional alloys, especially after normalization with respect to the melting point $T_{m}$ (determined by the authors to be $1607 \mathrm{~K}$, presumably a liquidus temperature based on the comparison with literature values). The values of diffusivities, presented with the use of the Arrhenius plot and normalized with respect to $T_{m}$, are presented in Figure 2.

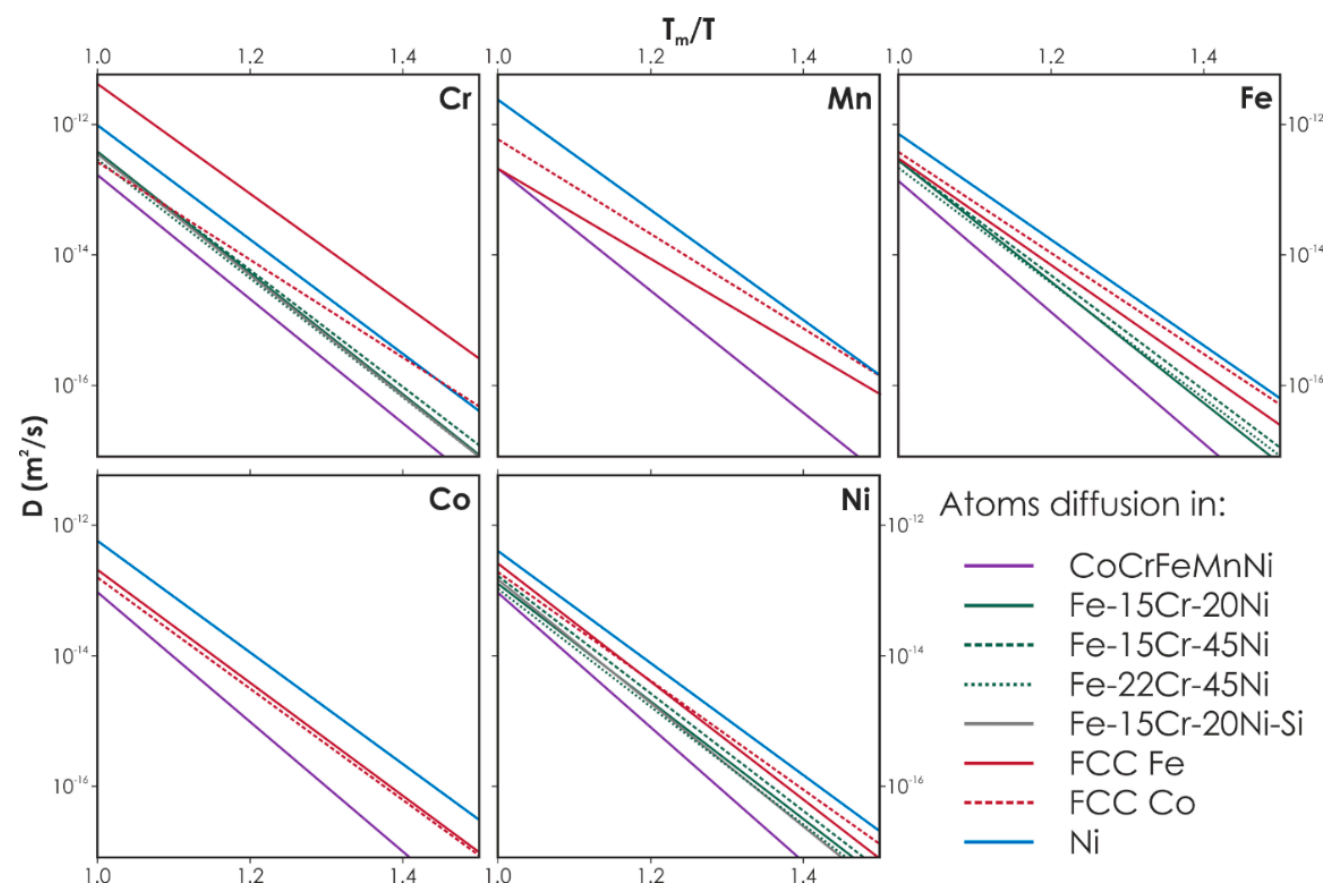

Figure 2. Temperature dependence of the tracer diffusion coefficients for $\mathrm{Cr}, \mathrm{Mn}, \mathrm{Fe}, \mathrm{Co}$, and $\mathrm{Ni}$ in different matrices (after [28]), presented as a function of the normalized temperature. Reprinted from Acta Materialia 61 (2013), Sluggish diffusion in Co-Cr-Fe-Mn-Ni high-entropy alloys, 4887-4897 Copyright 2013, with permission from Elsevier.

As can be seen, after such interpretation of the data, the values of tracer diffusivities were clearly smaller than in the case of conventional alloys and pure metals, which led the authors to the conclusion that diffusion in high entropy alloys is indeed sluggish. To explain the origins of such behavior, Tsai et al. proposed a quasi-chemical model, which took into account the fluctuations of the lattice potential energy (LPE). Due to the presence of a very high number of components and their stochastic distribution within the lattice, each lattice site has different overall interaction energy 
with the surrounding. Based on the seven-bond interaction energy (SBIE) model [59], the authors calculated the interaction energies for singular bonds, determined all possible configurations of the seven neighbors and probability of occurrence for each configuration. Then, to compare the results with other materials, the probability distributions of SBIE for $\mathrm{Ni}$ in different matrices were calculated (for HEA, the average composition $\mathrm{CoCrFeMn}_{0.5} \mathrm{Ni}$ was considered). It turned out that the considered HEA had a much wider distribution of SBIE than ternary alloys. Such effect resulted from the fact that while for ternary systems, there are 36 different combinations of seven neighbors, in the case of quinary alloy, we have to consider 330 such combinations. Additionally, the strongly negative interaction between $\mathrm{Mn}$ and $\mathrm{Ni}$ was also reflected, as a significant spread towards negative values of SBIE could be observed. According to Tsai et al., similar behavior was observed not only for Ni but for all other elements in the system as well. The authors pointed out that such behavior is much more likely to occur only in HEAs, as in the alloys with a smaller number of components, it would most likely lead to phase separation. Since in HEAs, all components are "diluted" (e.g., the content of the strongest $\mathrm{Mn}-\mathrm{Ni}$ bonds is just $5 \%$ ), it is possible for strong interactions to be present within a stable single-phase structure. Based on the obtained values of SBIE, the authors calculated the average change of lattice potential energy (LPE) value during the migration of the atom (as a difference of SBIE before and after the migration process). It turned out that the average LPE change for a Ni atom migrating to an adjacent site in $\mathrm{CoCrFeMn}{ }_{0.5} \mathrm{Ni}$ was about 1.5 times those in $\mathrm{Fe}-\mathrm{Cr}-\mathrm{Ni}$ ternary alloys (see Figure 3). This indicated that a diffusing atom experienced significantly greater LPE fluctuation in HEA. It should have a pronounced effect on the diffusion, as atoms tend to stay in low LPE sites, in order to minimize the energy. The bigger the average difference in LPE, the higher the occupation time for Ni atom in the lower energy site. As a result, the low LPE sites play the role of the atomic traps, lowering the diffusion rate and resulting in the sluggish diffusion behavior.

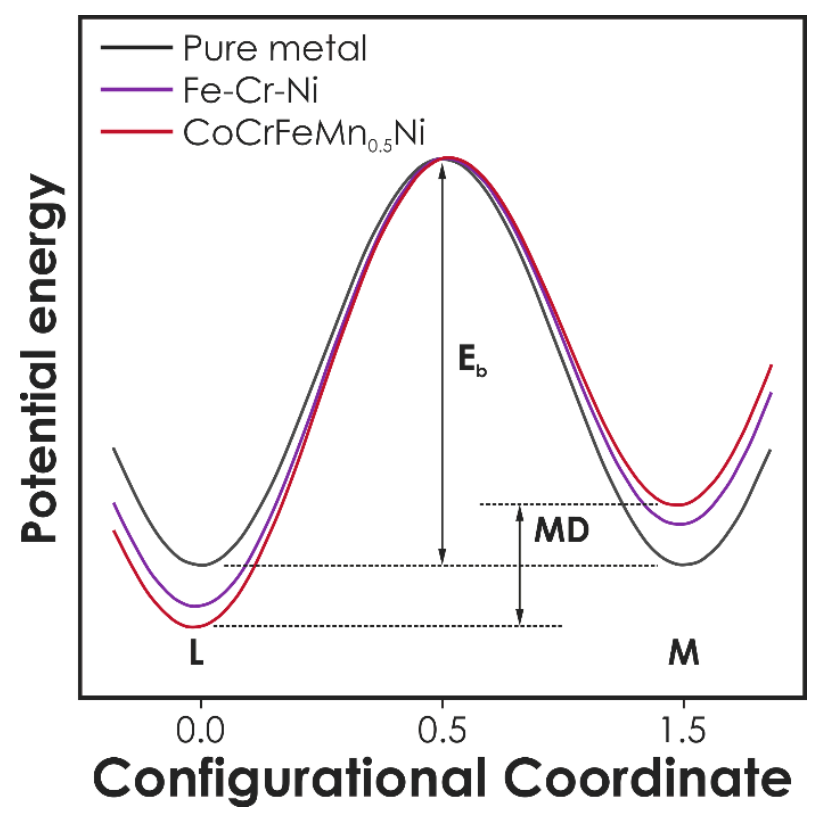

Figure 3. Schematic diagram of the variation of lattice potential energy and mean difference (MD) during the migration of a Ni atom in different matrices (after [28]). Reprinted from Acta Materialia 61 (2013), Sluggish diffusion in Co-Cr-Fe-Mn-Ni high-entropy alloys, 4887-4897 Copyright 2013, with permission from Elsevier.

The study of Tsai et al. [28], while certainly, pioneering has been widely discussed, is being controversial in some of the aspects. The first argument here is that the values of diffusion coefficients seem to be retarded only with respect to melting temperature. Such behavior can hardly be used to explain the phenomena, which originally led Yeh to postulate the existence of the sluggish diffusion 
effect in the first place. What is more, Miracle and Senkov [4] pointed out that even the normalized values obtained by Tsai et al. could hardly be considered abnormal, as they are well within the range for the other FCC metals and alloys at the melting point. This was further studied by Zhang et al. [34] and has been discussed later on.

Another argument can be raised against the methodology of the data analysis applied by Tsai et al. [28]. It was strongly criticized by Aloke Paul in his comments [46] to [28], as well as in the later review article [51]. Paul, himself an author of the various theoretical approaches to diffusion couples analysis, including quasi-binary ones [60,61], focused on some of the most basic assumptions adapted by Tsai et al. The first one was the possibility to obtain two different interdiffusion coefficients from the single, quasi-binary profile. In the opinion of Paul, such a statement contradicts the very foundations of the quasi-binary approach, as the sum of interdiffusion fluxes of the two main elements must be equal zero; otherwise, the whole formalism becomes invalid. Furthermore, at the very beginning, the data should be smoothened and normalized, with the assumption that the sum of the molar fractions of elements with prominent gradients $n_{A}+n_{B}$ must equal 1 . Only then, the obtained values can be considered reliable. Next, Paul criticized the assumption that in the light of a very small Kirkendall shift, the intrinsic and interdiffusion coefficients can be treated as equal. While the assumption itself is correct, it contradicts the assumption of the different interdiffusion coefficients for each main element. Finally, Paul found the assumption that in an ideal system, the concentration-dependent interdiffusivities can be treated as tracer ones, to also stand in contrary to the first two. As a result, it was suggested that the data obtained by Tsai et al. should be reprocessed with the use of appropriate methodology and that diffusivities computed by Tsai et al. are of little value. The Taiwanese team responded to Paul's arguments [47], defending their approach. However, it is hard to argue with some of the points raised in [46]. Nevertheless, it should be noted that while there are some controversies regarding the theoretical approach behind the study of Tsai et al. [28], the data obtained by the Taiwanese team compares really well with the results obtained for the Co-Cr-Fe-Mn-Ni system by other authors, including tracer measurements [40], which suggest that, at least, in this particular case, the eventual errors did not have a prominent impact on the determined values.

It is worth noting that most of the criticism addressed towards the work by Tsai et al. [28] is concentrated mainly on the methodology and interpretation of the experimental data. None of the further works discussed the quasi-chemical model derived by the authors of the original study. Still, there are some statements concerning this model, which seem to be not completely justified. The authors calculated the histogram of SBIE for different alloys, showing the much wider spread of values for the HEA (see Figure 3). It was stated that such behavior is typical for the high entropy alloys and occurs not only for the Ni but also for all other elements in the system. However, at the same time, the authors attributed the long negative "tail" to the presence of strongly negative $\mathrm{Mn}-\mathrm{Ni}$ interaction. The question that occurs is whether the widespread of energies is a result of a high number of components and is correlated with the configurational entropy of the quinary system, or is it just a result of chemical interactions, which are more or less independent from the number of elements.

While the number of possible seven neighbors' configurations is obviously higher for the systems with a high number of components, the energy spread does not seem to be a product of the high entropy approach, at least, not in this particular case. If such a situation was indeed true, the whole further discussion concerning the influence of residence time of the atoms in low LPE sites on the diffusion behavior can only be applied to the Co-Cr-Fe-Mn-Ni system. Even then, the model does not explain why the sluggish behavior is only visible with respect to the melting temperature of the alloy. It would certainly be more convincing if the SBIE histogram was also calculated for other systems, e.g., the $\mathrm{Co}-\mathrm{Cr}-\mathrm{Fe}-\mathrm{Ni}$, in which the enthalpies of mixing between elements are much closer to ideal behavior than in $\mathrm{Co}-\mathrm{Cr}-\mathrm{Fe}-\mathrm{Mn}-\mathrm{Ni}$. That would allow verifying whether the SBIE energy spread and resulting LPE fluctuations are indeed a byproduct of a high-entropy approach.

Chronologically, the second experimental study, on the subject of diffusion in HEAs, was conducted by Kulkarni et al. [29]. In their work, they concentrated on the diffusional interactions in the Co-Cr-Fe-Ni 
system. The experimental part of the study consisted of a single diffusion couple experiment (between $\mathrm{Co}_{20} \mathrm{Cr}_{30} \mathrm{Fe}_{20} \mathrm{Ni}_{30}$ and $\mathrm{Co}_{30} \mathrm{Cr}_{20} \mathrm{Fe}_{30} \mathrm{Ni}_{20}$ ), carried out for $50 \mathrm{~h}$ at $1100{ }^{\circ} \mathrm{C}$. Their analysis was based on the multicomponent Fick's law, in which the fluxes are formulated in the same way as in the mass conservation law applied by Tsai et al. (Equation (1)):

$$
\widetilde{J_{i}}=-\sum_{j=1}^{r} \tilde{D}_{i j} \frac{\partial c_{j}}{\partial x}(\mathrm{i}=1, \ldots, r)
$$

or, if only independent fluxes are considered:

$$
\widetilde{J}_{i}=-\sum_{j=1}^{r-1} \tilde{D}_{i j}^{r} \frac{\partial c_{j}}{\partial x}(\mathrm{i}=1, \ldots, r-1)
$$

where the relation between interdiffusion coefficients is as follows [62]:

$$
\tilde{D}_{i j}^{r}=\tilde{D}_{i j}-\tilde{D}_{i n}
$$

In this formalism, the independent interdiffusion fluxes at any plane within the diffusion zone for a given moment in time can be expressed as:

$$
\tilde{J}_{i}(x)=\frac{1}{2 t} \int_{c_{i}^{-}}^{c_{i}(x)}\left(x-x_{0}\right) d c_{i}
$$

In order to extract values of $(r-1)^{2}$ interdiffusion coefficients from the single diffusion couple, the authors used the method proposed by Dayananda and Sohn [63], which relies on evaluating the moments of concentrations and fluxes about the Matano plane to establish the required equations. The results indicated that Fe was the fastest diffuser in the system, while Ni was the slowest one. What is more, the values of the main interdiffusion coefficients were compared with the results for the Fe-Cr-Ni system, turning out to be about a magnitude smaller than in this ternary system and proving in the process, the sluggishness of diffusion in the quaternary system. However, probably the most interesting result was the values of off-diagonal interdiffusion coefficients. They were on a similar level as the main interdiffusion coefficients, showing the pronounced diffusional interactions between elements, which puts the system ideality assumption of Tsai et al. [28] into question. Most of the mentioned diffusional interactions were correlated directly with the binary enthalpies of mixing with a good agreement, further proving the correctness of the applied approach. Nevertheless, considering the relatively low values of the mixing enthalpies in the Co-Cr-Fe-Ni system, the high values of the off-diagonal terms should be considered surprising.

In the next study by Dabrowa et al. [30], the Al-Co-Cr-Fe-Ni system was studied, as well as a reevaluation of the results by Tsai et al. [28] was conducted. In the case of the Al-Co-Cr-Fe-Ni system, the FCC-structured $\mathrm{Al}_{8} \mathrm{Co}_{28} \mathrm{Cr}_{18} \mathrm{Fe}_{28} \mathrm{Ni}_{18}, \mathrm{Al}_{8} \mathrm{Co}_{19} \mathrm{Cr}_{27} \mathrm{Fe}_{18} \mathrm{Ni}_{28}$, and $\mathrm{Al}_{7} \mathrm{Co}_{28} \mathrm{Cr}_{11} \mathrm{Fe}_{28} \mathrm{Ni}_{26}$ alloys were cast and put together in all possible combinations to form the diffusion couples. Prepared couples were then annealed at three different temperatures: 1273, 1323, and $1373 \mathrm{~K}$. In order to extract the values of tracer diffusivities, the authors applied a so-called combinatorial approach, developed by Kucza [64]. In this approach, all profiles from given temperature are evaluated simultaneously by optimizing the values of tracer diffusivities and comparing the shapes of the resulting, theoretical profiles with experimental data, what is possible through the use of Levenberg-Marquardt optimization method coupled with Darken-Manning description of interdiffusion [62]. Additionally, the genetic algorithm calculations were performed in order to check the correctness and consistency of the solutions provided by the Levenberg-Marquardt method. For both systems, their ideality was assumed. The described approach was firstly verified on the results obtained by Tsai et al. [28] for Co-Cr-Fe-Mn-Ni, yielding a good qualitative agreement, with some quantitative differences, mainly the slightly lower energies of 
activation. The sequence of the fastest to slowest element was matching the one reported by Tsai et al. Additionally, the results obtained for both the Levenberg-Marquardt method and genetic algorithm were similar, further proving the consistency and correctness of both approaches. The same procedure was then applied to the experimental data from $\mathrm{Al}-\mathrm{Co}-\mathrm{Cr}-\mathrm{Fe}-\mathrm{Ni}$ diffusion couples; the obtained values of energies of activation and pre-exponential factors are presented in Table 5. Due to the low gradients of $\mathrm{Al}$, the parameters for this particular element were not treated as physically sound.

Table 5. Energies of activation $\left(\mathrm{kJ} \cdot \mathrm{mol}^{-1}\right)$ and pre-exponential factors $\left(\mathrm{m}^{2} \cdot \mathrm{s}^{-1}\right)$ obtained for the tracer diffusion coefficient by means of Levenberg-Marquardt method for the Al-Co-Cr-Fe-Ni system [30].

\begin{tabular}{ccc}
\hline Component & $\boldsymbol{E}_{\boldsymbol{a}}$ & $\boldsymbol{D}_{\boldsymbol{i}_{0}}$ \\
\hline $\mathrm{Co}$ & 228.6 & $8.93 \times 10^{-7}$ \\
\hline $\mathrm{Cr}$ & 283.1 & $1.95 \times 10^{-4}$ \\
\hline $\mathrm{Fe}$ & 279.6 & $1.25 \times 10^{-4}$ \\
\hline $\mathrm{Ni}$ & 227.1 & $1.90 \times 10^{-7}$ \\
\hline
\end{tabular}

The sequence of the diffusivities from fastest to slowest was similar to the one in the $\mathrm{Co}-\mathrm{Cr}-\mathrm{Fe}-\mathrm{Mn}-\mathrm{Ni}$ system, namely $D_{\mathrm{Cr}}^{*}>D_{\mathrm{Fe}}^{*}>D_{\mathrm{Co}}^{*}>D_{\mathrm{Ni}}^{*}$. The determined values of diffusion coefficients for both considered systems were of a similar order of magnitude, which, in the opinion of the authors, supported the presence of the sluggish diffusion effect. However, the temperature scale normalized with respect to the melting point of the alloys was not considered, making these findings inconclusive.

In 2016, Vaidya et al. [31] conducted the first study of diffusion in HEAs, benefitting from the use of the tracer method, a method that should be considered to be the most reliable and straightforward in the interpretation of the results amongst all methods used in diffusion studies. The authors considered the diffusion of ${ }^{63} \mathrm{Ni}$ isotope in $\mathrm{CoCrFeNi}$ and $\mathrm{CoCrFeMnNi}$ equimolar alloys. The studies were conducted on the homogenized samples at three different temperatures: 1073, 1173, and $1373 \mathrm{~K}$. Additionally, long term annealing studies were simultaneously carried out, confirming the stability of the considered materials.

In order to extract the values of tracer diffusivities, the Gaussian solution of the bulk diffusion equation was deemed to be appropriate:

$$
c(x, t)=\frac{M}{\sqrt{\pi D t}} \exp \left(-\frac{x^{2}}{4 D t}\right)
$$

where $M$ is the initial tracer amount. Surprisingly, the experimental concentration profiles also indicated a pronounced influence of grain boundary diffusion, even at the temperature of $1373 \mathrm{~K}$, which was considered to be rather atypical. To describe this contribution, a B-type kinetic regime was assumed, and Le Clair's functional form was used during its analysis:

$$
c(x, t)=c_{0} \exp \left(-A \cdot x^{6 / 5}\right) .
$$

The determined diffusivities are presented in Figure 4 in the function of temperature, both absolute and normalized with respect to $T_{m}$ (so-called "homologous temperature scale"): 

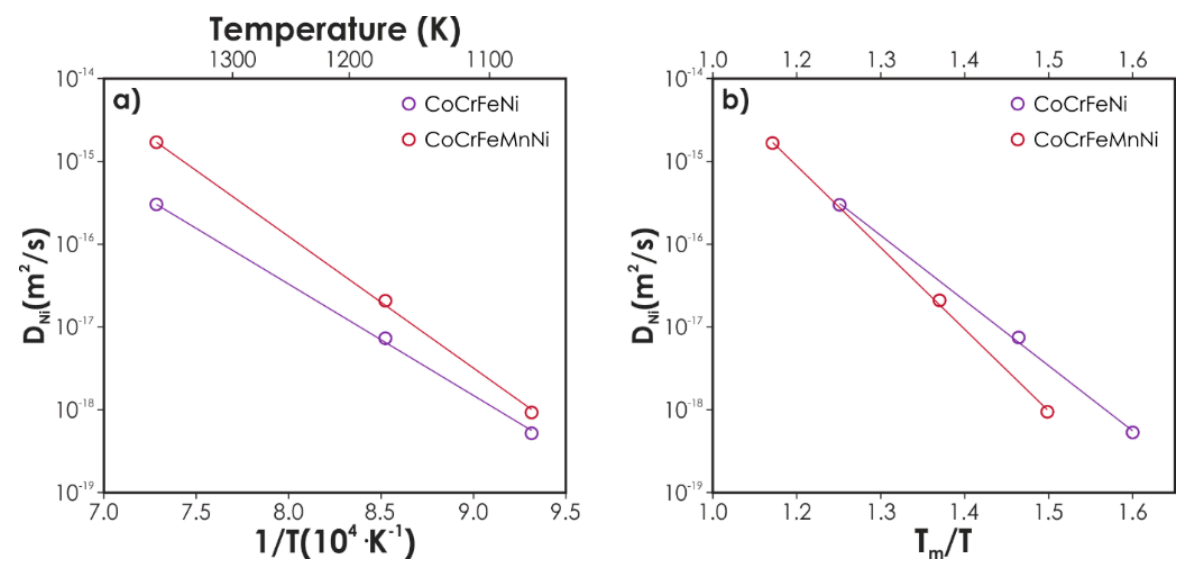

Figure 4. Arrhenius plots for Ni diffusion in $\mathrm{CoCrFeNi}$ and $\mathrm{CoCrFeMnNi}$ alloys plotted using: (a) inverse absolute temperature, (b) inverse normalized temperature (after [31]). Reprinted from Journal of Alloys and Compounds 688 (2016), Ni tracer diffusion in CoCrFeNi and CoCrFeMnNi high entropy alloys, 994-1001, Copyright 2016, with permission from Elsevier.

As can be seen, when the absolute temperature was considered, the number of elements seemed to be not correlated with the values of diffusivities, with diffusion in the quinary system being actually faster. This was attributed to the presence of $\mathrm{Mn}$ in the system, which depressed the melting point of the alloy and presumably resulted in the higher equilibrium vacancy concentration at a given temperature. When the normalized temperature was considered, the influence of components' number seemed to be noticeable, although not in a straightforward manner, as the crossover temperature was observed on the Arrhenius plot. Comparison with more conventional systems yielded similar results, with no signs of retardation of diffusion in the function of components number at absolute temperature and visible effect at normalized one.

Based on the Arrhenius plots, energies of activation for Ni were calculated for both $\mathrm{CoCrFeNi}$ and $\mathrm{CoCrFeMnNi}$. The presence of the crossover temperature was a result of different diffusion behavior of both systems: in $\mathrm{CoCrFeNi}$, the pre-exponential factor, as well as the energy of activation, were relatively low, while the contrary situation was reported for CoCrFeMnNi (see Table 6).

Table 6. Activation parameters for Ni diffusion in $\mathrm{CoCrFeNi}$ and $\mathrm{CoCrFeMnNi} \mathrm{[31].}$

\begin{tabular}{|c|c|c|c|}
\hline Alloy & $D_{0}\left(10^{-4} \mathrm{~m}^{2} \cdot \mathrm{s}^{-1}\right)$ & $E_{a}\left(\mathrm{~kJ} \cdot \mathrm{mol}^{-1}\right)$ & $E_{a}^{*}=E_{a} / R T_{m}$ \\
\hline $\mathrm{CoCrFeNi}$ & 0.020 & 257.8 & 18.1 \\
\hline CoCrFeMnNi & 6.2 & 303.9 & 22.7 \\
\hline
\end{tabular}

The small value of $D_{0}$ in the quaternary alloy was, in the opinion of the authors, a result of a low value of diffusion entropy (Figure 5), which might suggest the presence of localized, short-range order in the alloy. On the other hand, the high value of activation energy in the quinary alloy, also in the normalized form, was most probably a result of strong Ni-Mn interactions. 

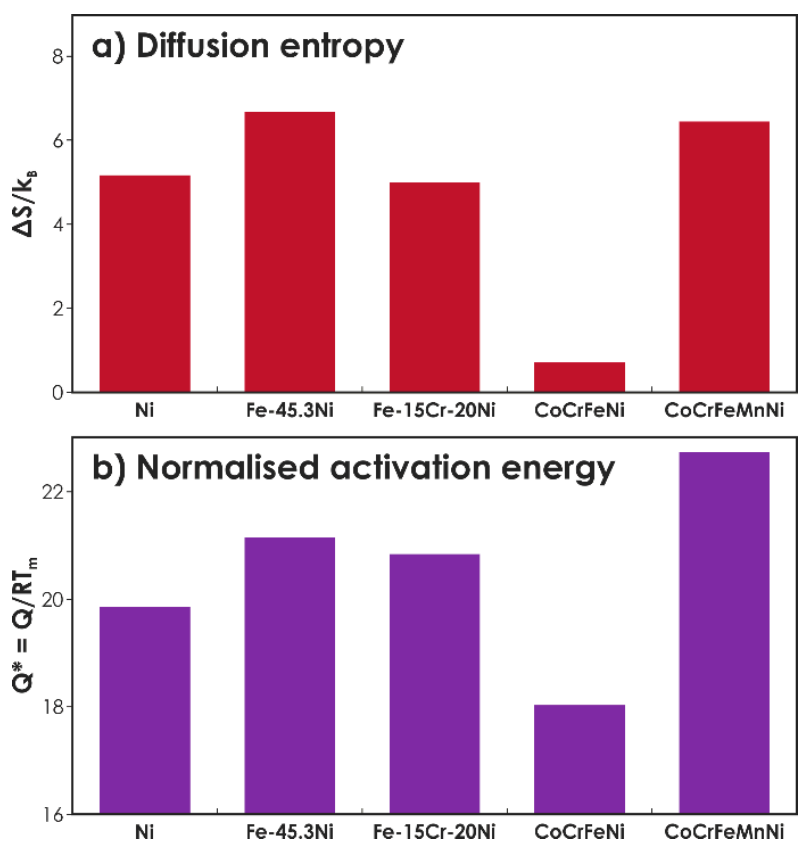

Figure 5. (a) Diffusion entropy and (b) normalized activation enthalpies for the FCC systems (after [31]). Reprinted from Journal of Alloys and Compounds 688 (2016), Ni tracer diffusion in CoCrFeNi and CoCrFeMnNi high entropy alloys, 994-1001, Copyright 2016, with permission from Elsevier.

In conclusion, the authors stated that the diffusion in HEAs is not inevitably sluggish and even can be considered to be enhanced at absolute temperatures. Only normalized values of diffusivities and activation energies indicated the presence of any atypical behavior.

The topic of tracer studies in HEAs was further investigated by the same team in 2017 [32]; this time, however, the main focus was on the subject of grain boundary (GB) diffusion, which was deemed to be rather atypical in their earlier study. The considered materials were the same as previously: $\mathrm{CoCrFeNi}$ and $\mathrm{CoCrFeMnNi}$ equimolar alloys. In order to investigate the GB diffusion, tracer measurements were conducted at $673,723,873,1073$, and $1173 \mathrm{~K}$. The extensive characterization of materials was carried out. It was found out that in both materials, the majority of grain boundaries consisted of high-angle ones (HAGB (high-angle grain boundaries), with the content of low-angle grain boundaries (LAGB) being relatively small $(<8 \%)$ and similar for both materials (the kinetics of diffusion through LAGB is, in general, slower than in HAGB). The possibility of segregation in the area of grain boundaries was investigated with the use of the atom probe tomography (APT) technique, with no segregation effects being visible.

Two regimes of GB diffusion were considered: B and C. In the first one, the contribution of bulk diffusion to the total mass transport was considered to be substantial, while in regime $\mathrm{C}$, typical for the lower temperature range, the bulk diffusion was negligible.

To differentiate between both these regimes, the value of Le Claire parameter was considered:

$$
\alpha=\frac{s \mathcal{K}}{2 \sqrt{D_{v} t}}
$$

$\alpha>1$-regime $C ; \alpha<0.1$-regime B. Where $s$ is the segregation factor (assumed to be equal 1 ), $\kappa$ is the diffusional GB width, and $D_{v}$ is the bulk diffusion coefficient. Based on the result, it was determined that the temperature limit for the $\mathrm{C}$ type GB diffusion was, respectively, 673 and $723 \mathrm{~K}$ for $\mathrm{CoCrFeNi}$ and $\mathrm{CoCrFeMnNi}$. Above these values, a B type GB diffusion was observed. The summary of the results is presented in Figure 6. 

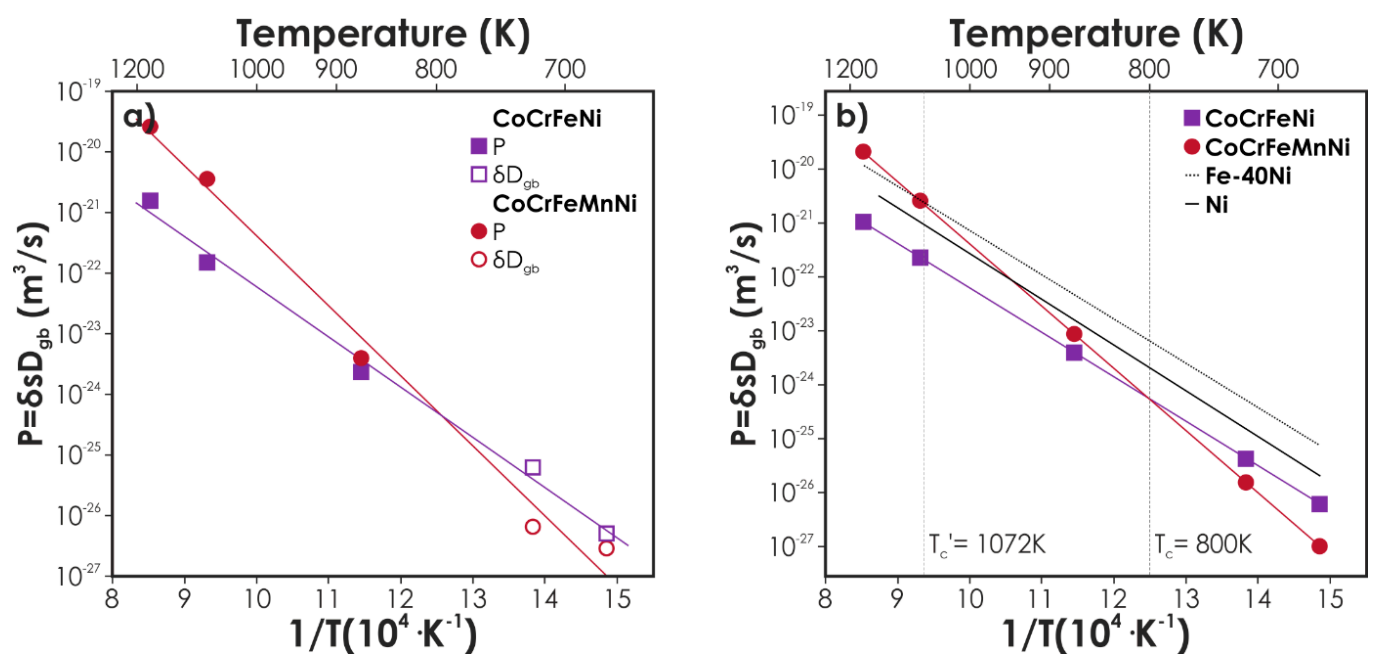

Figure 6. (a) Arrhenius plots of Ni grain boundary (GB) diffusion in CoCrFeNi and CoCrFeMnNi measured in B- (solid symbols) and C-type (open symbols) kinetic regimes. The width of the GB $(\delta)$ was taken as $0.5 \mathrm{~nm}$. (b) Comparison of GB diffusivities of $\mathrm{Ni}$ in $\mathrm{CoCrFeNi}, \mathrm{CoCrFeMnNi}$, with pure $\mathrm{Ni}$ and Fe-Ni alloy (after [32]).

In general, the authors concluded that no signs of GB diffusion retardation could be found, especially in the high-temperature range. The results were in good agreement with the studies of bulk diffusion; the crossover temperature was again observed (about $800 \mathrm{~K}$ ), with the same factors being held responsible for it. Additionally, the grain boundary energy $\gamma_{G B}$ was calculated, a parameter important for wetting and corrosion properties, as well as stability and nucleation processes. It was found that the energy was higher for the $\mathrm{CoCrFeMnNi}$ alloy, which indicated the presence of higher driving force for nucleation at grain boundaries, in agreement with the observations of other authors [53,54].

The high interest in kinetics in HEAs recently culminated in the special issue of the Journal of Phase Equilibria and Diffusion, titled "Thermodynamics and Kinetics of High Entropy Alloys", published in 2017. This issue contained three articles, focused strictly on the diffusion in HEAs. These articles provide some of the latest developments in this area of study.

The first article by Verma et al. [33] is a direct continuation of the [29]. The formalism applied during the data analysis was the same as presented in Equations (7)-(10). What deserves special attention in this study is the use of established thermodynamic relations between elements in the $\mathrm{Co}-\mathrm{Cr}-\mathrm{Fe}-\mathrm{Mn}-\mathrm{Ni}$ system during the process of experiment design. In general, the diffusional interactions can be divided into negative and positive ones. In the first case, if elements $i$ and $j$ diffuse in opposite directions, it can be expected that the interdiffusion flux of the $i$-th element will be enhanced. On the other hand, if both elements diffuse in the same direction, the flux will be reduced. Of course, contrary effects will be observed for positive interactions. The type of interaction is directly correlated with the value of enthalpy of mixing between $i$-th and $j$-th components-if its value is negative, a negative diffusional interaction is to be expected and vice versa. In their work, Verma et al. used available literature data [65-70], which led to designing two different diffusion couples, one in which the interdiffusion effects were expected to be reduced (RD couple), and one in which enhanced interdiffusion was expected (EN couple).

In the first step, the authors evaluated the interdiffusion fluxes, using Equation (10). Both uphill effects ( $\mathrm{Cr}$ in both EN and RD, Fe in EN) and zero-flux planes (Fe in EN) were identified. It was confirmed that the design of the couples was successful, as the interdiffusion zone for EN couple was two times larger than in RD one. Then, using the tracer data for all components from CoCrFeMnNi alloy provided by Vaidya et al. [31] (including results unpublished at the time), the authors estimated values of interdiffusivities, for various compositions within the diffusion zones. To obtain the values of the necessary thermodynamic parameters, the authors used the Thermocalc TCHEA1 database. 
The resulting values of interdiffusion coefficients were deemed to be in a very good agreement with the thermodynamics of the system; e.g., the $\tilde{D}_{\mathrm{NiMn}}^{\mathrm{Cr}}$ was highly negative, reaching an absolute value similar to some of the main interdiffusion coefficients. Additionally, the Mn and Ni were determined to be, respectively, the fastest and the slowest elements in the system, and in the opinion of the authors, they were, in fact, controlling the diffusion process in the system. Finally, the calculated interdiffusivities were used to reproduce the concentration profiles, with the use of Dayananda's transfer matrix method [71], with an excellent agreement in comparison to experimental data.

Zhang et al. [34] presented a different approach to the topic. The experimental part consisted of two diffusion couple experiments $\left(\mathrm{Co}_{25} \mathrm{Cr}_{25} \mathrm{Fe}_{25} \mathrm{Ni}_{25}-\mathrm{Ni}_{50} \mathrm{Cr}_{25} \mathrm{Fe}_{25}\right.$ and $\mathrm{Co}_{20} \mathrm{Cr}_{20} \mathrm{Fe}_{20} \mathrm{Mn}_{20} \mathrm{Ni}_{20}-$ $\mathrm{Cr}_{20} \mathrm{Fe}_{20} \mathrm{Mn}_{20} \mathrm{Ni}_{40}$ ), but its role was just to allow verification of the theoretical part. This was based entirely on the Calphad approach, with the calculations being conducted using Pandat software combined with the PanHEA database.

In the Calphad approach, it is assumed that properties of multicomponent systems can be predicted, based strictly on the properties of their binary and ternary subsystems. Such a methodology can also be applied to the mobilities of the atoms. The atomic mobilities $M_{i}$ were expressed according to the following relation:

$$
M_{i}=\frac{M_{i}^{0}}{R T} \exp \left(\frac{-E_{a}}{R T}\right)=\frac{1}{R T} \exp \left(\frac{-E_{a}+R T \ln M_{i}^{0}}{R T}\right)=\frac{1}{R T} \exp \left(\frac{\Phi_{i}}{R T}\right) .
$$

The $\Phi_{i}$ parameter was given by the composition-dependent Redlich-Kister polynomial [72]:

$$
\begin{gathered}
\Phi_{i}=\sum_{j} n_{j} \Phi_{i}^{j}+\sum_{p} \sum_{j>p} n_{p} n_{j} \sum_{k} \Phi_{i}^{p j}\left(n_{p}-n_{j}\right)^{k} \\
+\sum_{p} \sum_{j>p} \sum_{q>j} n_{p} n_{j} n_{q}\left(v_{p j q}^{s} \Phi_{i}^{p j q}\right)(s=p, j, q),
\end{gathered}
$$

where:

$$
v_{p j q}^{s}=n_{s}+\frac{1-n_{p}-n_{j}-n_{q}}{3}
$$

Looking at the form of Redlich-Kister polynomial, it is obvious that the influence of quaternary and quinary terms is negligible due to the very small values of the molar content products in both cases. The relation between mobilities and interdiffusivities was defined as follows:

$$
\tilde{D}_{p q}^{n}=\sum_{i=1}^{n}\left(\delta_{i p}-n_{p}\right) n_{i} M_{i}\left(\frac{\partial \mu_{i}}{\partial n_{q}}-\frac{\partial \mu_{i}}{\partial n_{n}}\right)
$$

where $\delta_{i p}$ is the Kronecker delta. In order to obtain sufficient data for the assessment of the mobilities, the authors used the available diffusion data for $\mathrm{Co}-\mathrm{Fe}, \mathrm{Co}-\mathrm{Ni}, \mathrm{Cr}-\mathrm{Fe}, \mathrm{Cr}-\mathrm{Ni}$, Fe-Ni, Fe-Mn, Mn-Ni, $\mathrm{Co}-\mathrm{Fe}-\mathrm{Ni}, \mathrm{Co}-\mathrm{Cr}-\mathrm{Ni}, \mathrm{Cr}-\mathrm{Fe}-\mathrm{Ni}$ systems, as well as data for Ni-based superalloys. The obtained database of mobilities was further verified by comparison of both values of diffusivities and concentration profiles with the literature and experimental ones.

The verified database was then used to predict the tracer diffusivities of Ni in most of Ni-containing, FCC-structured subsystems of the Co-Cr-Fe-Mn-Ni quinary system. Furthermore, based on the predicted melting points, the diffusivities were recalculated for the normalized temperature. Both results are presented in Figure 7. 

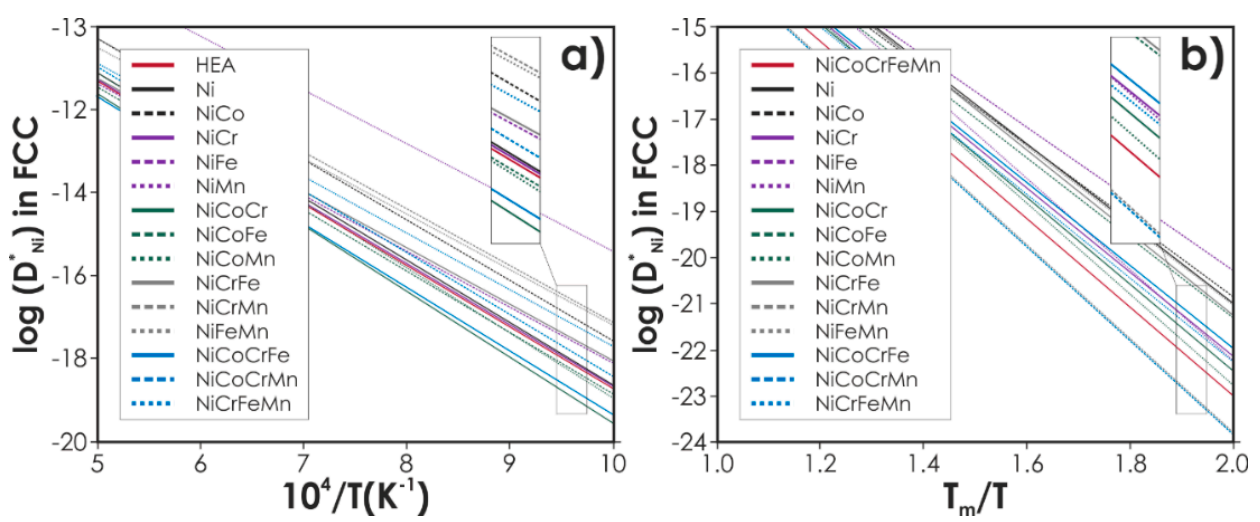

Figure 7. (a) Calculated Ni tracer diffusion coefficients vs. the inverse of the absolute temperature, determined at equimolar ratios, (b) Calculated Ni tracer diffusion coefficients vs. the inverse of the normalized temperature (after [34]). Reprinted by permission from Springer Nature: Springer, Journal of the Phase Equilibrium and Diffusion, Zhang, C.; Zhang, F.; Jin, K.; Bei, H.; Chen, S.; Cao, W.; Zhu, J.; Lv, D. Understanding of the Elemental Diffusion Behavior in Concentrated Solid Solution Alloys, 2017.

As can be seen, when the absolute temperature was considered, no correlation between the number of components and the rate of diffusion was found. Also, it is worth noting that systems Mn-containing alloys exhibited relatively high diffusivities, which supports the findings of Vaidya et al. [31]. For the normalized temperature, there was also no correlation between the number of components and values of Ni tracer diffusion coefficients, which puts into question the findings of previous authors [28]. Similar calculations were also carried out, with comparable results, for tracer diffusivities of Co and Fe Figure.

Finally, the authors calculated the composition dependence of Ni tracer diffusivities in the Co-Cr-Fe-Mn-Ni system at different temperatures. The results are presented in Figure 8:
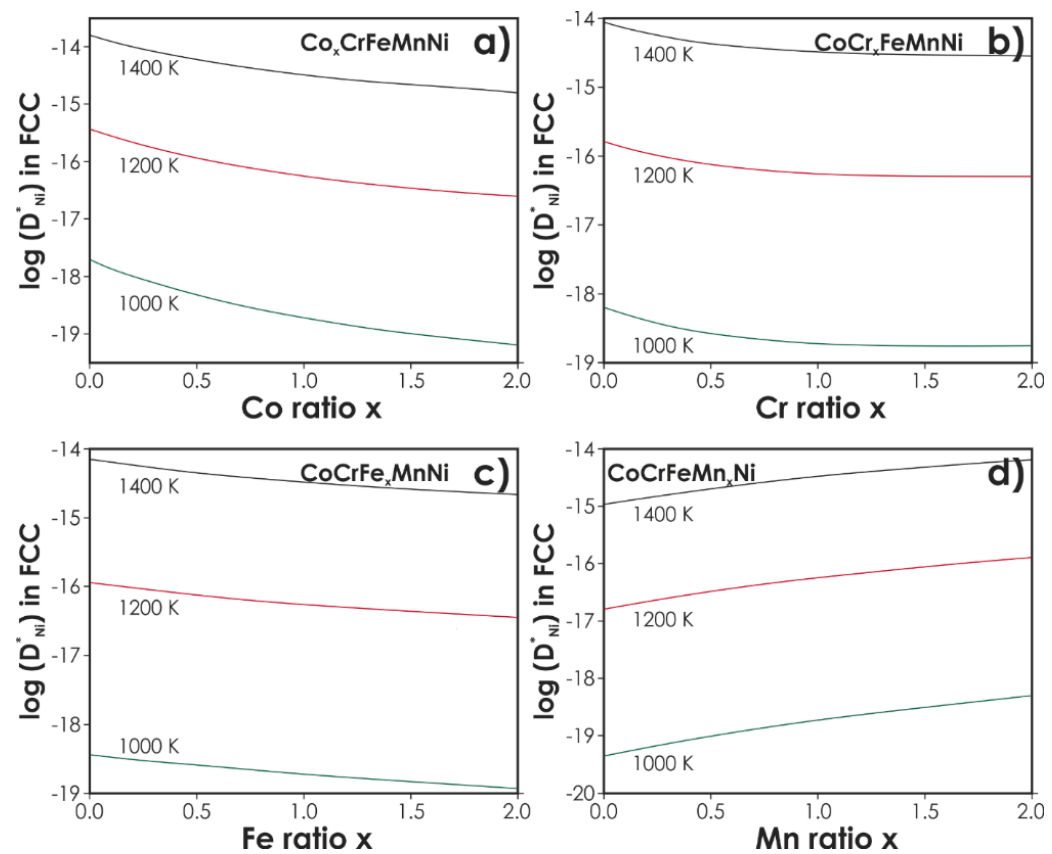

Figure 8. Calculated composition dependence of Ni tracer diffusivities in the Co-Cr-Fe-Mn-Ni system at different temperatures, for different content of considered elements ( $x$ ) (after [34]). Reprinted by permission from Springer Nature: Springer, Journal of the Phase Equilibrium and Diffusion, Zhang, C.; Zhang, F.; Jin, K.; Bei, H.; Chen, S.; Cao, W.; Zhu, J.; Lv, D. Understanding of the Elemental Diffusion Behavior in Concentrated Solid Solution Alloys, 2017. 
As can be seen, in some cases, the concentration dependence of tracer diffusivities was a very strong one, with the differences between $x=0$ and $x=2$ compositions being as high as 1.5 orders of magnitude (e.g., in $\mathrm{Co}_{x} \mathrm{CrFeMnNi}$ ).

The above results are certainly of very high value, as they represent one of the most comprehensive approaches to the topic of diffusion studies in HEAs. Still, it should be remembered that all data used in this study, while based on the solid experimental foundation, was an extrapolation and, therefore, should be verified with further experimental results.

The last article published in the mentioned special issue of the Journal of Phase Equilibria and Diffusion was authored by Chen et al. [35] and could be treated as the beginning of the longer series of articles by this team. The authors investigated interdiffusion in Co-Cr-Fe-Mn-Ni alloys using the diffusion multiples experiment (conducted at $1373 \mathrm{~K}$ ), coupled with the so-called "pragmatic numerical inverse method" [73]. The applied theoretical description was based on Equations (1), (7) and (8) combined with Manning's formalisms. The "pragmatic numerical inverse method", while, in general, similar to the combinatorial approach developed earlier by Kucza [64], during the optimization, uses not only concentration profiles but also fluxes. Such an approach may offer some advantages in comparison to the one based strictly on the optimization of concentration profiles as it provides more information, enhancing the probability that as a result of the optimization process, the global minimum is reached. Still, the calculation of fluxes based on the experimental results is always affected by an error; therefore, the usefulness of such an approach is strictly correlated with the quality of the measured concentration profiles, as well as the quality of data processing. Also, another factor that may influence the obtained results is the applied weighting factors between the influence of the concentration profiles error and flux fitting error.

The last article published in the mentioned special issue of the Journal of Phase Equilibria and Diffusion was authored by Chen et al. [35] and could be treated as the beginning of the longer series of articles by this team. The authors investigated interdiffusion in Co-Cr-Fe-Mn-Ni alloys using the diffusion multiples experiment (conducted at $1373 \mathrm{~K}$ ), coupled with the so-called "pragmatic numerical inverse method" [73]. The applied theoretical description was based on Equations (1), (7) and (8) combined with Manning's formalisms. The "pragmatic numerical inverse method", while, in general, similar to the combinatorial approach developed earlier by Kucza [64], during the optimization, uses not only concentration profiles but also fluxes. Such an approach may offer some advantages in comparison to the one based strictly on the optimization of concentration profiles as it provides more information, enhancing the probability that as a result of the optimization process, the global minimum is reached. Still, the calculation of fluxes based on the experimental results is always affected by an error; therefore, the usefulness of such an approach is strictly correlated with the quality of the measured concentration profiles, as well as the quality of data processing. Also, another factor that may influence the obtained results is the applied weighting factors between the influence of the concentration profiles error and flux fitting error.

The obtained results, in general, agreed with the observations by other authors. When the Ni was treated as a dependent component, the following sequence of main interdiffusivities was reported: $\tilde{D}_{\mathrm{MnMn}}^{\mathrm{Ni}}>\tilde{D}_{\mathrm{CrCr}}^{\mathrm{Ni}}>\tilde{D}_{\mathrm{FeFe}}^{\mathrm{Ni}}>\tilde{D}_{\mathrm{CoCo}}^{\mathrm{Ni}}$ similar as in the study by Tsai et al. [28].

However, the mentioned sequence did not sustain through the whole composition of the sample (as visible in Figure 9), showing its strong influence on interdiffusivities. 


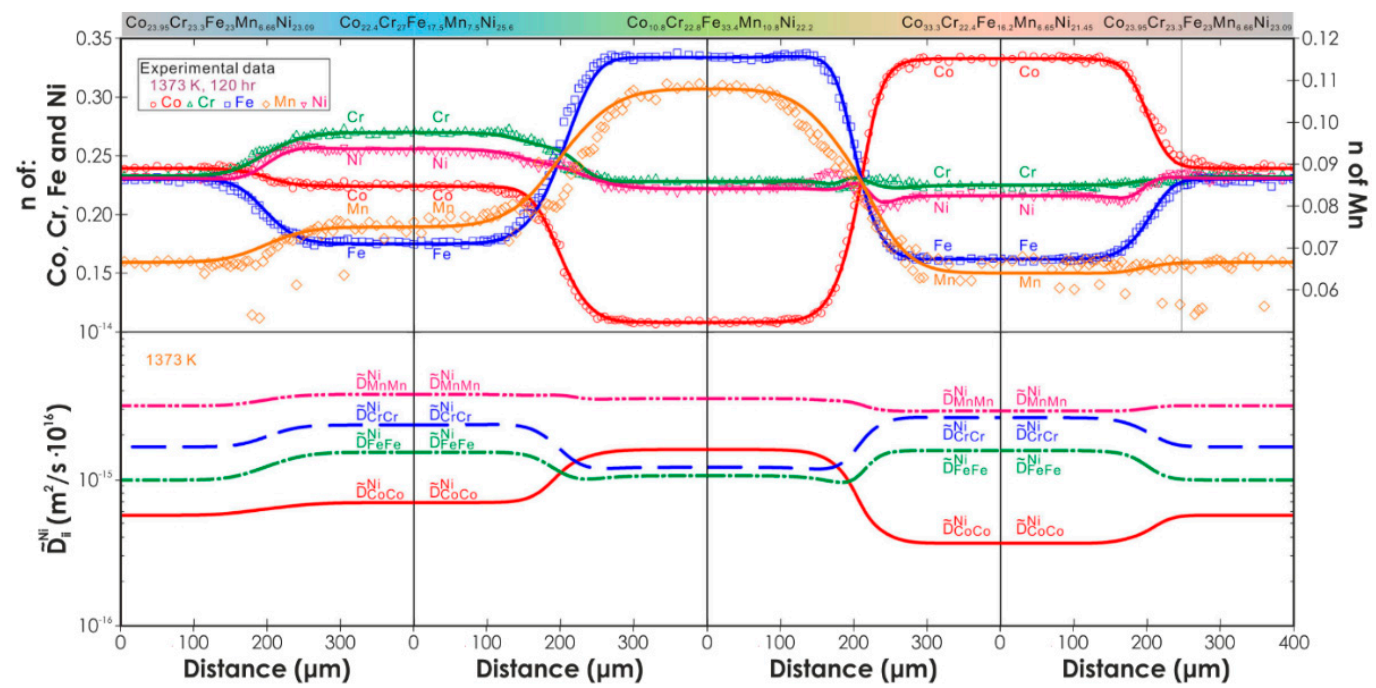

Figure 9. Composition profiles (both experimental and simulated) and the corresponding main interdiffusivities for the diffusion multiple (after [35]). Reprinted by permission from Springer Nature: Springer, Journal of the Phase Equilibrium and Diffusion, Chen, W.; Zhang, L. High-Throughput Determination of Interdiffusion Coefficients for Co-Cr-Fe-Mn-Ni High-Entropy Alloys, 2017.

The authors compared the value of the obtained $\tilde{D}_{\mathrm{FeFe}}^{\mathrm{Ni}}\left(0.98-1.98 \times 10^{-15} \mathrm{~m}^{2} / \mathrm{s}\right.$ at $\left.1373 \mathrm{~K}\right)$ with the $\tilde{D}_{\mathrm{FeFe}}^{\mathrm{Ni}}$ obtained by Kulkarni et al. [29] for Co-Cr-Fe-Ni $\left(1.06 \times 10^{-15} \mathrm{~m}^{2} / \mathrm{s}\right.$ at $\left.1273 \mathrm{~K}\right)$. In their opinion, the fact that the values were of the same order, despite the temperature difference of $100 \mathrm{~K}$, could be treated as direct evidence of the existence of the sluggish diffusion effect. The authors further compared the estimated value of $\mathrm{Ni}$ tracer diffusivity with the available data from binary, ternary, and quaternary alloys. However, this time, the results indicated that tracer diffusivity of nickel was higher for the investigated HEA than in considered ternary and quaternary alloys. That led them to the conclusion that the sluggishness of diffusion is much more visible with regard to interdiffusivities.

In the case of results obtained by Chen et al. [35], there are some factors that should be further considered. First off, while optimization methods are extremely useful, it should be remembered that they are highly dependent on the input data. The more input data is provided, the more unambiguous the results. The question is, whether a single diffusion multiple at one temperature (in this case, containing four diffusion couples, Figure 9) is enough to ensure reaching the global minimum during the optimization process, especially considering the fact that some of the thermodynamic interaction parameters used in the model were fitted simultaneously with concentration profiles and fluxes. Secondly, the authors during the analysis of diffusion coefficients values did not take into account the specifics of the system, especially the presence of $\mathrm{Mn}$ in it (and corresponding low $T_{m}$ value). As shown before in the example of studies by Vaidya et al. [31] and Zhang et al. [34], the addition of this particular element has a pronounced influence on the interpretation of the data due to its tendency towards drastic lowering of the melting point and relatively strong interactions with other elements.

The same group published another research in 2018 [36], in which, using the same methodology as in the previous one, they investigated the Al-Co-Cr-Fe-Ni system. The authors performed diffusion couple experiments at three different temperatures: 1273, 1323, and $1373 \mathrm{~K}$, using sandwich-type diffusion multiples. The multiples were based on three different compositions: $\mathrm{Al}_{4.88} \mathrm{Co}_{29.53} \mathrm{Cr}_{18.58} \mathrm{Fe}_{19.62} \mathrm{Ni}_{27.39}, \mathrm{Co}_{25.33} \mathrm{Cr}_{25.77} \mathrm{Fe}_{24.53} \mathrm{Ni}_{24.37}$, and $\mathrm{Al}_{6.64} \mathrm{Co}_{23.82} \mathrm{Cr}_{23.66} \mathrm{Fe}_{23.01} \mathrm{Ni}_{22.87}$, characterized by the FCC structure. The influence of vacancy wind was disregarded, and the system was treated as an ideal one. The interaction parameters used in the Redlich-Kister expression, used in the formula describing composition-dependent mobilities, Equation (14), were also obtained by fitting the experimental data whenever the data was not available in the literature. The exemplary 
results of the performed calculations, including the obtained values of interdiffusivities, are presented in Figure 10.

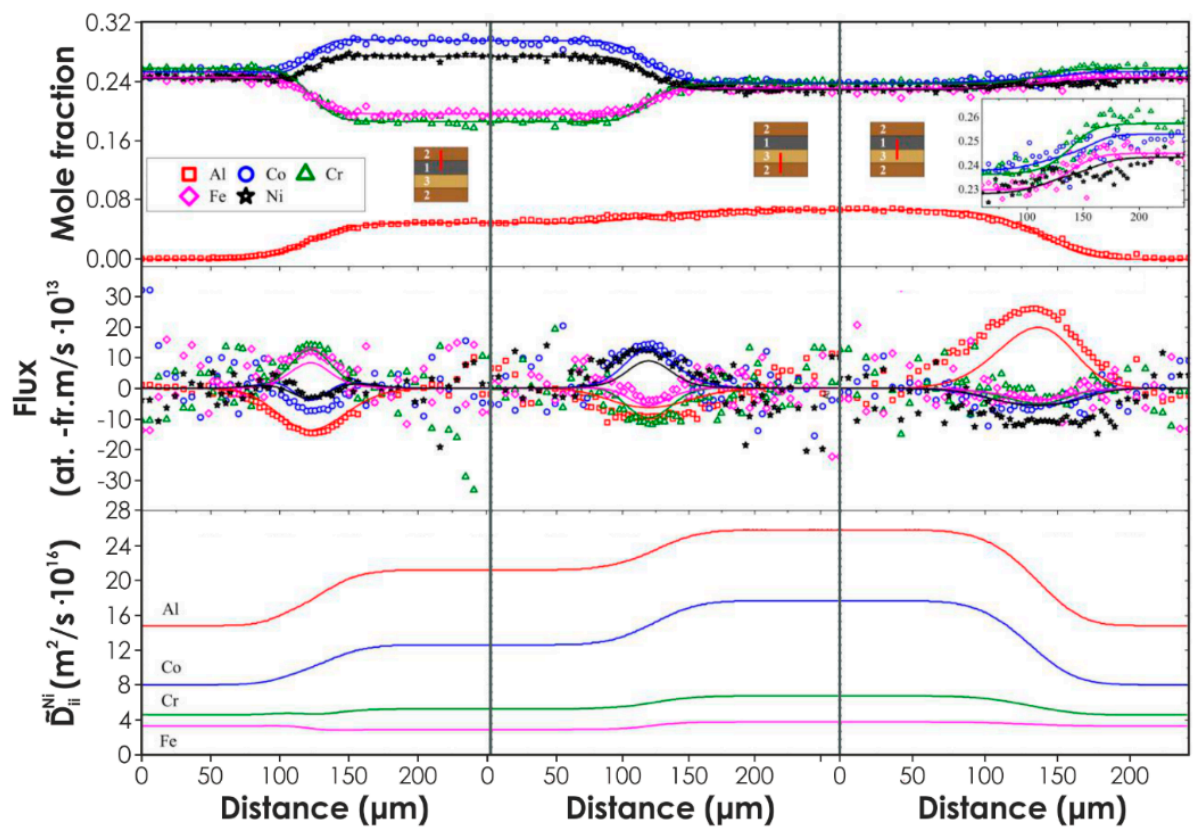

Figure 10. Comparison between the experimental and the simulated concentration profiles and interdiffusion fluxes in Al-Co-Cr-Fe-Ni diffusion couples annealed at $1323 \mathrm{~K}$ for $46 \mathrm{~h}$, as well as the evaluated diagonal interdiffusivities (after [36]).

The results indicated that taking nickel as a reference element led to the following sequence of the diagonal interdiffusivities from fastest to slowest: $\mathrm{Al}, \mathrm{Co}, \mathrm{Cr}$, and $\mathrm{Fe}$, which was consistent with the findings of Dabrowa et al. [30]. The authors also estimated the tracer diffusivities and compared them with literature values for other FCC metals and alloys, as shown in Figure 11.
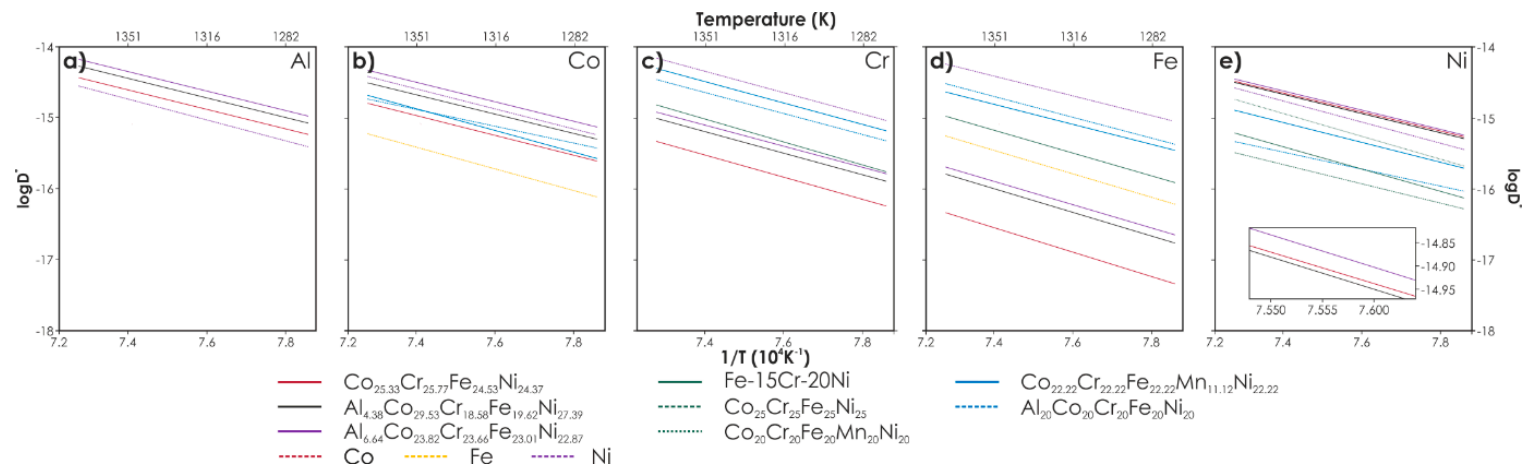

Figure 11. Tracer diffusivities estimated for Al-Co-Cr-Fe-Ni and comparison with the literature data on diffusion in various FCC pure metals and alloys (after [36]).

The results in the absolute temperature scale did not reveal sluggish behavior in the system. Relatively low values of tracer diffusivities were observed for $\mathrm{Fe}$ and $\mathrm{Cr}$ only. Similar dependencies were also visible for the normalized temperature scale. 
Another study published by the group of Chen in 2018 focused on the diffusion in the $\mathrm{Co}-\mathrm{Cr}-\mathrm{Cu}-\mathrm{Fe}-\mathrm{Ni}$ high entropy alloys [37]. The authors performed diffusion couple experiments at three different temperatures: 1273,1323 , and $1373 \mathrm{~K}$, using sandwich-type diffusion multiples. The multiples were based on three different compositions: $\mathrm{Co}_{22.5} \mathrm{Cr}_{22.5} \mathrm{Cu}_{5.5} \mathrm{Fe}_{22.5} \mathrm{Ni}_{27}, \mathrm{Co}_{25} \mathrm{Cr}_{25} \mathrm{Fe}_{25} \mathrm{Ni}_{25}$, and $\mathrm{Co}_{26.4} \mathrm{Cr}_{22} \mathrm{Cu}_{3.2} \mathrm{Fe}_{22} \mathrm{Ni}_{26.4}$. The overall methodology, applied to extract the interdiffusion coefficients, was again similar as in [35]. Again, the influence of vacancy wind was disregarded, and the system was treated as an ideal one. The interaction parameters used in the Redlich-Kister expression, used in the formula describing composition-dependent mobilities, Equation (14), were also obtained by fitting the experimental data whenever the data was not available in the literature. The exemplary results of the performed calculations, including the obtained values of interdiffusivities, are presented in Figure 12.

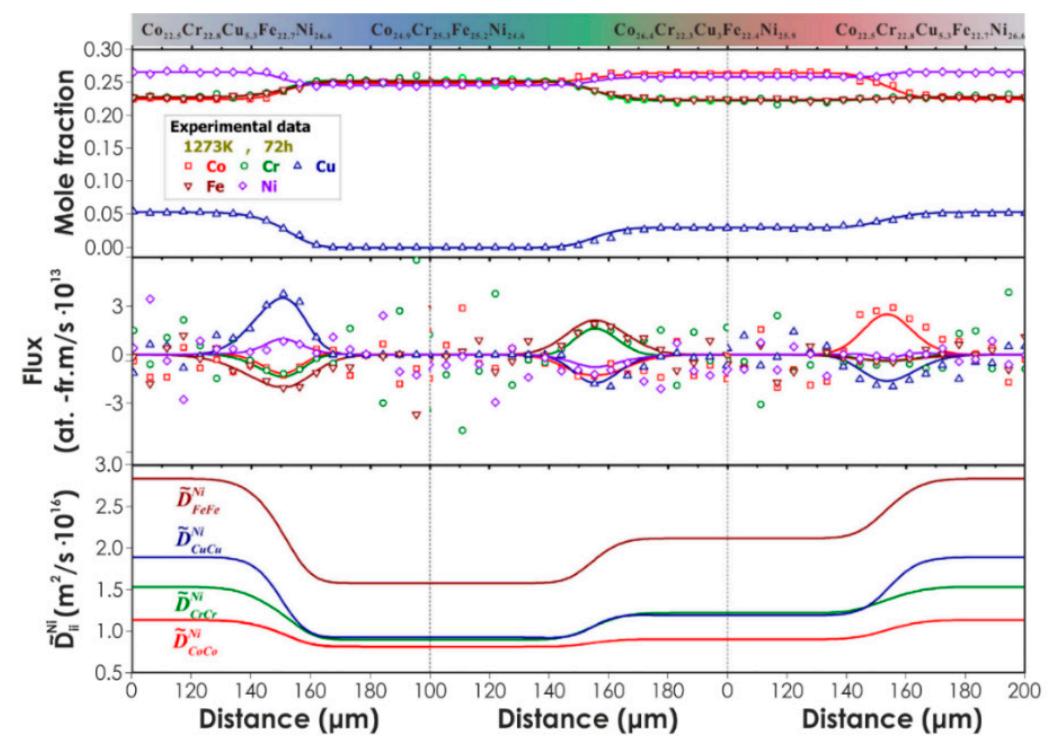

Figure 12. Comparisons of the model-predicted concentration/interdiffusion profiles with the corresponding experimental data (symbols), and the evaluated diagonal interdiffusivities along the diffusion paths of the diffusion multiples annealed at $1273 \mathrm{~K}$ for $72 \mathrm{~h}$ (after [37]). Reprinted from Journal of Materials Science \& Technology 34 (2018), Experimental and numerical studies on the sluggish diffusion in face-centered cubic Co-Cr-Cu-Fe-Ni high-entropy alloys, 434-444, Copyright 2018, with permission from Elsevier.

The choice of the $\mathrm{Ni}$ as the reference element in the interdiffusion matrix allowed the authors to compare the obtained values with the literature ones, measured for systems with less composing elements, as shown in Figure 13.

Additionally, the authors evaluated the values of tracer diffusivities and compared them to the available data for other HEAs and their subsystems, as shown in Figure 14.

Based on the obtained results, the authors came to the same conclusions as in [35] that the sluggishness of diffusion in high entropy alloys is much more pronounced in the case of interdiffusion coefficients than in the case of tracer diffusivities. 

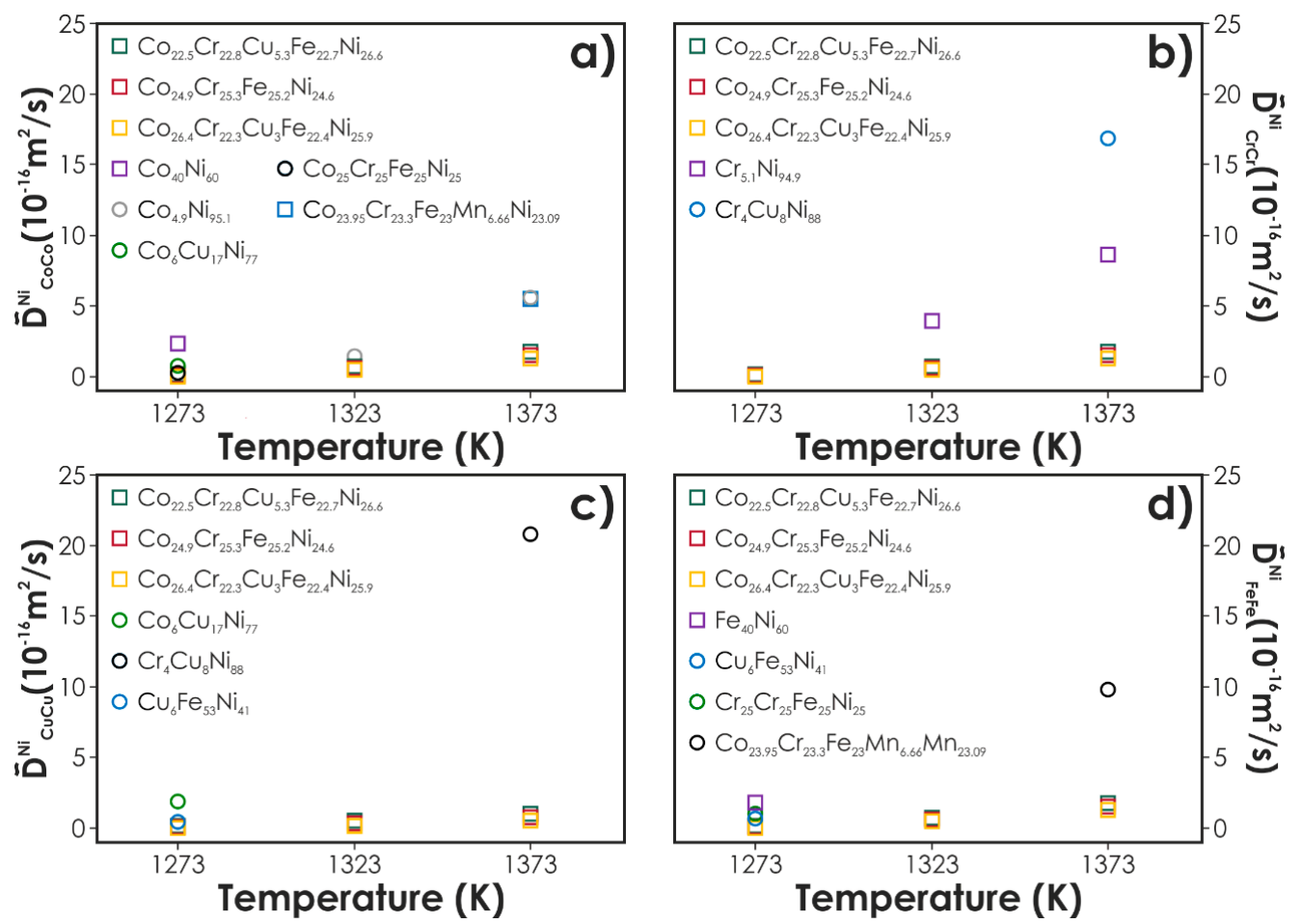

Figure 13. Comparisons of diagonal interdiffusivities determined for the Co-Cr-Cu-Fe-Ni system, with the reported experimental diffusion data at 1273, 1323, or $1373 \mathrm{~K}$ in various subsystems of FCC $\mathrm{CoCrCuFeNi}$ system with $\mathrm{Ni}$ as the solvent (after [37]). Reprinted from Journal of Materials Science \& Technology 34 (2018), Experimental and numerical studies on the sluggish diffusion in face-centered cubic Co-Cr-Cu-Fe-Ni high-entropy alloys, 434-444, Copyright 2018, with permission from Elsevier.

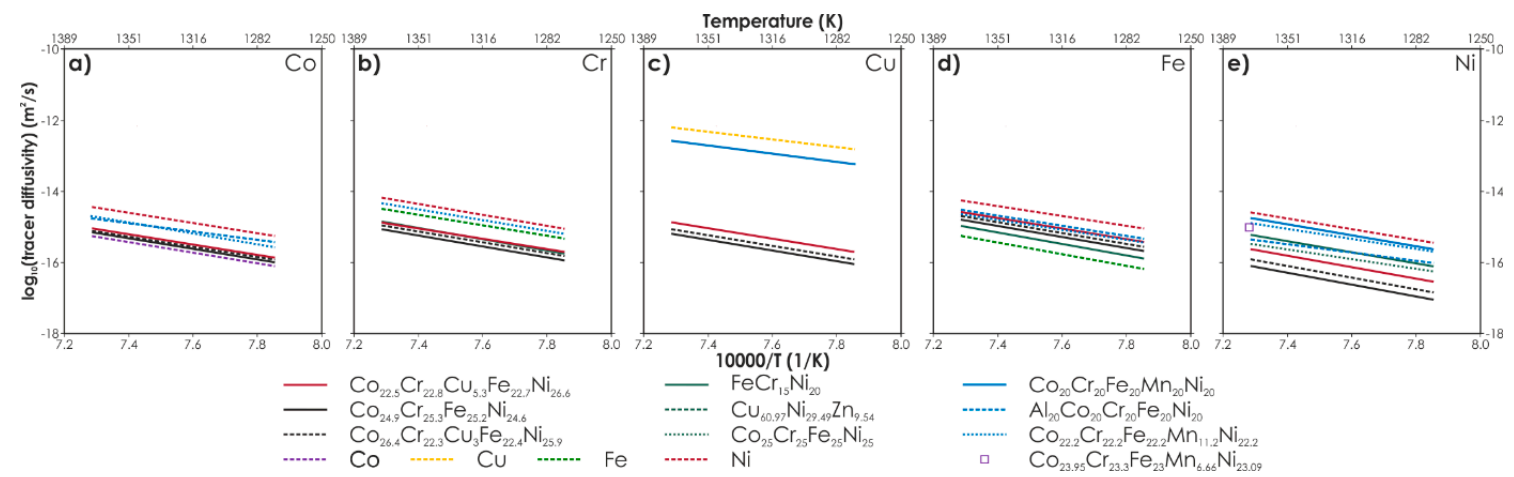

Figure 14. Comparisons of Arrhenius plots of the obtained tracer diffusivities in the Co-Cr-Cu-Fe-Ni system, with the reported temperature-dependent data on diffusion in various FCC systems (after [37]). Reprinted from Journal of Materials Science \& Technology 34 (2018), Experimental and numerical studies on the sluggish diffusion in face-centered cubic Co-Cr-Cu-Fe-Ni high-entropy alloys, 434-444, Copyright 2018, with permission from Elsevier.

The last study authored by the Chinese team was published in 2019 and described the diffusion behavior of the FCC-structured Al-Co-Cr-Fe-Ni-Ti high entropy superalloys (HESAs) [38]. The composition space of HESAs locates in between traditional Ni-based superalloys and HEAs, combining dual-phase structure, typical for Ni-based superalloys (FCC- $\gamma$ matrix plus $\mathrm{L}_{2}-\gamma^{\prime}$ precipitates), with the benefits of the high-entropy approach. Their excellent performance makes them extremely promising for high-temperature applications. In their work, Chen et al. again used the diffusion multiples technique, with four 
composing alloys: $\mathrm{Al}_{4.8} \mathrm{Co}_{24.7} \mathrm{Cr}_{18.2} \mathrm{Fe}_{16.1} \mathrm{Ti}_{3.9} \mathrm{Ni}_{32.7}$ (alloy \#1), $\mathrm{Al}_{7.8} \mathrm{Co}_{20.6} \mathrm{Cr}_{12.2} \mathrm{Fe}_{11.5} \mathrm{Ti}_{7.2} \mathrm{Ni}_{40.7}$ (\#2), $\mathrm{Al}_{10.3} \mathrm{Co}_{18.8} \mathrm{Cr}_{7.5} \mathrm{Fe}_{9.0} \mathrm{Ti}_{5.8} \mathrm{Ni}_{48.6}$ (\#3), and $\mathrm{Al}_{8.9} \mathrm{Co}_{17.2} \mathrm{Cr}_{9.2} \mathrm{Fe}_{8.2} \mathrm{Ti}_{6.0} \mathrm{Ni}_{50.5}$ (\#4), all characterized by a single-phase FCC structure. The choice of a single-phase structured HESAs was dictated by the ability to interpret the diffusion data. To confirm the phase homogeneity of the studied alloys, the authors performed measurements with a transmission electron microscope (TEM). The homogenized materials were initially hot-pressed in a vacuum furnace for $2 \mathrm{~h}$ at $1473 \mathrm{~K}$, followed by annealing under the same temperature conditions for the next $30 \mathrm{~h}$. Similarly, as in previous studies of this group, the same methodology as in [35] was applied in order to extract the diffusion data from the measured concentration profiles, with the "pragmatic numerical inverse method" being implemented in the HitDIC software. The obtained values of interdiffusion coefficients as a function of position within the diffusion zone are presented below in Figure 15.

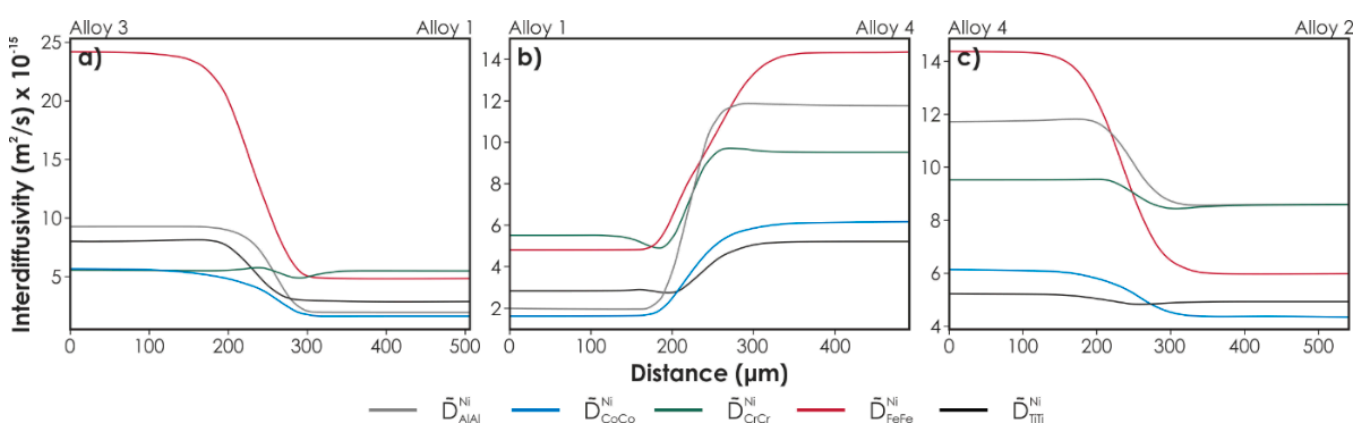

Figure 15. Main interdiffusivities evaluated by HitDIC software along the diffusion paths of the diffusion multiple (after [38]). Reprinted from Journal of Alloys and Compounds 791 (2019), On diffusion behaviors in face centered cubic phase of Al-Co-Cr-Fe-Ni-Ti high-entropy superalloys, 255-264, Copyright 2019, with permission from Elsevier.

As visible, the interdiffusivities were strongly dependent on the composition of the alloys. Nevertheless, the authors established a following sequence of interdiffusivities from the fastest to the slowest: $\tilde{D}_{\mathrm{FeFe}}^{\mathrm{Ni}}>\tilde{D}_{\mathrm{AlAl}}^{\mathrm{Ni}}>\tilde{D}_{\mathrm{CoCo}}^{\mathrm{Ni}}>\tilde{D}_{\mathrm{CrCr}}^{\mathrm{Ni}}>\tilde{D}_{\mathrm{TiTi}}^{\mathrm{Ni}}$. The obtained values of the main interdiffusion coefficients were then compared with analogous data for conventional alloys, as shown in Figure 16.

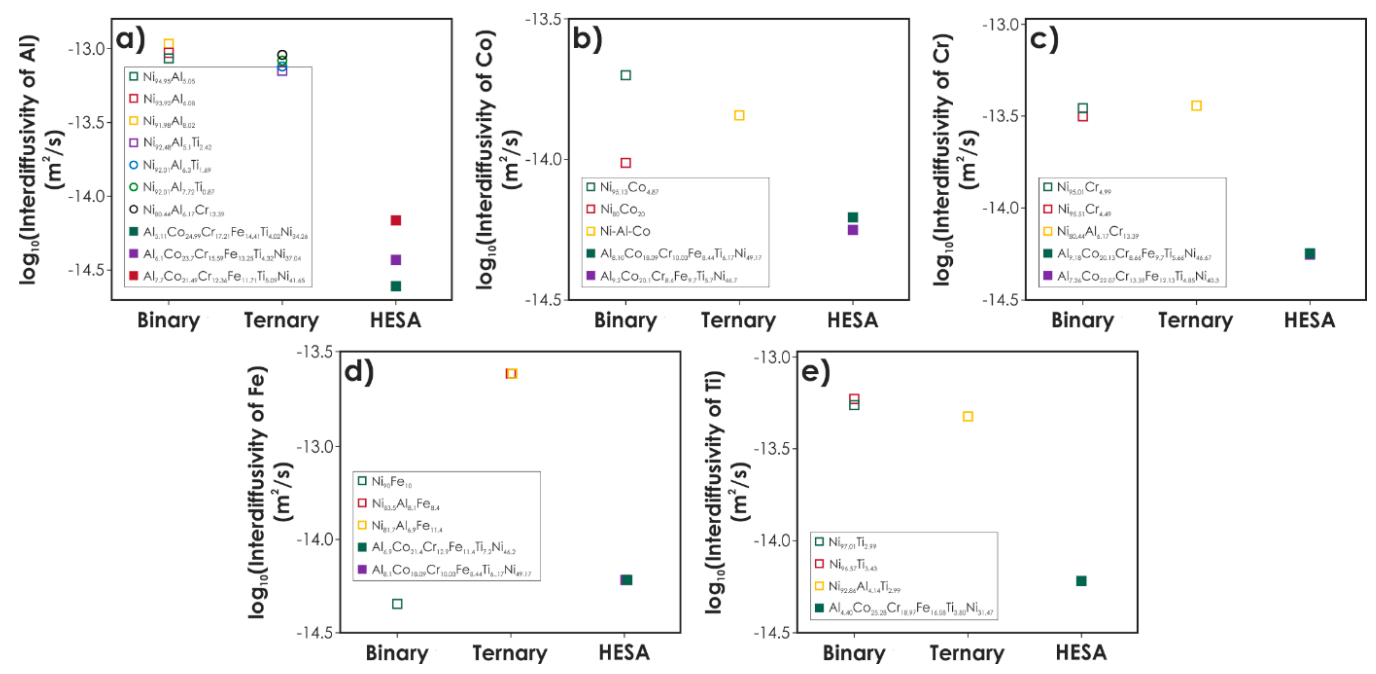

Figure 16. Comparisons of the main interdiffusivities for the Al-Co-Cr-Fe-Ni-Ti system with the literature data in the other FCC alloys when Ni was taken as the solvent (after [38]). Reprinted from Journal of Alloys and Compounds 791 (2019), On diffusion behaviors in face centered cubic phase of Al-Co-Cr-Fe-Ni-Ti high-entropy superalloys, 255-264, Copyright 2019, with permission from Elsevier.

Furthermore, the tracer diffusion coefficients were also evaluated, as shown in Figure 17. 

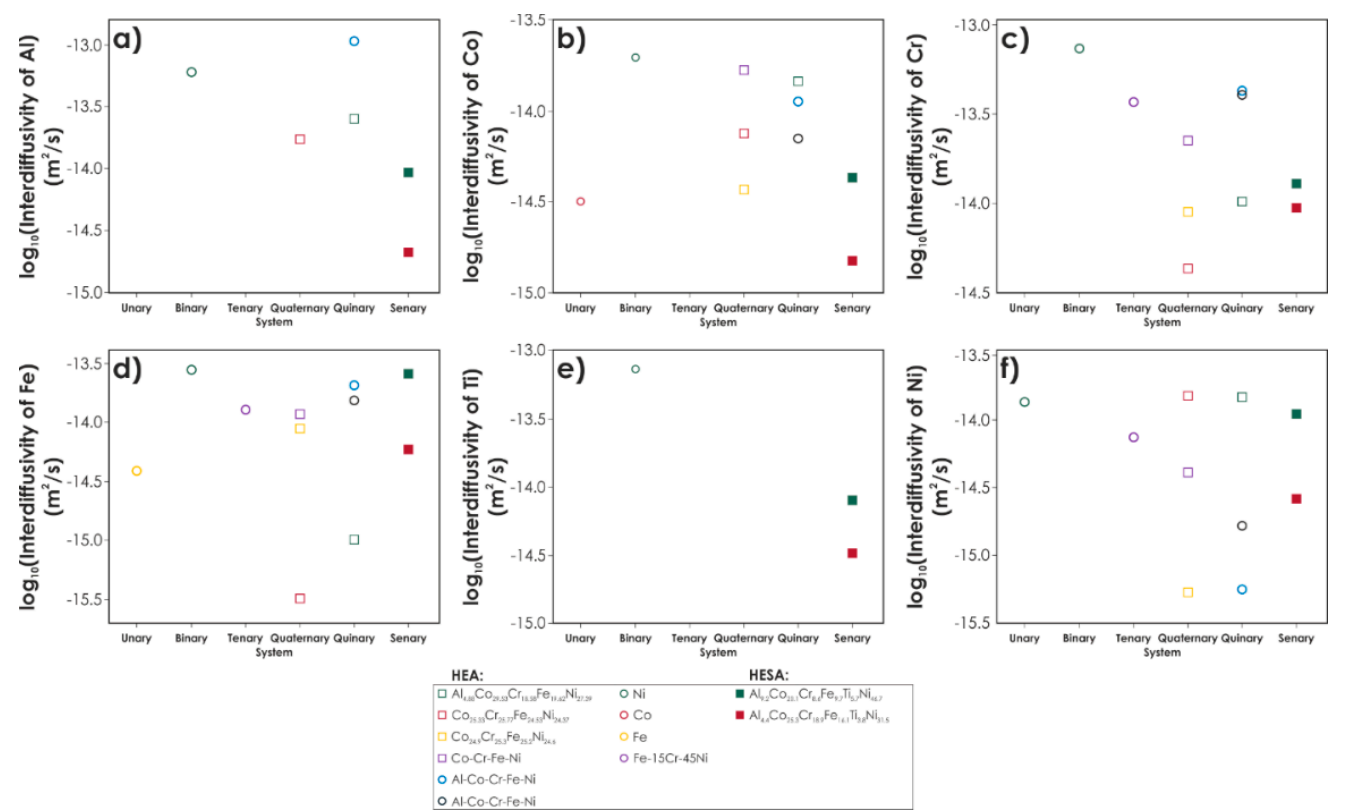

Figure 17. Comparisons of the tracer diffusivities for the Al-Co-Cr-Fe-Ni-Ti system with the literature data in the other FCC alloys and pure metals (after [38]). Reprinted from Journal of Alloys and Compounds 791 (2019), On diffusion behaviors in face centered cubic phase of Al-Co-Cr-Fe-Ni-Ti high-entropy superalloys, 255-264, Copyright 2019, with permission from Elsevier.

Based on the above comparison, the authors stated that interdiffusivities of the following elements could be considered sluggish: $\mathrm{Al}, \mathrm{Co}, \mathrm{Cr}$, and $\mathrm{Ti}$, while in the case of tracer diffusion, only the $\mathrm{Al}$ exhibits significantly abnormal behavior (sluggish), which is similar to other works of this group, suggesting that the sluggishness of diffusion is mainly observed for the interdiffusion coefficients.

The presented series of articles [36-38] can be considered very consistent from the point of view of the applied methodology. In all of them, the pragmatic numerical inverse method was applied. As a result, they all share the same advantages and disadvantages as the one already described for the [35]. Probably the biggest obstacle here is the constant use of the ideal solution approximation, which probably cannot be justified, at least, for some of the applied compositions. Therefore, at least, partial validation of the tracer data by independent, tracer studies is necessary.

Another study, one of the most comprehensive ones, was published in 2018 by Vaidya et al. [39] and became the beginning of a series of articles authored by the team from Münster. The article is a direct continuation of the tracer studies presented in [31]. However, while the latter one was limited only to studies of $\mathrm{Ni}$ diffusion behavior, this time, the authors focused on the diffusion of all other elements, in both $\mathrm{CoCrFeNi}$ and $\mathrm{CoCrFeMnNi}$ equimolar alloys, with the use of ${ }^{57} \mathrm{Co},{ }^{51} \mathrm{Cr},{ }^{54} \mathrm{Mn}$, and ${ }^{59} \mathrm{Fe}$ isotopes. The general methodology applied in this study was similar to the one presented for [31], with the main difference being five different annealing temperatures (1073, 1123, 1173, 1223, and $1373 \mathrm{~K})$ instead of three. Additionally, the authors conducted measurements with the use of the APT method, which allowed determining the level of distribution randomness for each of the elements within the crystal lattice. To quantify it, a $\mu$ parameter was used ( $\mu=0$ —complete randomness, 1 -clustering or precipitations). The results proved that both alloys could be considered as random solid solutions, although in $\mathrm{CoCrFeNi}$, a small tendency of $\mathrm{Cr}$ towards ordering was observed $(\mu=0.119)$.

The values of tracer diffusion coefficients, obtained by Vaidya et al., are presented on the Arrhenius plots in Figure 18. 

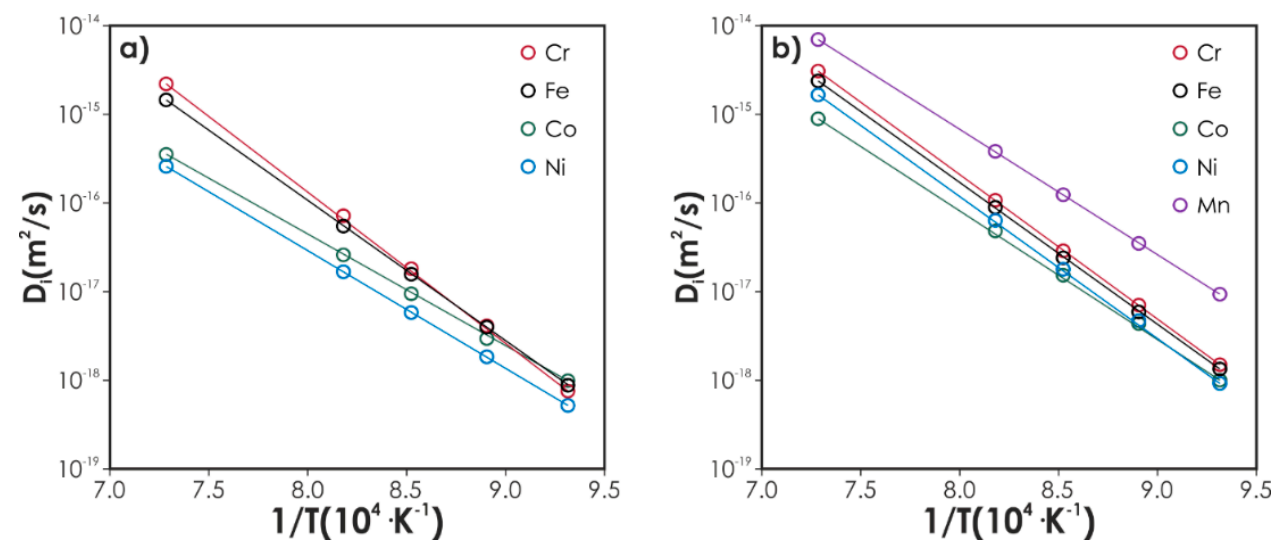

Figure 18. Temperature dependence of tracer bulk diffusion of all constituents in (a) CoCrFeNi, (b) CoCrFeMnNi (after [39]). Reprinted from Acta Materialia 146 (2018), Bulk tracer diffusion in $\mathrm{CoCrFeNi}$ and CoCrFeMnNi high entropy alloys, 211-224, Copyright 2018, with permission from Elsevier.

The summary of values of pre-exponential factors $D_{0}$ and energies of activation $E_{a}$ is presented in Table 7.

Table 7. Activation energies $E_{a}$ and the pre-exponential factors $D_{0}$ for bulk diffusion of the constituents in $\mathrm{CoCrFeNi}$ and $\mathrm{CoCrFeMnNi}[39]$.

\begin{tabular}{ccccc}
\hline \multirow{2}{*}{ Tracer } & \multicolumn{2}{c}{ Diffusion in CoCrFeNi } & \multicolumn{2}{c}{ Diffusion in CoCrFeMnNi } \\
\cline { 2 - 5 } & $\boldsymbol{E}_{\boldsymbol{a}} \mathbf{( \mathbf { k J } / \mathbf { m o l } )}$ & $\boldsymbol{D}_{\mathbf{0}}\left(\mathbf{m}^{\mathbf{2}} \mathbf{s}\right)$ & $\boldsymbol{E}_{\boldsymbol{a}} \mathbf{( \mathrm { kJ } / \mathbf { m o l } )}$ & $\boldsymbol{D}_{\mathbf{0}}\left(\mathbf{m}^{\mathbf{2}} \mathbf{\mathbf { s }}\right)$ \\
\hline $\mathrm{Co}$ & $240 \pm 20$ & $4.6_{-3.9}^{+26} \times 10^{-7}$ & $270 \pm 22$ & $1.6_{-1.6}^{+69} \times 10^{-5}$ \\
\hline $\mathrm{Cr}$ & $323 \pm 5$ & $4.2_{-0.8}^{+0.9} \times 10^{-3}$ & $313 \pm 13$ & $2.4_{-2.1}^{+17} \times 10^{-3}$ \\
\hline $\mathrm{Fe}$ & $303 \pm 3$ & $4.9_{-1.3}^{+1.8} \times 10^{-4}$ & $309 \pm 11$ & $1.3_{-1.1}^{+9} \times 10^{-3}$ \\
\hline $\mathrm{Mn}$ & - & - & $272 \pm 13$ & $1.6_{-1.5}^{+26} \times 10^{-4}$ \\
\hline $\mathrm{Ni}$ & $253 \pm 8$ & $1.1_{-0.4}^{+0.6} \times 10^{-5}$ & $304 \pm 9$ & $6.2_{-1.5}^{+18} \times 10^{-4}$ \\
\hline
\end{tabular}

As can be seen, the sequences of slowest to fastest diffusing elements were, respectively, $D_{\mathrm{Ni}} \leq D_{\mathrm{Co}}$ $<D_{\mathrm{Fe}} \leq D_{\mathrm{Cr}}$ for $\mathrm{CoCrFeNi}$ and $D_{\mathrm{Ni}}<D_{\mathrm{Co}}<D_{\mathrm{Fe}}<D_{\mathrm{Cr}}<D_{\mathrm{Mn}}$ for CoCrFeMnNi and were similar to the ones reported by Tsai et al. [28] and the ones observed in conventional alloys. The diffusivities were compared using both absolute and normalized temperature scales. In the first of them, the diffusivities in $\mathrm{CoCrFeNi}$ were generally lower than in the 5-component alloy. On the other hand, for all elements common for both alloys, the diffusivities presented with respect to melting temperature were lower in the case of CoCrFeMnNi, exhibiting similar, "sluggish" effect to the one postulated by Tsai et al. [28].

The energies of activation in both alloys in the opinion of Vaidya et al. correlated with the average, effective enthalpies of mixing for a given element-the more negative the enthalpy, the higher the activation energy is. This effect was most probably responsible for differences in energies of activation between $\mathrm{CoCrFeNi}$ and $\mathrm{CoCrFeMnNi}$ alloys and resulting presence of crossover temperatures, as the $\mathrm{Mn}$ introduced in the latter one exhibited highly negative enthalpies of mixing with $\mathrm{Ni}$ and $\mathrm{Co}$. $D_{0}$ values were used to calculate the diffusion entropy $\Delta S$, i.e., the change of the entropy of lattice vibrations originating from a constrained movement of the diffusing atom through a saddle point configuration. Its relatively low values for $\mathrm{Co}$ and Ni suggested a need for detailed investigations of elastic constants and short-range order.

A comparison of the tracer diffusivities with those reported for other FCC alloys (Figure 19) shows small retardation of their values with the increased number of elements, although it can be seen only in the normalized temperature scale. 

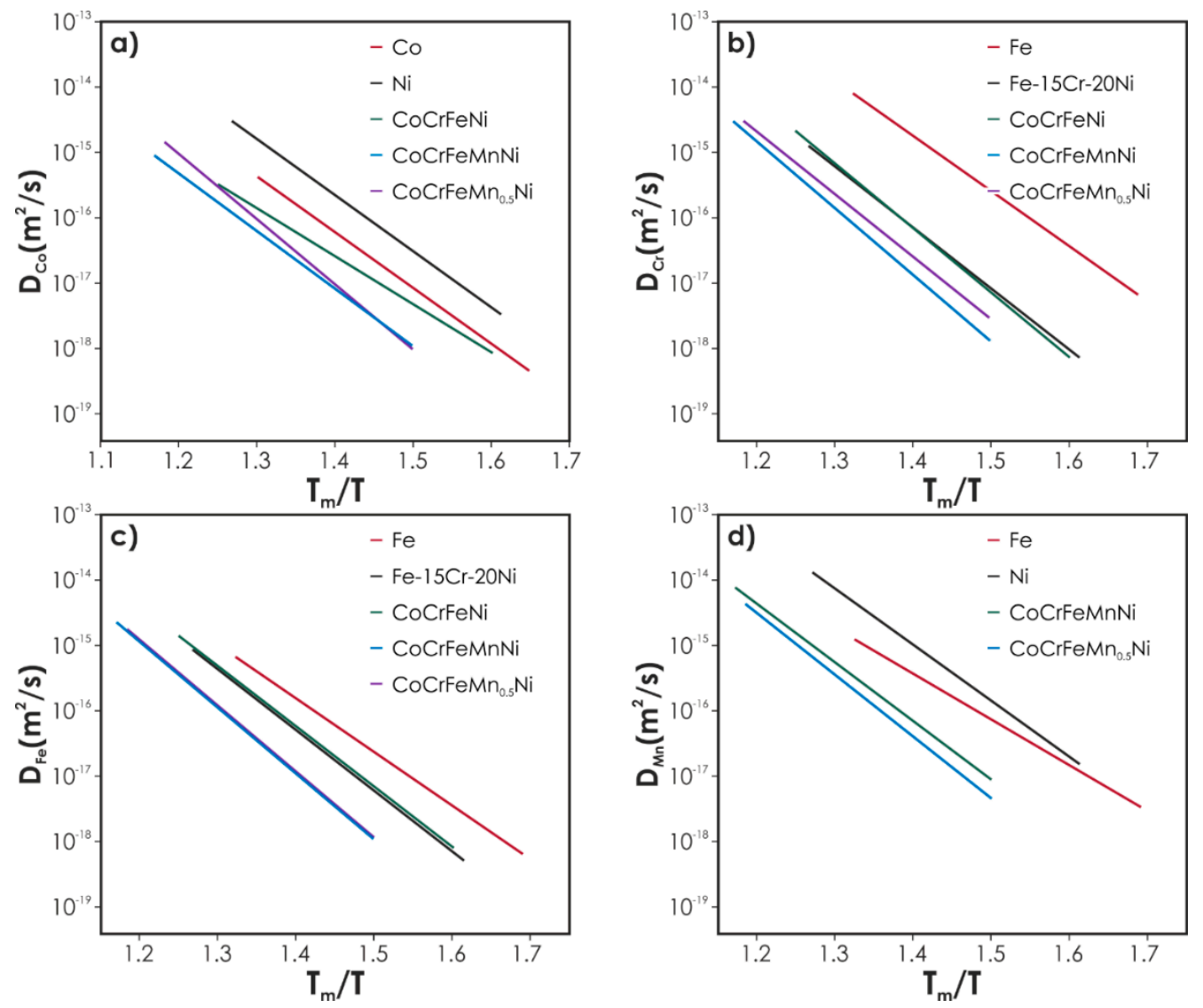

Figure 19. Tracer diffusion coefficients in high entropy alloys (HEAs) [28,39] in comparison to other FCC-structured alloys and pure elements: (a) Co; (b) Cr; (c) Fe; (d) Mn (after [39]). Reprinted from Acta Materialia 146 (2018), Bulk tracer diffusion in CoCrFeNi and CoCrFeMnNi high entropy alloys, 211-224, Copyright 2018, with permission from Elsevier.

Despite that, the authors suggested that the diffusion in HEAs might not necessarily be sluggish. Further analysis of the data showed that examined alloys followed the Meyer-Neldel rule, similar to other FCC alloys (empirical, linear correlation between $D_{0}$ and $E_{a}$ ). Additionally, the examined HEAs exhibited very good agreement with other alloys, in terms of the relation between $\Delta S$ and $E_{a}$ (see Figure 20). As a result, the authors concluded that the increased number of components does not alter the atomistic processes of diffusion in comparison to materials with a similar crystal structure. More significant may be here the actual composition of the high entropy alloy and thermodynamic interactions between the elements. As it is hard to separate the influence of interactions between given pair of the elements and the configurational entropy of the whole system, the authors postulated that studies of different compositions within the given system should be pursued, in order to fully understand the relation between configurational entropy of the system and diffusion kinetics. 


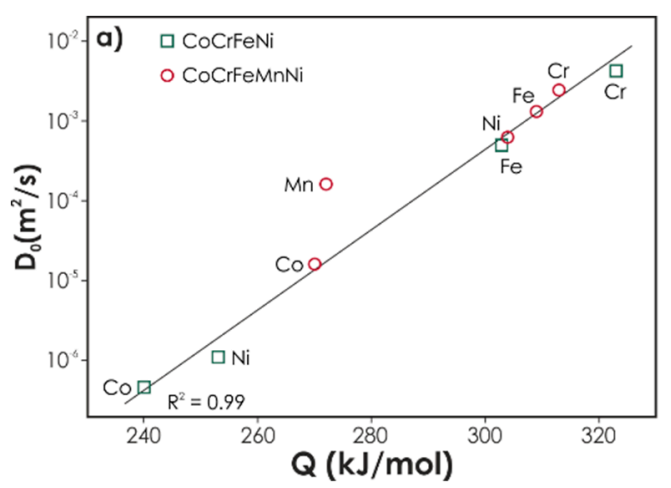

Figure 20. The pre-exponential factors for bulk diffusion in $\mathrm{CoCrFeNi}$ (squares) and CoCrFeMnNi (circles) as a function of respective activation energy $E_{a}$ (after [39]). Reprinted from Acta Materialia 146 (2018), Bulk tracer diffusion in CoCrFeNi and CoCrFeMnNi high entropy alloys, 211-224, Copyright 2018, with permission from Elsevier.

The work of Vaidya et al. [39] should be considered the most reliable one amongst all diffusion studies in HEAs, especially considering the controversies around the work by Tsai et al. $[28,46]$. The use of the tracer method, the most basic and straightforward in the interpretation of all methods applied in diffusion studies, makes the presented results a benchmark for further studies of diffusion in HEAs. Still, it should be remembered that these results apply to tracer diffusivities of elements for equimolar compositions of $\mathrm{CoCrFeNi}$ and $\mathrm{CoCrFeMnNi}$ systems. This, of course, will yield certain differences when compared with data from diffusion couple experiments, where the compositions across the diffusion zone may change in a significant manner, e.g., due to the variation of the tracer diffusivities with a composition (see [34]) or thermodynamic interactions between elements.

Further refinement of the tracer diffusion data was performed by the same team in 2018, this time using a single crystalline sample of both $\mathrm{CoCrFeNi}$ and $\mathrm{CoCrFeMnNi}[40]$. The ${ }^{57} \mathrm{Co},{ }^{51} \mathrm{Cr},{ }^{59} \mathrm{Fe}$, and ${ }^{54} \mathrm{Mn} \gamma$-emitting radiotracers, as well as $\beta$-emitting ${ }^{63} \mathrm{Ni}$, were applied to the surfaces of the sample in $\mathrm{HCl}$ solutions. The prepared samples were then annealed at $1373 \mathrm{~K}$ for chosen times $(6 \mathrm{~h}, 3$ days, and 14 days). Additionally, the diffusion of ${ }^{64} \mathrm{Cu}$ radiotracer was separately studied in the CoCrFeNi alloy, in the temperature range of 973 to $1173 \mathrm{~K}$. The methodology applied to the data processing was similar as in $[31,39]$. As expected, the results indicated that the volume diffusion coefficients in both alloys are time-independent (no GB effect) and isotropic. The results showed good consistency with the data obtained in [39].

In the case of copper, the following Arrhenius dependence was established:

$$
D_{V}^{C u}=\left(6.6_{-5.0}^{+19.5}\right) \times 10^{-10} \exp \left(-\frac{(149.9 \pm 12.1) \mathrm{kJ} / \mathrm{mol}}{R T}\right)\left(\mathrm{m}^{2} \cdot \mathrm{s}^{-1}\right) .
$$

The behavior of $\mathrm{Cu}$ was extraordinary, as on the one hand, it was significantly faster than all other studied radiotracers, but on the other, its energy of activation was about two times lower than for the other elements. Such behavior, in the opinion of the authors, might suggest a strong attractive interaction of $\mathrm{Cu}$ atoms with vacancies, which might indicate the presence of $\mathrm{Cu}$-rich particles in $\mathrm{CoCrFeNi}$.

The further works of the team from Münster include three articles [41-43]. In [41], the authors studied, using tracer method, tracer diffusion of $\mathrm{Co}, \mathrm{Cr}, \mathrm{Fe}$, and $\mathrm{Ni}$ in $\mathrm{Co}_{20} \mathrm{Cr}_{20} \mathrm{Fe}_{20} \mathrm{Mn}_{20} \mathrm{Ni}_{20}$, $\mathrm{Co}_{10} \mathrm{Cr}_{10} \mathrm{Fe}_{10} \mathrm{Mn}_{10} \mathrm{Ni}_{60}$, and $\mathrm{Co}_{2} \mathrm{Cr}_{2} \mathrm{Fe}_{2} \mathrm{Mn}_{2} \mathrm{Ni}_{92}$ alloys, at the temperature of $1373 \mathrm{~K}$. The microstructure of alloys was studied, showing exclusive existence of FCC solid solution in all considered materials. To allow comparing the results in the normalized temperature scale, melting points of all studied alloys were determined with the use of differential scanning calorimetry (DSC). The results are presented in Figure 21. 


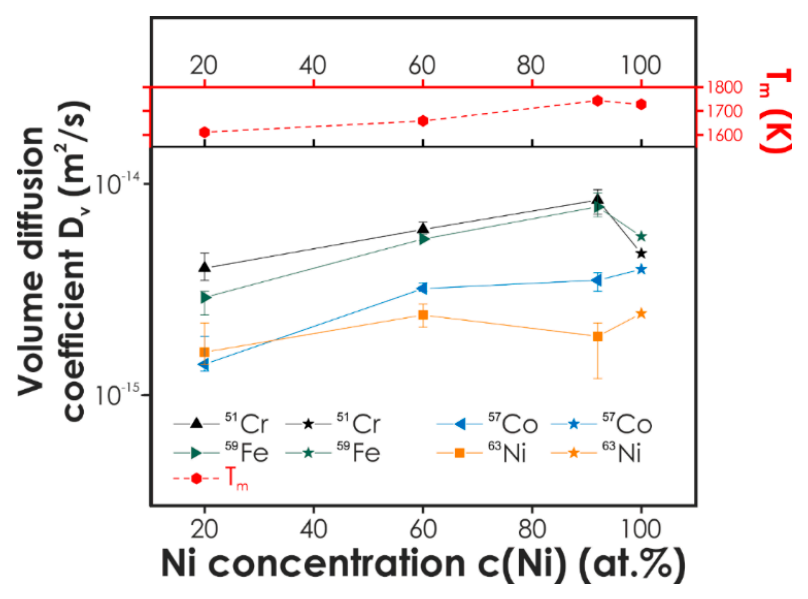

Figure 21. Volume diffusion coefficients determined for the $\mathrm{Co}_{20} \mathrm{Cr}_{20} \mathrm{Fe}_{20} \mathrm{Mn}_{20} \mathrm{Ni}_{20}$, $\mathrm{Co}_{10} \mathrm{Cr}_{10} \mathrm{Fe}_{10} \mathrm{Mn}_{10} \mathrm{Ni}_{60}$, and $\mathrm{Co}_{2} \mathrm{Cr}_{2} \mathrm{Fe}_{2} \mathrm{Mn}_{2} \mathrm{Ni}_{92}$ alloys, as functions of $\mathrm{Ni}$ content. The melting points are also presented. Data for pure Ni is given for comparison (after [41]). Reprinted from Scripta Materialia 159 (2018), Transition from a dilute solid solution to a high entropy alloy, 94-98, Copyright 2018, with permission from Elsevier.

Based on these results, the authors concluded that the volume diffusion coefficients of solutes (Co, $\mathrm{Cr}$, and $\mathrm{Mn}$ ) are slower in the high entropy alloy than in the dilute solid solutions. On the other hand, the diffusion coefficients in studied HEA were similar or even slower than in the pure nickel. The situation changed significantly when the normalized temperature scale was considered. It turned out that the diffusion coefficients were higher in $\mathrm{Co}_{10} \mathrm{Cr}_{10} \mathrm{Fe}_{10} \mathrm{Mn}_{10} \mathrm{Ni}_{60}$ by a factor of 3 (Ni) to 8 (Co) than in the $\mathrm{Co}_{20} \mathrm{Cr}_{20} \mathrm{Fe}_{20} \mathrm{Mn}_{20} \mathrm{Ni}_{20}$. In the case of $\mathrm{Co}_{2} \mathrm{Cr}_{2} \mathrm{Fe}_{2} \mathrm{Mn}_{2} \mathrm{Ni}_{92}$, the differences were even higher, varying by a factor of $10(\mathrm{Ni})$ to $30(\mathrm{Fe})$. Still, the observed differences, while significant, were within the expected range of values, typical for the FCC conventional alloys. Therefore, in the opinion of the authors, the observed dependencies do not support the existence of the sluggish diffusion effect.

In [42], Vaidya et al. investigated the thermodynamic factor $\phi$ for diffusion in $\mathrm{CoCrFeNi}$ and $\mathrm{CoCrFeMnNi}$ high entropy alloys, namely its product with the vacancy wind factor $S, \phi S$. In the experimental part of the study, the authors prepared a number of separate, quasi-binary diffusion couples, such as, e.g., the one based on the $\mathrm{Co}_{20} \mathrm{Cr}_{25} \mathrm{Fe}_{25} \mathrm{Ni}_{30}-\mathrm{Co}_{30} \mathrm{Cr}_{25} \mathrm{Fe}_{25} \mathrm{Ni}_{20}$ alloys, or the other one based on the $\mathrm{Co}_{15} \mathrm{Cr}_{20} \mathrm{Fe}_{20} \mathrm{Mn}_{20} \mathrm{Ni}_{25}-\mathrm{Co}_{25} \mathrm{Cr}_{20} \mathrm{Fe}_{20} \mathrm{Mn}_{20} \mathrm{Ni}_{15}$ (the "Co-Ni" diffusion couples). Such a procedure was applied to other diffusion couples as well: $\mathrm{Co}-\mathrm{Fe}, \mathrm{Cr}-\mathrm{Fe}$, and Fe-Ni. Such couples were then annealed at $1423 \mathrm{~K}$ for 100 and $240 \mathrm{~h}$. The choice of changing elements was based on the authors' desire to preserve the FCC structure within the whole diffusion zone. The concentration profiles measured on the annealed diffusion couples were then processed with the use of the quasi-binary approach [61], under the assumption of constant partial molar volumes of the elements, allowing obtaining the interdiffusion coefficients. The exemplary resulting plots are presented in Figure 22. 

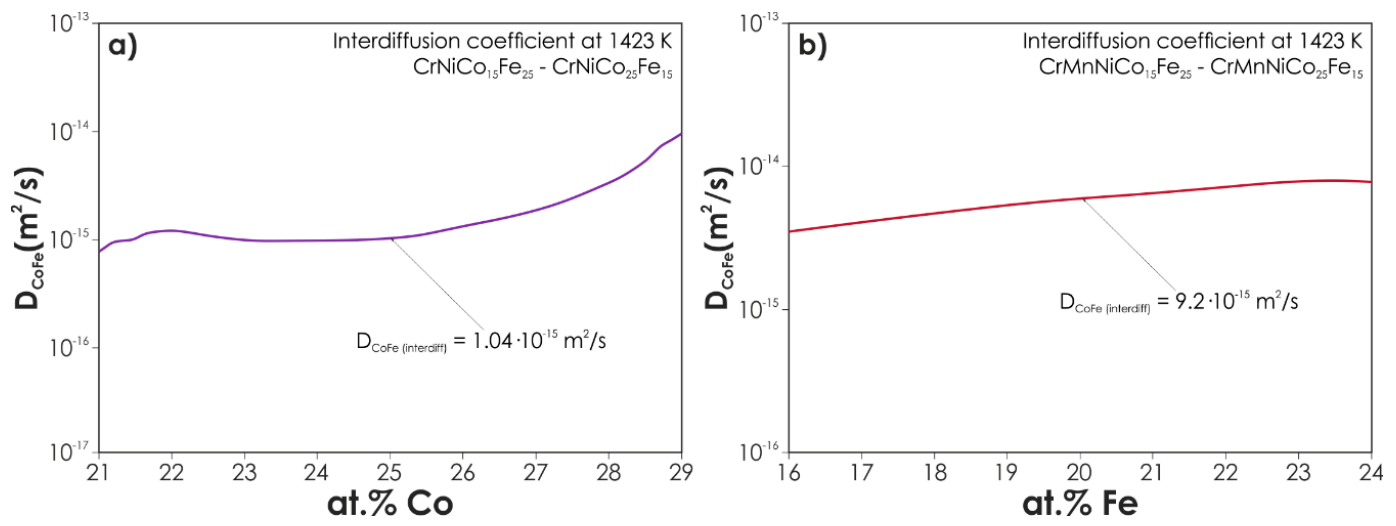

Figure 22. Concentration-dependent interdiffusion coefficients in (a) Co-Fe quaternary and (b) Co-Fe quinary diffusion couple (after [42]). Reprinted from Scripta Materialia 157 (2018), Experimental assessment of the thermodynamic factor for diffusion in $\mathrm{CoCrFeNi}$ and $\mathrm{CoCrFeMnNi}$ high entropy alloys, 81-85, Copyright 2018, with permission from Elsevier.

As can be seen, the interdiffusion coefficient was significantly lower in the case of the quaternary diffusion couple, which could be related to the fact that the melting points of $\mathrm{CoCrFeNi}$ and $\mathrm{CoCrFeMnNi}$ are, respectively, 1607 and $1717 \mathrm{~K}$, implying a higher vacancy concentration at a given temperature for the latter one, facilitating an easier atomic transport. Since the interdiffusion coefficient can be defined as:

$$
\tilde{D}=\left(n_{A} D_{B}^{*}+n_{B} D_{A}^{*}\right) \phi S
$$

where $D_{i}^{*}$ is the tracer diffusion component of the $i$-th element, the authors were able to calculate the values of $\phi S$, using tracer values determined in [39]. The obtained values are presented in Table 8.

Table 8. $\phi S$ for various diffusion couples at $1423 \mathrm{~K}$ [42].

\begin{tabular}{ccc}
\hline Diffusion Couple & $\phi S$ in CoCrFeNi & $\phi S$ in CoCrFeMnNi \\
\hline Co-Fe & $0.87_{-0.23}^{+0.35}$ & $5.85_{-1.19}^{+0.26}$ \\
Co-Ni & $1.03_{-1.0}^{+1.51}$ & $5.1_{-1.83}^{+1.17}$ \\
Cr-Fe & $1.54_{-0.45}^{+0.68}$ & $2.96_{-2.38}^{+2.27}$ \\
Fe-Ni & $1.31_{-0.80}^{+2.74}$ & $2.11_{-0.93}^{+0.70}$ \\
\hline
\end{tabular}

As visible, in the case of the quaternary CoCrFeNi system, the values of $\phi S$ were close to unity, confirming the ideality of solid solution, while in the case of $\mathrm{CoCrFeMnNi}$ system, the values exhibited strong deviation from ideal behavior, contrary to the assumption made by Tsai et al. in [28]. However, a recent reevaluation of the data obtained by Vaidya et al., performed by Belova and Murch [74], showed a very different view. In this study, the authors pointed out that the reference Manning factor should be taken for the quaternary and quinary system as, respectively, 2 and 2.5, instead of 1 as it was in [42]. As a result, the corrected values of thermodynamic factors varied in ranges of 0.43 to 0.77 and 0.84 to 2.34 for $\mathrm{CoCrFeNi}$ and $\mathrm{CoCrFeMnNi}$, respectively, indicating behavior much closer to ideal in the case of the latter alloy and more in line with the assumptions of Tsai et al. [28].

The culmination of studies by the group from Munster took place in [43], where the tracer and interdiffusion methods were combined, allowing obtaining the concentration-dependent tracer diffusivities in $\mathrm{CoCrFeMnNi}$. The experimental part consisted of a diffusion couple experiment, based on the $\mathrm{Co}_{15} \mathrm{CrFeMnNi}_{25}-\mathrm{Co}_{25} \mathrm{CrFeMnNi}_{15}$ couple, annealed at $1373 \mathrm{~K}$ for $48 \mathrm{~h}$. Additionally, each end member, as well as the initial contact interface between the alloys, was subjected to the deposition of the ${ }^{57} \mathrm{Co},{ }^{51} \mathrm{Cr},{ }^{59} \mathrm{Fe}$, and ${ }^{54} \mathrm{Mn}$ radiotracers from the $\mathrm{HCl}$ solutions, allowing simultaneous studies of both tracer and interdiffusion coefficients in one experiment. It is worth noting that despite the uniform initial distribution of $\mathrm{Mn}, \mathrm{Cr}$, and $\mathrm{Fe}$, a rather significant up-hill diffusion effects were present 
in the interdiffusion zone, suggesting a coupling between fluxes of different atoms. The tracer diffusion coefficients for the end-members of the couple, unaffected by the interdiffusion, were determined according to the Equation (10). In order to analyze the tracer concentration profiles measured near the interface of diffusion couple, another formalism was used, the one based on the thin layer isotope sandwich configuration [75], as the conventional Gaussian solution is not valid in the presence of a strong chemical driving force. Such an approach allowed obtaining concentration-dependent tracer diffusivities for the concentrations within the interdiffusion zone. The resulting values, together with the reference data from [41], are presented in Figure 23.

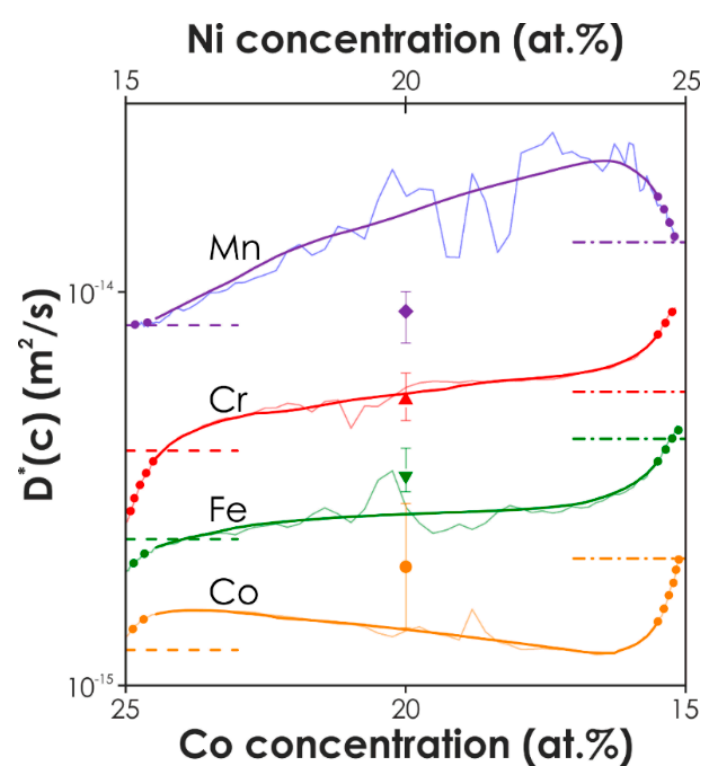

Figure 23. Tracer diffusion coefficients of $\mathrm{Co}, \mathrm{Cr}, \mathrm{Fe}$, and $\mathrm{Mn}$ as a function of the Co concentration (represented by solid lines) compared with the tracer diffusion coefficients measured in the sides with constant constituent concentration (represented by dashed lines for the Co-rich side and dashed-dot lines for the Ni-rich side) and with the tracer diffusion coefficients measured in single-crystalline CoCrFeMnNi HEA (represented by filled symbols) [40]. The dotted lines show the determined tracer diffusion coefficients for the near end-member compositions (after [43]). Reprinted from Acta Materialia 166 (2019), Concentration-dependent atomic mobilities in FCC CoCrFeMnNi high-entropy alloys, 357-370, Copyright 2019, with permission from Elsevier.

The obtained values of diffusion coefficients were then verified against the known thermodynamic and mobility databases (TCNI8/MOBNI4, TCFE9/MOBFE4, HEA-DB, developed by Hallsted's group/MOBNI4), as well as used to prepare new ones. The authors applied a newly developed theoretical formalism, so-called "pair-wise diffusion model", independent of the reference element. The atomic mobilities were described with the use of Redlich-Kister polynomials in a similar manner as presented in Equations (13) and (14), to make the resulting databases compatible with the CALPHAD approach. Two different approaches were applied for presentation of the concentration-dependent tracer diffusivities: a) linear interpolation of the coefficient, determined by tracer studies of unaffected end-members of the diffusion couple (MTIC-Lin database), b) values calculated using the approach from [41]. The comparison of the calculated atomic mobilities from different databases is presented in Figure 24. 

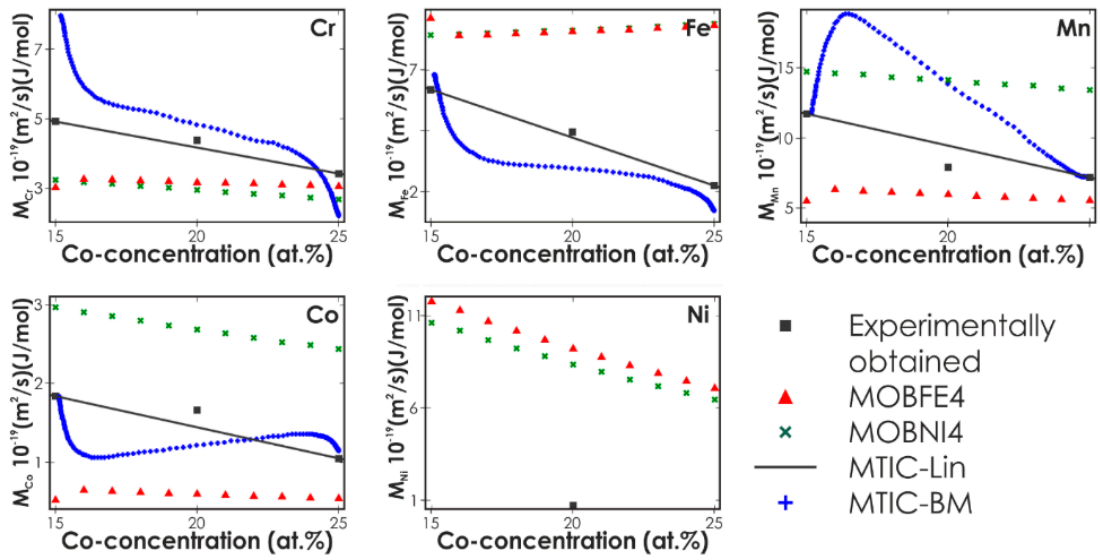

- Experimentally

obtained

- MOBFE4

$\times \quad M O B N I 4$

- MTIC-Lin

Figure 24. Composition-dependent atomic mobilities for $\mathrm{Co}, \mathrm{Cr}, \mathrm{Fe}, \mathrm{Mn}$, and $\mathrm{Ni}$. $\mathrm{Cr}, \mathrm{Fe}$, and $\mathrm{Mn}$ concentration were assumed to be constant (20 at. \% each). The black squares are the values determined from the experiments in constant composition, and a linear interpolation between the endpoints is shown as a solid line (MTIC-Lin). MTIC-BM (blue crosses) represents the result of the modified tracer-interdiffusion couple (after [43]). Reprinted from Acta Materialia 166 (2019), Concentration-dependent atomic mobilities in FCC CoCrFeMnNi high-entropy alloys, 357-370, Copyright 2019, with permission from Elsevier.

The application of the commercially available mobility databases turned out to be unsuccessful. None of the mentioned combinations was suitable to model the experimentally measured concentration profiles, and what is more, to model the directions of up-hill effects for $\mathrm{Cr}$ and Fe. On the other hand, the application of both MTIC databases proved to be the correct direction, as presented below in Figure 25.
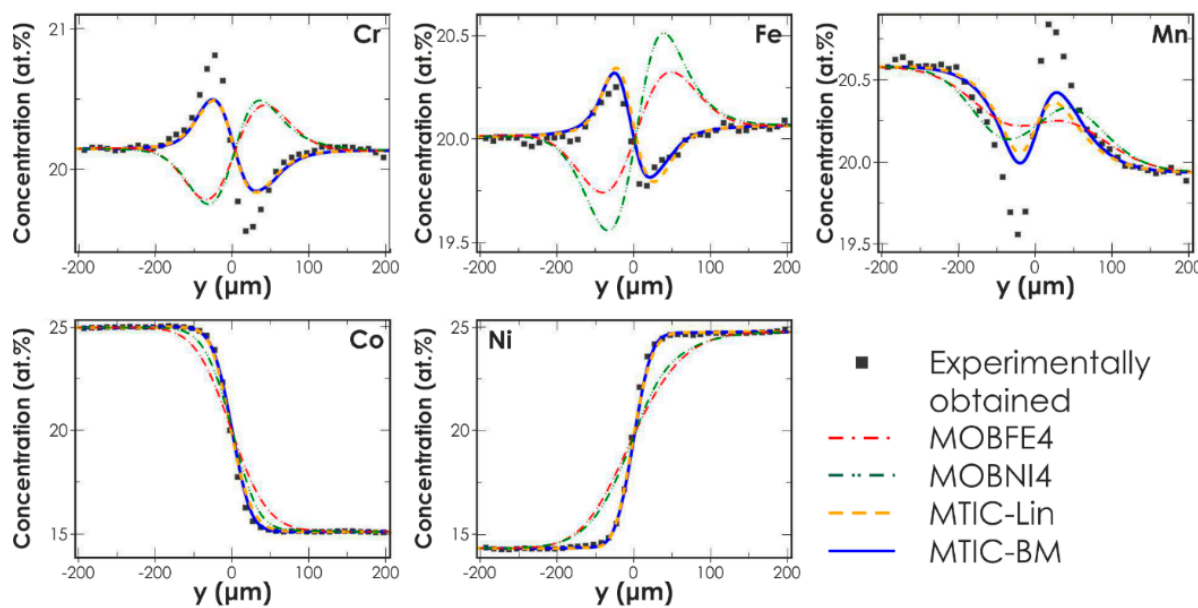

Figure 25. Comparison between experimentally obtained interdiffusion profiles and simulated ones using the HEA-DB mobility data base combined with different atomic mobility databases for all five elements (Co, $\mathrm{Cr}, \mathrm{Fe}, \mathrm{Mn}$, and Ni) after $48 \mathrm{~h}$ at $1373 \mathrm{~K}$ (after [43]). Reprinted from Acta Materialia 166 (2019), Concentration-dependent atomic mobilities in FCC CoCrFeMnNi high-entropy alloys, 357-370, Copyright 2019, with permission from Elsevier.

Additionally, the comparison between predictions of both databases and experimentally obtained tracer profiles also turned out to be successful. Once more, in the opinion of the authors, the obtained result did not confirm the presence of any specific anomalies in the diffusion behavior of the studied materials, which could be connected with the existence of the sluggish diffusion effect. 
The described series of papers, by a team from Münster, represent the current state-of-the-art in diffusion studies in HEAs. The applied methodology could be treated as the most reliable and unambiguous one, making the results extremely valuable. The only drawback of these articles lies in their focus on exclusively $\mathrm{Co}-\mathrm{Cr}-\mathrm{Fe}-\mathrm{Ni}$ and $\mathrm{Co}-\mathrm{Cr}-\mathrm{Fe}-\mathrm{Mn}-\mathrm{Ni}$ FCC-structured systems. However, it can be expected that further works, expanded on other high entropy systems, are soon to follow.

The next two articles were published by the group from Krakow and, in terms of the methodology, are a continuation of their first work [30]. The first study, published in 2018, was the article by Kucza et al. [44], who investigated diffusion in Co-Cr-Fe-Mn-Ni, Co-Cr-Fe-Ni, and Co-Fe-Mn-Ni systems. For each system, a number of diffusion couples were prepared and annealed at $1350 \mathrm{~K}$. Additionally, the pure element plus equimolar HEA, $X-\mathrm{CoCrFeMnNi}(\mathrm{X}=\mathrm{Fe}, \mathrm{Co}, \mathrm{Ni})$, single-phase diffusion couples were also prepared and annealed. Similarly, as in the previous study by this group [30], the combinatorial approach was applied in order to extract the values of tracer diffusivities. However, this time, the authors used a thermodynamic description provided by Miedema's scheme. What is more, the optimization process was conducted not for singular systems but for all three simultaneously, under the assumption that it is possible to describe all of them by the same set of composition-dependent tracer diffusivities. The last modification in comparison to the previous study was the usage of the experimentally determined position of Kirkendall plane as part of the optimization process.

For all systems, a very good agreement between experimental and fitted profiles was observed, indicating that all three of them could be described using the same matrix of tracer diffusivities. This, in turn, showed that the kinetics of diffusion was independent of the number of elements in the system, as no differences between quaternary and quinary system were visible. Such behavior contradicted the most basic assumptions of the sluggish diffusion theorem. The determined values of tracer diffusivities for pure elements were within 0.25 orders of magnitude from the values measured in the tracer measurements [57] and in good quantitative agreement with the values reported by Vaidya et al. [31]. The observed sequence of the fastest to the slowest element was similar as in other studies, with relations between diffusivities values in the CoCrFeMnNi composition being: $D_{M n}^{*}>D_{C r}^{*} \approx D_{F e}^{*}>D_{C o}^{*} \approx D_{N i}^{*}$. The thermodynamic factors, defined as:

$$
W_{i}=\frac{\partial \mu_{i}}{\partial \ln n_{i}}
$$

were calculated for the diffusion couples from the quinary system, for the position of the Kirkendall plane. The obtained values suggested the pronounced effect of the Mn on the thermodynamics of the system. Based on these results, the authors stated that the differences in diffusion behavior between quaternary and quinary systems are negligible and may result strictly from the thermodynamic interactions between different elements. However, the matter of the presumed abnormal behavior in the normalized temperature scale was not considered.

The subject of the existence of the sluggish diffusion effect was the main topic of the most recent work from Kraków, authored by Dabrowa et al. [45]. The authors studied diffusion behavior in $\mathrm{Co}-\mathrm{Cr}-\mathrm{Fe}-\mathrm{Mn}-\mathrm{Ni}$, Co-Cr-Fe-Ni, Co-Fe-Mn-Ni, and Co-Cr-Mn-Ni high entropy systems, as well as reevaluated the result for $\mathrm{Al}-\mathrm{Co}-\mathrm{Cr}-\mathrm{Fe}-\mathrm{Ni}$ system from [30]. In the experimental part, the diffusion couple experiments were carried out at 1230, 1270, 1310, and $1350 \mathrm{~K}$ for each system. Based on the obtained concentration profiles, the tracer diffusivities were determined using a modification of the combinatorial approach applied previously in [30,44]. Similarly, as in [44], the thermodynamic description was provided by the values of interaction parameters from Miedema's scheme. Due to relatively low values of concentration gradients (typically not exceeding 12 at. \%), the authors used an assumption of the composition-independent tracer diffusivities. For all systems, the authors determined the melting temperature, which allowed further analysis of the data in both absolute and normalized temperature scales. 
For all systems and all elements, the values of pre-exponential factors and energies of activation were determined, see Table 9.

Table 9. Values of energies of activation $E_{a}$, pre-exponential factors $D_{i, 0}$, and coefficients of determination $R^{2}$, obtained as a result of fitting the results with the Arrhenius relation [45].

\begin{tabular}{|c|c|c|c|}
\hline Element & $E_{a}(\mathrm{~kJ} / \mathrm{mol})$ & $D_{i, 0}\left(\mathrm{~m}^{2} / \mathrm{s}\right)$ & $R^{2}$ \\
\hline \multicolumn{4}{|c|}{$\mathrm{Co}-\mathrm{Cr}-\mathrm{Fe}-\mathrm{Mn}-\mathrm{Ni}$} \\
\hline $\mathrm{Cr}$ & $313.5 \pm 19.4$ & $3.59^{+21.43} \times 10^{-3}$ & 0.9924 \\
\hline $\mathrm{Mn}$ & $303.2 \pm 18.9$ & $3.95^{+22.35} \times 10^{-3}$ & 0.9923 \\
\hline $\mathrm{Fe}$ & $313.1 \pm 17.5$ & $4.05_{-3.26}^{+20.06} \times 10^{-3}$ & 0.9938 \\
\hline Co & $336.2 \pm 38.2$ & $1.5_{-151}^{+54.72} \times 10^{-2}$ & 0.9749 \\
\hline $\mathrm{Ni}$ & $314.1 \pm 14.4$ & $1.19_{-0.88}^{+4.25} \times 10^{-3}$ & 0.9958 \\
\hline \multicolumn{4}{|c|}{ Co-Cr-Fe-Ni } \\
\hline $\mathrm{Cr}$ & $315.6 \pm 8.2$ & $1.67_{-0.89}^{+1.92} \times 10^{-3}$ & 0.9987 \\
\hline $\mathrm{Fe}$ & $303.9 \pm 20.0$ & $7.06_{-5.97}^{+38.60} \times 4$ & 0.9914 \\
\hline Co & $396.9 \pm 42.5$ & $2.00_{-1.96}^{+103.56} \times 10^{0}$ & 0.9776 \\
\hline $\mathrm{Ni}$ & $374.8 \pm 42.8$ & $7.98_{-7.83}^{+427.83} \times 10^{-2}$ & 0.9746 \\
\hline \multicolumn{4}{|c|}{ Co-Fe-Mn-Ni } \\
\hline $\mathrm{Mn}$ & $250.7 \pm 10.3$ & $6.10_{-4.78}^{+9.93} \times 10^{-5}$ & 0.9966 \\
\hline $\mathrm{Fe}$ & $263.2 \pm 11.9$ & $9.05_{-6.06}^{+18.33} \times 10^{-5}$ & 0.9960 \\
\hline Co & $314.5 \pm 18.7$ & $4.18_{-3.48}^{+20.66} \times 10^{-3}$ & 0.9927 \\
\hline $\mathrm{Ni}$ & $243.5 \pm 6.1$ & $2.80_{-1.22}^{+2.15} \times 10^{-6}$ & 0.9988 \\
\hline \multicolumn{4}{|c|}{ Co-Cr-Mn-Ni } \\
\hline $\mathrm{Cr}$ & $281.9 \pm 9.8$ & $3.60_{-215}^{+5.35} \times 10^{-4}$ & 0.9976 \\
\hline Mn & $263.5 \pm 17.3$ & $2.31_{-1.85}^{+9.34} \times 10^{-4}$ & 0.9914 \\
\hline Co & $270.0 \pm 12.7$ & $1.05_{-0.73}^{+-1.40} \times 10^{-4}$ & 0.9956 \\
\hline $\mathrm{Ni}$ & $508.7 \pm 83.2$ & $3.74_{-3.74}^{+8839.77} \times 10^{4}$ & 0.9493 \\
\hline \multicolumn{4}{|c|}{ Al-Co-Cr-Fe-Ni } \\
\hline $\mathrm{Al}$ & $349.9 \pm 10.6$ & $2.75_{-172}^{+4.63} \times 10^{-1}$ & 0.9991 \\
\hline $\mathrm{Cr}$ & $278.1 \pm 15.2$ & $1.34_{-1.01}^{+4.15} \times 10^{-4}$ & 0.9970 \\
\hline $\mathrm{Fe}$ & $280.1 \pm 7.8$ & $1.76_{-0.90}^{+1.85} \times 10^{-4}$ & 0.9992 \\
\hline Co & $268.6 \pm 16.5$ & $3.81_{-2.99}^{+13.85} \times 10^{-5}$ & 0.9962 \\
\hline $\mathrm{Ni}$ & $184.8 \pm 206.9$ & $1.99_{-1.99}^{+4.2 E+8} \times 10^{-9}$ & 0.4438 \\
\hline
\end{tabular}

In the case of the $\mathrm{Co}-\mathrm{Cr}-\mathrm{Fe}-\mathrm{Mn}-\mathrm{Ni}$, the above results were compared with the available literature data $[28,34,39]$, showing good agreement on both quantitative and qualitative levels. For Co-Cr-Fe-Ni, the values of energies of activation for $\mathrm{Co}$ and $\mathrm{Ni}$ were deemed to be slightly too high, which was most probably a result of the relatively narrow diffusion zones obtained for this system, as well as deficiencies of the combinatorial approach itself. The next two systems, namely Co-Fe-Mn-Ni and $\mathrm{Co}-\mathrm{Cr}-\mathrm{Mn}-\mathrm{Ni}$, were investigated for the first time. For the first one, excellent quality of fitting was reported, together with relatively very low values of errors for the determined energies of activation. What is interesting, the energy of activation for cobalt was significantly higher than for other elements. In the case of the Co-Cr-Mn-Ni system, the applied methodology did not allow extracting the values of tracer diffusivity for the Ni. On the other hand, the values for other elements exhibited excellent agreement with the Arrhenius relation. 
The reevaluation of the results for $\mathrm{Al}-\mathrm{Co}-\mathrm{Cr}-\mathrm{Fe}-\mathrm{Ni}$, this time without the assumption of the system's ideality, brought several differences in comparison to [30], with the biggest one being an excellent agreement with the Arrhenius relation for the aluminum, despite its very low concentration gradient within the couple. The influence of the thermodynamic description on the determined values of tracer diffusivities was further investigated in the example of the Co-Fe-Mn-Ni system. The optimization process was conducted for two different descriptions-for the ideal system and for the system described with Miedema's values. The results are presented in Figure 26.

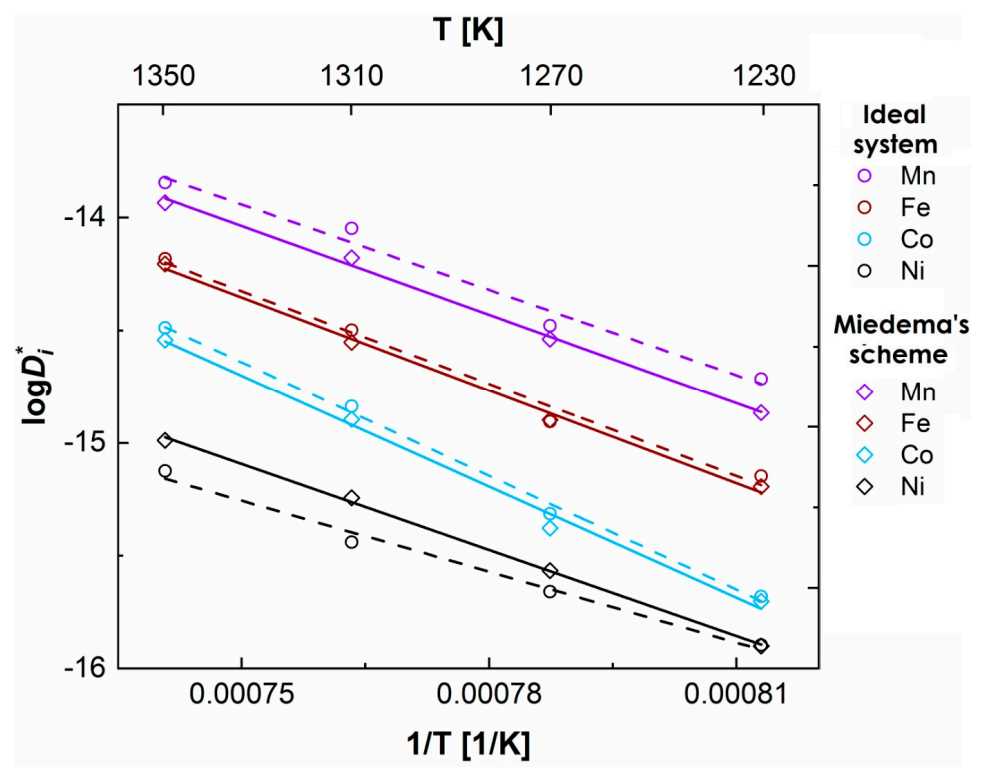

Figure 26. Comparison of the Arrhenius plots for the tracer diffusivities obtained for the Co-Fe-Mn-Ni using ideal system assumptions and values of interaction parameters provided by Miedema's scheme [45]. Reprinted from Journal of Alloys and Compounds 783 (2019), Demystifying the sluggish diffusion effect in high entropy alloys, 193-207, Copyright 2019, with permission from Elsevier.

As can be seen, the differences in the values of applied interaction parameters could lead to differences in values of diffusivities, although in the opinion of the authors, they do not have a major effect on our perception of diffusion being sluggish or not.

In order to verify the existence of the sluggish diffusion effect, the authors performed the comparison of obtained results with the data for conventional systems, for bo9th absolute and normalized temperatures scales, presented, respectively, in Figures 27 and 28.

As a result of this analysis, the authors concluded that in the absolute temperature scale, the rate of diffusion in HEAs does not differ from the one observed in conventional alloys and, therefore, cannot be treated as sluggish. On the other hand, in the case of the normalized temperature scale, several high entropy systems exhibited behavior similar to the one postulated by Tsai et al. [28], being significantly slower than other systems. However, such behavior was observed only for systems with $\mathrm{Mn}$. What is more, it turned out that even conventional binary and ternary systems with Mn shared the same behavior, being even slower than the high entropy systems. Therefore, in the authors' opinion, the notion of sluggish diffusion in HEAs should be considered false, and the only sluggishness, accidentally observed for Co-Cr-Fe-Mn-Ni system, is the one occurring in the Mn-containing alloys. 

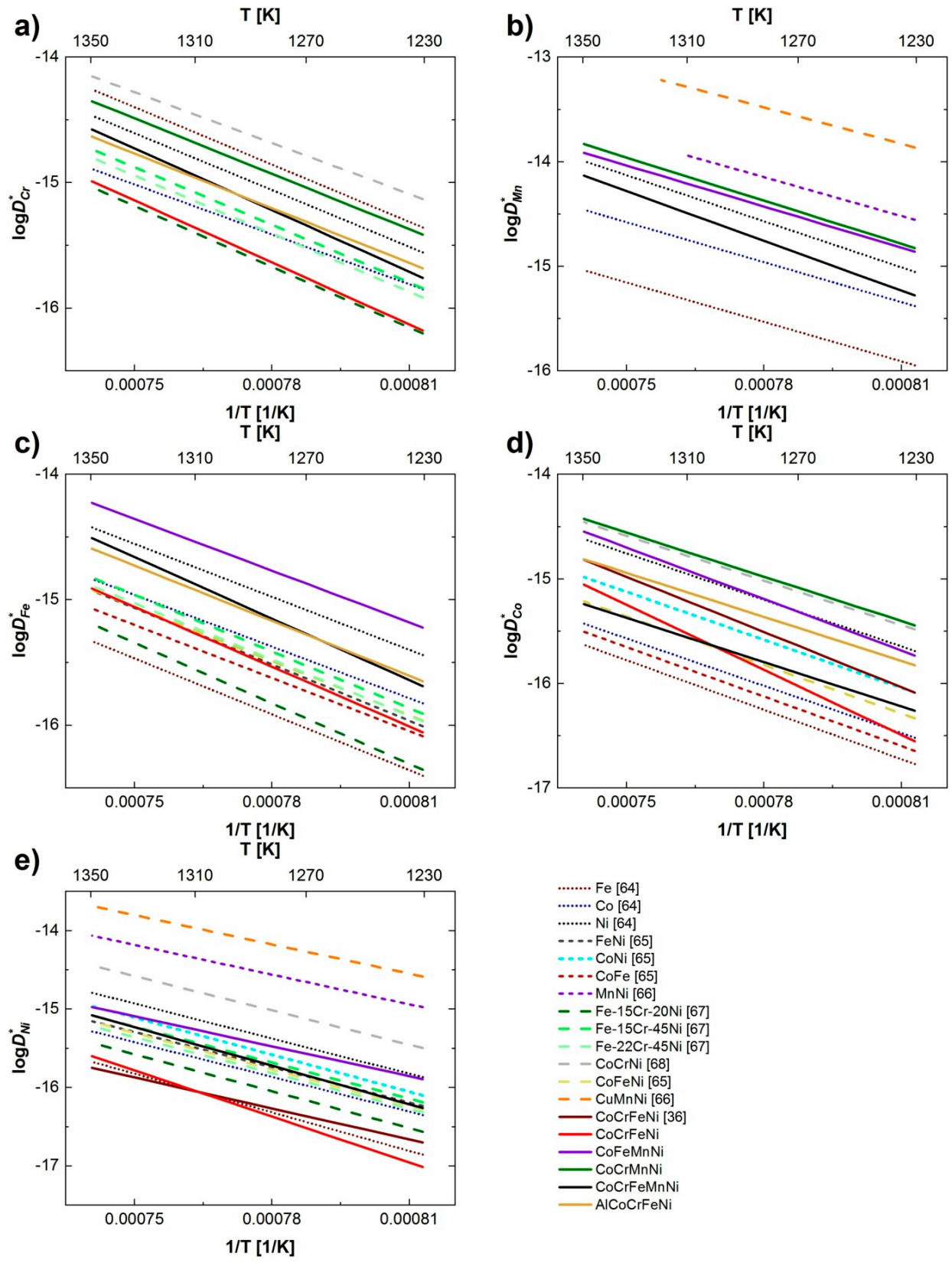

Figure 27. Tracer diffusion coefficients of different elements in different FCC matrices: (a) Cr, (b) Mn, (c) $\mathrm{Fe}$, (d) $\mathrm{Co},(\mathbf{e}) \mathrm{Ni}$. All plots are presented on an absolute temperature scale [45]. Reprinted from Journal of Alloys and Compounds 783 (2019), Demystifying the sluggish diffusion effect in high entropy alloys, 193-207, Copyright 2019, with permission from Elsevier. 
a)

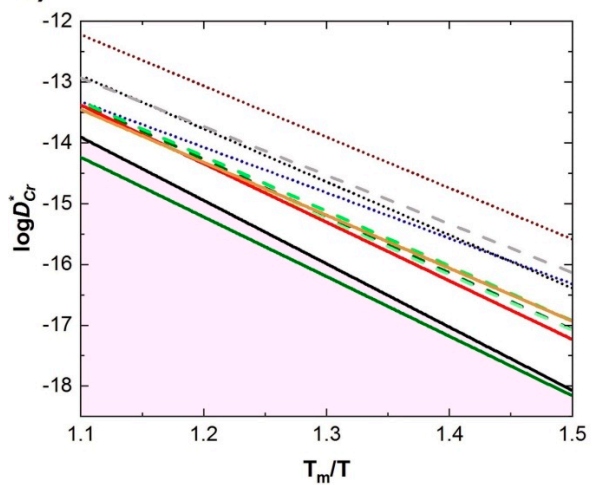

c)

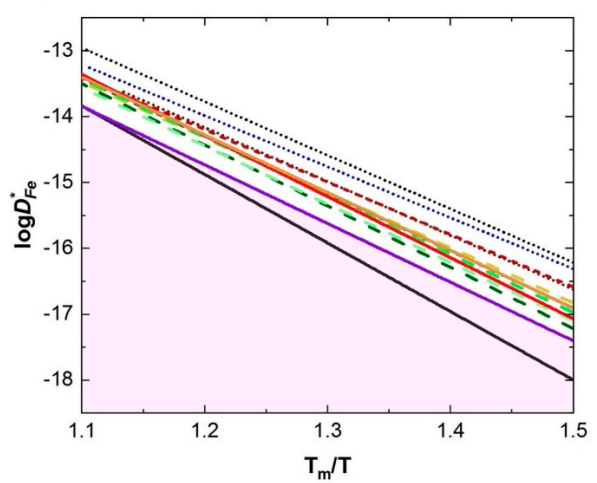

e)

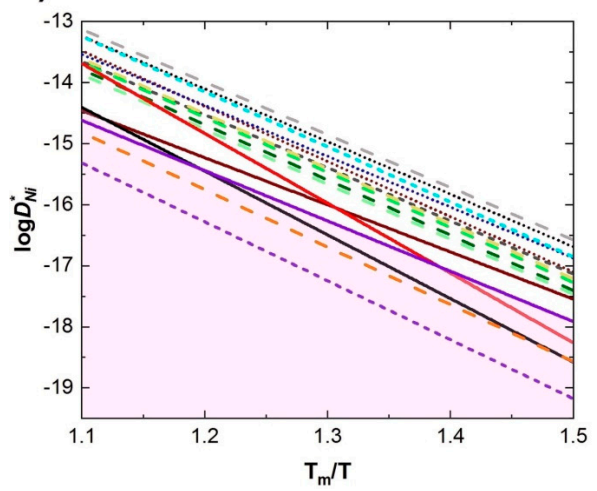

b)

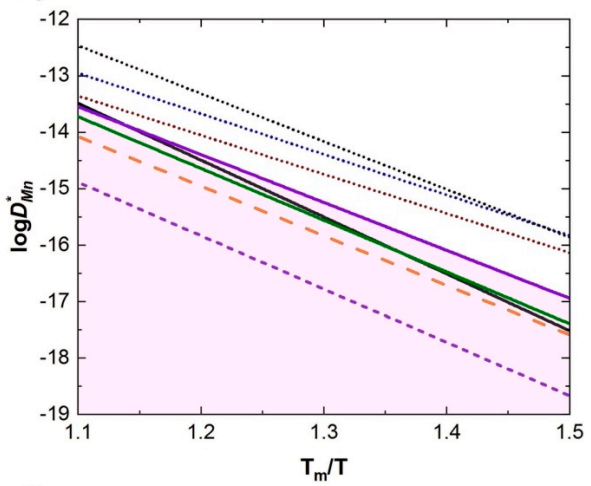

d)
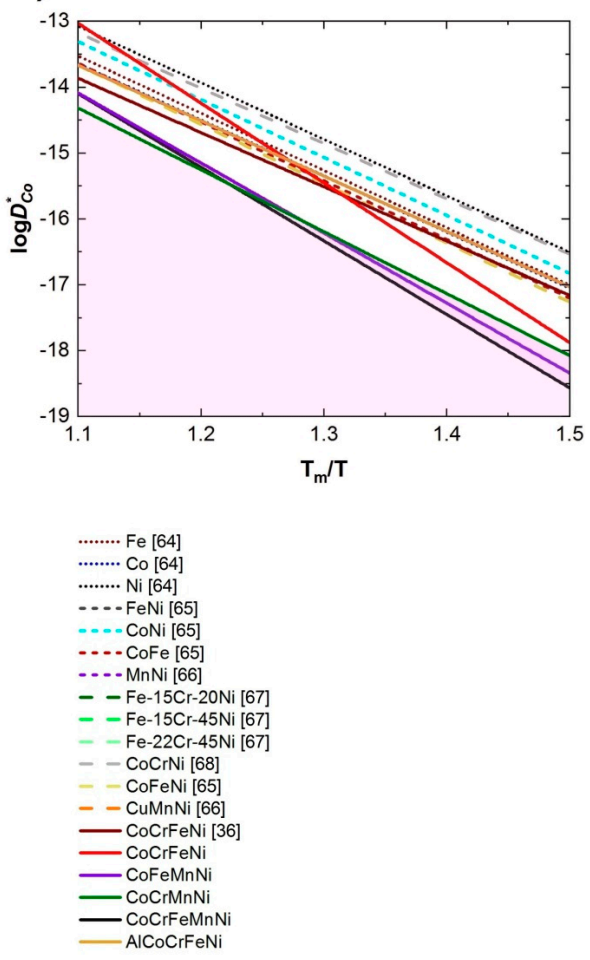

Figure 28. Tracer diffusion coefficients of different elements in different FCC matrices: (a) Cr, (b) Mn, (c) $\mathrm{Fe},(\mathbf{d}) \mathrm{Co},(\mathbf{e}) \mathrm{Ni}$. All plots are presented in temperature scale, normalized with respect to melting points of the alloys. The colored area is limited by the fastest diffusing Mn-containing system [45]. Reprinted from Journal of Alloys and Compounds 783 (2019), Demystifying the sluggish diffusion effect in high entropy alloys, 193-207, Copyright 2019, with permission from Elsevier.

\subsection{State-of-the-Art in Theoretical Studies}

Despite the mentioned deficiencies, the results of Tsai et al. [28] were further used as a benchmark or subject of analysis by other authors. Beke and Erdelyi conducted a comparative "theoretical" analysis of the normalized diffusivities in HEAs and other FCC-structured metallic alloys [48]. They used the following form of Arrhenius relation:

$$
D_{0}^{\text {norm }}=D_{0}^{\text {norm }} \exp \left(-\frac{E_{a}^{\text {norm }}}{k T_{m}^{\text {norm }}}\right)
$$




$$
T_{m}^{\text {norm }}=\frac{T}{T_{\mathrm{m}}} ; E_{a}^{\text {norm }}=\frac{E_{\mathrm{a}}}{k T_{\mathrm{m}}} ; D_{0}^{\text {norm }}=D_{0}\left(\frac{\mathrm{kT}_{\mathrm{m}} \mathrm{a}^{2}}{M_{i}}\right)^{-1 / 2}
$$

where $M_{i}$ is the molar mass of the $i$-th component, and $a$ is the lattice constant. The resulting, normalized plots for $\mathrm{Ni}$ and Fe are presented in Figure 29:
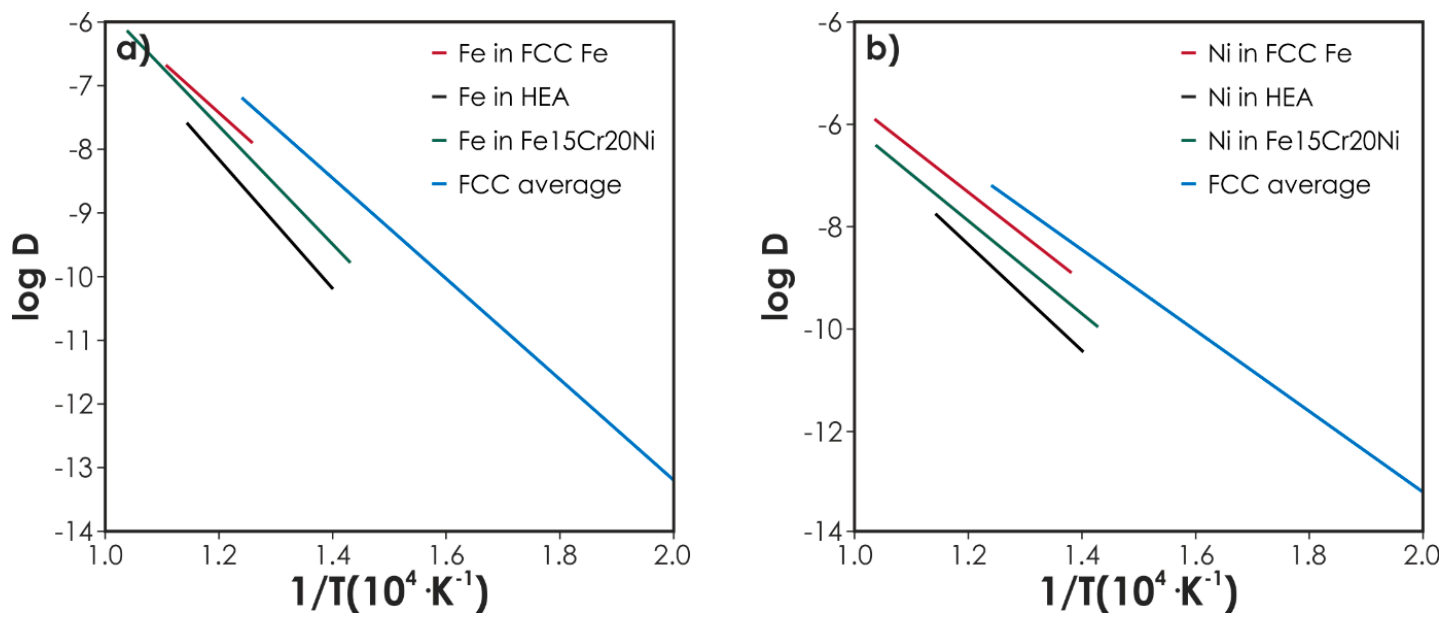

Figure 29. Normalized diffusion data (Equation (20)) vs. reciprocal reduced temperature for (a) Fe and Fe alloys, (b) Ni and Ni alloys (after [48]). Reprinted from Materials Letters (2016), On the diffusion in high-entropy alloys, 193-207, Copyright 2016, with permission from Elsevier.

As can be seen, there was a systematic shift down for the Fe-Cr-Ni and HEA lines (although the slopes of the lines were relatively similar to the average values). In the opinion of the authors, these results confirmed the sluggish character of diffusion in HEA, although they rather attributed it to the correlation effects.

Another two studies [49,50], authored by the team of Murch and Belova, were widely considered to be authorities in the field of theory of diffusion. Both studies focused strictly on the theoretical description of the diffusion in high entropy alloys, with no additional experimental data. The first work was dedicated to the derivation of new formalism for high entropy systems. The authors reviewed a number of currently used ones, coming to the conclusion that the Moleko-Allnatt-Allnatt (MAA) theory should be considered the most accurate and general description. However, the complexity of the MAA theory is so high that it is impossible to apply it to systems with more than three components. As a result, they proposed a new theory, the so-called MAA-light, which could be applied to the 5-component systems when combined with suitable, iterative, numerical methods. The description of the MAA-light formalism is beyond the scope of the current thesis; therefore, only some of the conclusions have been discussed here. It was shown that in the random alloy model, tracer correlation effects could be observed, which might result in the reduction of the fastest tracer diffusion up to $85 \%$ for the quinary systems (depending on the values of diffusivities in the system), while not affecting the slowest diffusion processes. Additionally, in the authors' opinion, the presence of tracer correlation effects should be considered an important contribution to the total activation energies, especially for the fastest components (e.g., up to $4 \%$ of its total value for $\mathrm{Cr}$ and $\mathrm{Mn}$ in $\mathrm{Co}-\mathrm{Cr}-\mathrm{Fe}-\mathrm{Mn}-\mathrm{Ni}$ system).

The second article by this team concentrated strictly on the analysis of the results by Tsai et al. [28], with the use of the MAA-light theory. For comparison, the results of the analysis with the use of both the Darken [76] and the Manning-Holdsworth-Elliot [77] theories were also presented. The comparison of the obtained self-diffusivities showed that in all cases, only the diffusion coefficient of Ni was significantly corrected in comparison to the tracer data provided by Tsai et al. (see Figure 30). 

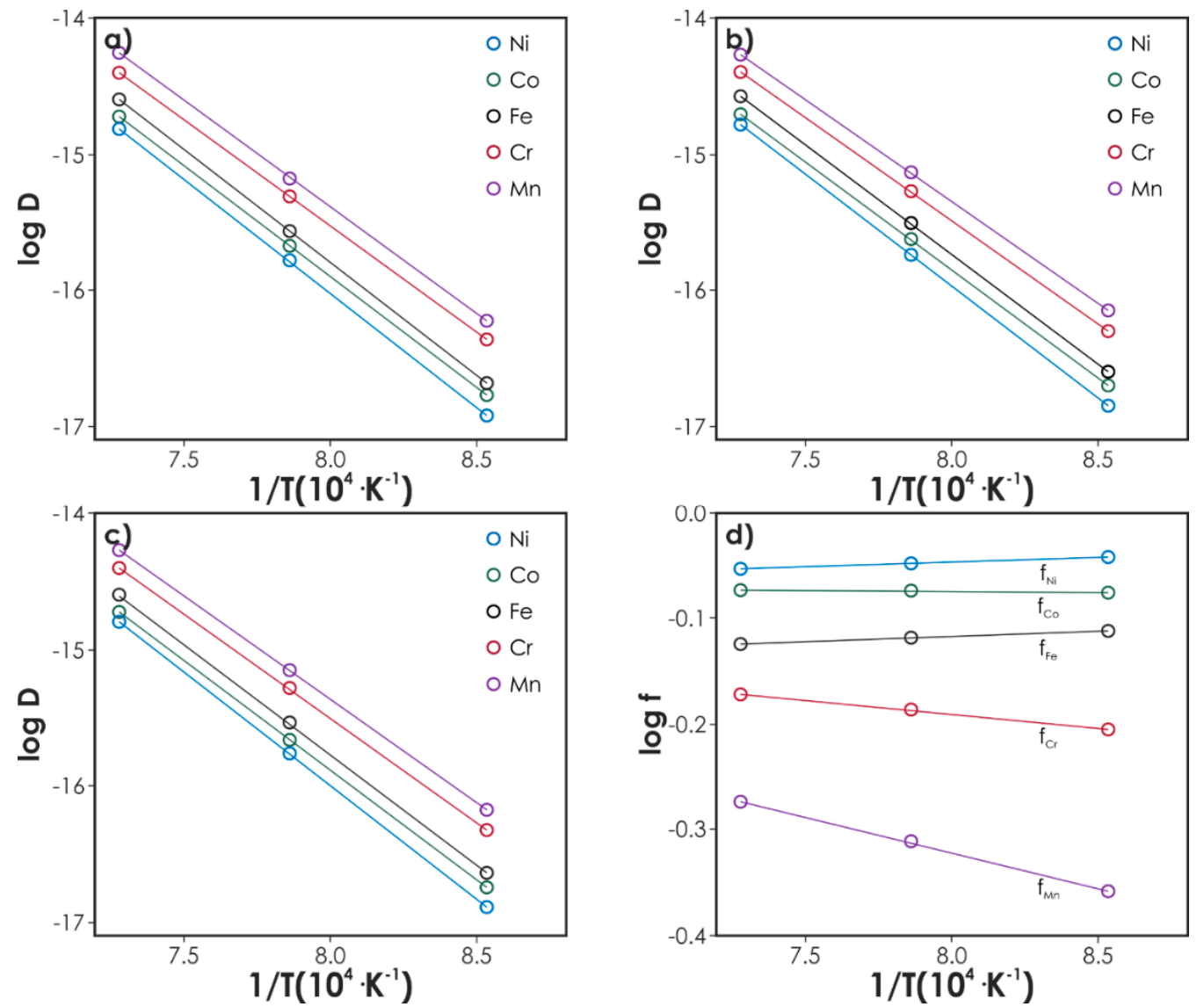

Figure 30. Self-diffusion coefficients calculated, based on the experimental data by Tsai et al. [28], with the use of three different approaches: (a) Darken, (b) Manning-Holdsworth-Elliot, (c) light Moleko-Allnatt-Allnatt (MAA). d) Correlation factors for the self-diffusion coefficients calculated by the MAA-light approach (after [50]). Reprinted from Materials Chemistry and Physics (2018), Analysis of diffusion in high entropy alloys, 193-207, Copyright 2018, with permission from Elsevier.

Furthermore, the use of MAA-light formalism allowed calculating the contribution of the correlation factors to total activation energies, with the highest one being determined for $\mathrm{Mn}$ $\left(+12.3 \mathrm{~kJ} \cdot \mathrm{mol}^{-1}\right)$. Finally, the authors calculated the values of phenomenological coefficients, showing that in the MAA-light approach, the off-diagonal terms might be significant, reaching up to $31 \%$ of the value for diagonal ones.

Studies by Allnatt et al. [49] and Paul et al. [50] provided a very valuable insight into the nature of correlation effects in high entropy alloys, as well as valuable theoretical tools for analysis of diffusion phenomena in high entropy alloys. However, it should be remembered that MAA-light theory, while simplified in comparison to legacy MAA, is still an extremely complex description of the diffusion process, far more complicated than the Darken or Manning theories. Additionally, the conclusions formulated by Paul et al. [50] should be treated very carefully, as all theoretical analyses performed in this study are based on the results by Tsai et al. [28], which can be considered as controversial [46], as discussed previously.

\section{Conclusions}

The question of sluggish diffusion effect existence is one of the most prominent ones, regarding this group of materials. Its alleged presence, along with other "core effects", is one of the driving forces for their development, especially with regard to their application as high-temperature structural materials. It implies the possibility of obtaining materials of better thermal stability, improved mechanical 
properties, better creep resistance, and higher resistance to the high-temperature corrosion. If obtained, such a combination of properties would most probably result in a completely new generation of high-temperature materials. However, despite years of effort, the scientific community is still far from proving the overall superiority of high entropy alloys over conventional materials. Such lack of convincing evidence is one of the main reasons, why during the last few years, the existence of "core effects", including sluggish diffusion one, has been put into question.

For years, the sluggish diffusion effect was taken for granted, as during the first decade of high entropy alloys development, none of the efforts to verify its presence was undertaken. This changed with the pioneering study of Tsai et al. [28], who claimed to observe its existence in the Co-Cr-Fe-Mn-Ni system and shaped the leading narration for the next years. However, the study of Tsai et al. has become widely criticized in the diffusion community, and the correctness of the data is now questioned. What is more, even in this study, the sluggishness of diffusion was observed only after normalizing the diffusion data with respect to the melting temperature of the alloy. This yields an important question-are there any further pieces of evidence supporting the presence of sluggish diffusion in HEAs? The answer is a complicated one, as it depends on one's expectations set upon the sluggish diffusion effect. Looking at the described state-of-the-art of diffusion studies in HEAs, it can be said that there is completely no evidence of any diffusion sluggishness in the absolute temperature scale if the tracer diffusivities are considered. The extensive tracer studies of a group of Divinski et al. showed in an indisputable way that even in the Co-Cr-Fe-Mn-Ni system, the tracer diffusivities in considered HEAs were not abnormal in any way. Similar conclusions were reached by Dabrowa et al. [45], as well as by Zhang et al. [34]. This already contradicts the most important assumptions of the sluggish diffusion effect, as described behavior cannot be used to justify the number of features postulated by Yeh, such as slow rates of nucleation of other phases or slow rates of high-temperature oxidation. The next question concerns the sluggishness of diffusion observed by Tsai et al. in Co-Cr-Fe-Mn-Ni in the normalized temperature scale. It was, in fact, this feature that was used as proof of the sluggish diffusion effect existence. Indeed, further studies on the Co-Cr-Fe-Mn-Ni system confirmed it as having much slower diffusion kinetics than other FCC systems in the normalized temperature scale. However, it is worth noting that similar behavior was not observed for other high entropy systems, e.g., Co-Cr-Fe-Ni, making the whole argument much less convincing. The recent study of Dabrowa et al. revealed that the mentioned sluggishness was strictly correlated with the presence of Mn in the system and, in fact, was common for all Mn-containing systems, irrespective of the high-entropy. Therefore, there is absolutely no evidence that the number of components in the alloy influences the tracer and self-diffusivities on any level or in any temperature scale. The only unresolved question in terms of diffusion sluggishness is the question of interdiffusivities. The sluggish interdiffusion coefficients were reported by Cheng et al., who applied their "pragmatic numerical inverse method" to a number of different high-entropy systems in all cases, observing values of interdiffusion coefficients, which were interpreted by them as sluggish. However, in most cases, they used the ideal system assumption, which could lead to relatively big errors, especially when one considers results of Kulkarni et al. and Verma et al., who proved that the thermodynamic interactions in Co-Cr-Fe-Ni and Co-Cr-Fe-Mn-Ni, commonly treated as near-ideal ones, were, in fact, far from being neglectable. Therefore, to completely answer the question of sluggish interdiffusivities in HEAs, further studies benefiting from the detailed thermodynamic description of the systems would be necessary. But even if confirmed, the diffusion sluggishness on the level of interdiffusivities would not change the general outlook, as it still would be more of the thermodynamic product than an inherent property of HEAs correlated with the number of components in the alloy.

To sum it up, as of today, there is absolutely no evidence supporting the existence of sluggish diffusion effect in high entropy alloys, a view, which was also shared by Divinski et al. in their latest review article [51]. Such a conclusion has a number of consequences. Firstly, it takes out the "magic" factor from HEAs-there is no reason to believe that these materials, as a group, carry some inherited advantage over conventional ones in terms of their potential as high-temperature materials. 
As pointed by Miracle and Senkov in their excellent review [4], the high entropy alloys should be rather thought of as an extension of more conventional systems rather than a completely new family of alloys. It also translates on their properties-development of the new compositions may lead to better materials, but can as well result in vastly inferior ones, and each case should be treated as a specific one. The next consequence is a much more complicated one. Throughout the whole history of high entropy alloys, the sluggish diffusion effect was constantly used as a way of explaining a number of different phenomena observed in HEAs. Assuming its nonexistence, the metallurgical community would face a need for a revision of its previous assumptions and finding new ways of explaining the properties of these alloys. Lastly, it is hard not to notice the rapid development of other groups of high entropy materials, such as oxides, carbides, diborides, and silicides. It is already apparent that theoretical descriptions of these systems greatly benefit from the experiences with metallic systems. As a result, the idea of "core effects", including the sluggish diffusion one, has already been mentioned as applicable to these systems. While presence of more than one sublattice in the ionic compounds certainly may result in drastically different properties than in metals, and the existence sluggish diffusion theorem should be verified for each of them rather than outrightly dismissed, lack of the presence of HEAs should result in much higher dose of skepticism toward this idea in other types of system than the one currently observed.

Does it all mean that the matter of sluggish diffusion existence in high entropy alloys is a completely closed one? Actually, it is quite far from it. Until now, there is no proof of its existence. But if one takes a close look at the summary of diffusion studies in HEAs presented in Table 1, one thing becomes noticeable-all of them considered exclusively the FCC phase. By definition, the FCC-structured HEAs are characterized by a relatively low lattice distortion, resulting in the lower lattice strain. As a result, they are not particularly predisposed to exhibit anomalous diffusion behavior, as the atomic movement should not be affected by lattice distortion. On the other hand, the BCC-structured HEAs represent the opposite side of the spectrum, with their relatively highly distorted lattices, which bring them much closer to the behavior, originally envisioned by Yeh. It is not out of the question that some kind of sluggish diffusion may be present in them. For years, the diffusion studies in BCC-structured HEAs were hindered by their compositions, characterized by the almost exclusive presence of refractory elements, resulting in prohibitively high melting and Tamman's temperatures. Fortunately, the recent developments in the field of BCC HEAs open doors for such studies, by the introduction of stable BCC high entropy alloys, without or with the only minor addition of troublesome refractory metals. Some of the examples are Al-Cr-Fe-Mn-V, Al-Mn-Nb-Ti-V, Al-Cr-Mn-Ti-V, Co-Fe-Mn-Ni-V, Al-Cr-Fe-Mo-W, $\mathrm{Co}-\mathrm{Cu}-\mathrm{Fe}-\mathrm{Mn}-\mathrm{Ni}, \mathrm{Co}-\mathrm{Cr}-\mathrm{Fe}-\mathrm{Mn}-\mathrm{Ni}$, and $\mathrm{Al}-\mathrm{Cr}-\mathrm{Fe}-\mathrm{Mo}-\mathrm{V}$ systems. The development of these alloys leads to a completely new, uncharted territory of diffusion studies in HEAs, one which should drastically differ from the currently known. Therefore, it can be said that there is still enough work in the field of sluggish diffusion in HEAs to keep scientists busy for years to come.

Funding: This work is supported by the National Science Centre for OPUS 13, project no. 2017/25/B/ST8/02549.

Acknowledgments: The authors would like to express their gratitude towards Mirosław Stygar for his help with the graphics.

Conflicts of Interest: The authors declare no conflict of interest.

\section{References}

1. Cantor, B.; Chang, I.T.; Knight, P.; Vincent, A.J. Microstructural development in equiatomic multicomponent alloys. Mater. Sci. Eng. A Struct. 2004, 375-377, 213-218. [CrossRef]

2. Yeh, J.W.; Chen, S.K.; Lin, S.J.; Gan, J.Y.; Chin, T.S.; Shun, T.T.; Tsau, C.H.; Chang, S.Y. Nanostructured high-entropy alloys with multiple principal elements: Novel alloy design concepts and outcomes. Adv. Eng. Mater. 2004, 6, 299-303. [CrossRef]

3. Zhang, Y.; Zuo, T.T.; Tang, Z.; Gao, M.C.; Dahmen, K.A.; Liaw, P.K.; Lu, Z.P. Microstructures and properties of high-entropy alloys. Prog. Mater. Sci. 2014, 61, 1-93. [CrossRef] 
4. Miracle, D.B.; Senkov, O.N. A critical review of high entropy alloys and related concepts. Acta Mater. 2017, 112, 448-511. [CrossRef]

5. Yeh, J.W. Recent Progress in High-entropy Alloys. Ann. Chim. Sci. Mater. 2006, 31, 633-648. [CrossRef]

6. Rost, C.M.; Schaet, R.; Borman, T.; Moballegh, A.; Dickey, E.C.; Hou, D.; Jones, J.L.; Curtarolo, S.; Maria, J.P. Entropy-stabilized oxides. Nat. Commun. 2015, 6, 8485. [CrossRef]

7. Pickering, E.J.; Jones, N.G. High-entropy alloys: A critical assessment of their founding principles and future prospects. Int. Mater. Rev. 2016, 61, 183-202. [CrossRef]

8. Otto, F.; Yang, Y.; Bei, H.; George, E.P. Relative effects of enthalpy and entropy on the phase stability of equiatomic high-entropy alloys. Acta Mater. 2013, 61, 2628-2638. [CrossRef]

9. Zhang, F.; Zhang, C.; Chen, S.L.; Zhu, J.; Cao, W.S.; Kattner, U.R. An understanding of high entropy alloys from phase diagram calculations. Calphad 2014, 45, 1-10. [CrossRef]

10. Senkov, O.N.; Miller, J.D.; Miracle, D.B.; Woodward, C. Accelerated exploration of multi-principal element alloys with solid solution phases. Nat. Commun. 2015, 6, 6529. [CrossRef]

11. Senkov, O.N.; Miller, J.D.; Miracle, D.B.; Woodward, C. Accelerated exploration of multi-principal element alloys for structural applications. Calphad 2015, 50, 32-48. [CrossRef]

12. Toda-Caraballo, I.; Wróbel, J.S.; Dudarev, S.L.; Nguyen-Manh, D.; Rivera-Diaz-del-Castillo, P.E.J. Interatomic spacing distribution in multicomponent alloys. Acta Mater. 2015, 97, 156-169. [CrossRef]

13. Owen, L.R.; Pickering, E.J.; Playford, H.Y.; Stone, H.J.; Tucker, M.G.; Jones, N.G. An assessment of the lattice strain in the CrMnFeCoNi high-entropy alloy. Acta Mater. 2017, 122, 11-18. [CrossRef]

14. Huang, P.P.; Yeh, J.W.; Shun, T.T.; Chen, S.K. Multi-Principal-Element Alloys with Improved Oxidation and Wear Resistance for Thermal Spray Coating. Mater. Sic. Forum 2004, 6, 74-78. [CrossRef]

15. Tong, C.J.; Chen, Y.L.; Chen, S.K.; Yeh, J.W.; Shun, T.T.; Tsau, C.H.; Lin, S.J.; Chang, S.Y. Microstructure Characterization of $\mathrm{Al}_{\mathrm{x}} \mathrm{CoCrCuFeNi}$ High-Entropy Alloy System with Multiprincipal Elements. Metal. Mater. Trans. A 2005, 36, 881-893. [CrossRef]

16. Sathiaraj, G.D.; Bhattacharjee, P.P. Effect of cold-rolling strain on the evolution of annealing texture of equiatomic CoCrFeMnNi high entropy alloy. Mater. Charact. 2015, 109, 189-197. [CrossRef]

17. Sathiaraj, G.D.; Bhattacharjee, P.P. Effect of starting grain size on the evolution of microstructure and texture during thermo-mechanical processing of CoCrFeMnNi high entropy alloy. J. Alloys Compd. 2015, 647, 82-96. [CrossRef]

18. Sathiaraj, G.D.; Ahmed, M.Z.; Bhattacharjee, P.P. Microstructure and texture of heavily cold-rolled and annealed fcc equiatomic medium to high entropy alloys. J. Alloys Compd. 2016, 664, 109-119. [CrossRef]

19. Tsai, C.W.; Chen, Y.L.; Tsai, M.H.; Yeh, J.W.; Shun, T.T.; Chen, S.K. Deformation and annealing behaviors of high-entropy alloy Al0.5CoCrCuFeNi. J. Alloys Compd. 2009, 486, 427-435. [CrossRef]

20. Ng, C.; Guo, S.; Luan, J.; Shi, S.; Liu, C.T. Entropy-driven phase stability and slow diffusion kinetics in an Al0.5CoCrCuFeNi high entropy alloy. Intermetallics 2012, 31, 165-172. [CrossRef]

21. Shun, T.T.; Hung, C.H.; Lee, C.F. Formation of ordered/disordered nanoparticles in FCC high entropy alloys. J. Alloys Compd. 2010, 493, 105-109. [CrossRef]

22. Ng, C.; Guo, S.; Luan, J.; Wang, Q.; Lu, J.; Shi, S.; Liu, C.T. Phase stability and tensile properties of Co-free Al0.5CrCuFeNi2 high-entropy alloys. J. Alloys Compd. 2014, 584, 530-537. [CrossRef]

23. Zhang, C.; Zhang, F.; Chen, S.; Cao, W. Computational Thermodynamics Aided High-Entropy Alloy Design. JOM 2012, 64, 839-845. [CrossRef]

24. Chang, S.Y.; Chen, D.S. 10-nm-thick quinary (AlCrTaTiZr)N film as effective diffusion barrier for Cu interconnects at $900{ }^{\circ} \mathrm{C}$. Appl. Phys. Lett. 2009, 94, 231909. [CrossRef]

25. Butler, T.M.; Alfano, J.P.; Martens, R.L.; Weaver, M.L. High-Temperature Oxidation Behavior of Al-Co-Cr$\mathrm{Ni}$-(Fe or Si) multicomponent High-Entropy Alloys. JOM 2014, 16, 246-259. [CrossRef]

26. Lee, D.H.; Seok, M.Y.; Zhao, Y.J.; Choi, I.C.; He, J.; Lu, Z.; Suh, J.Y.; Ramamurty, U.; Kawasaki, M.; Langdon, T.G.; et al. Spherical nanoindentation creep behavior of nanocrystalline and coarse-grained CoCrFeMnNi high-entropy alloys. Acta Mater. 2016, 109, 314-322. [CrossRef]

27. Hsu, C.Y.; Juan, C.C.; Wang, W.R.; Sheu, T.S.; Yeh, J.W.; Chen, S.K. On the superior hot hardness and softening resistance of $\mathrm{AlCoCr}_{x} \mathrm{FeMo}_{0.5} \mathrm{Ni}$ high entropy alloys. Mater. Sci. Eng. A 2011, 528, 3581-3588. [CrossRef]

28. Tsai, K.Y.; Tsai, M.H.; Yeh, J.W. Sluggish diffusion in Co-Cr-Fe-Mn-Ni high-entropy alloys. Acta Mater. 2013, 61, 4887-4897. [CrossRef] 
29. Kulkarni, K.; Chauhan, G.P.S. Investigations of quaternary interdiffusion in a constituent system of high entropy alloys. AIP Adv. 2015, 5, 097162. [CrossRef]

30. Dabrowa, J.; Kucza, W.; Cieślak, G.; Kulik, T.; Danielewski, M.; Yeh, J.W. Interdiffusion in the FCC-structured Al-Co-Cr-Fe-Ni high entropy alloys: Experimental studies and numerical simulations. J. Alloys Compd. 2016, 674, 455-462. [CrossRef]

31. Vaidya, M.; Trubel, S.; Murty, B.S.; Wilde, G.; Divinski, S.V. Ni tracer diffusion in CoCrFeNi and CoCrFeMnNi high entropy alloys. J. Alloys Compd. 2016, 688, 994-1001. [CrossRef]

32. Vaidya, M.; Pradeep, K.G.; Murty, B.S.; Wilde, G.; Divinski, S.V. Radioactive isotopes reveal a non sluggish kinetics of grain boundary diffusion in high entropy alloys. Sci. Rep. UK 2017, 7, 12293. [CrossRef] [PubMed]

33. Verma, V.; Tripathi, A.; Kulkarni, K.N. On Interdiffusion in FeNiCoCrMn High Entropy Alloy. J. Phase Equilib. Diff. 2017, 38, 445-456. [CrossRef]

34. Zhang, C.; Zhang, F.; Jin, K.; Bei, H.; Chen, S.; Cao, W.; Zhu, J.; Lv, D. Understanding of the Elemental Diffusion Behavior in Concentrated Solid Solution Alloys. J. Phase Equilib. Diff. 2017, 38, 434-444. [CrossRef]

35. Chen, W.; Zhang, L. High-Throughput Determination of Interdiffusion Coefficients for Co-Cr-Fe-Mn-Ni High-Entropy Alloys. J. Phase Equilib. Diff. 2017, 38, 457-465. [CrossRef]

36. Li, Q.; Chen, W.; Zhong, J.; Zhang, L.; Chen, Q.; Liu, Z. On Sluggish Diffusion in Fcc Al-Co-Cr-Fe-Ni High-Entropy Alloys: An Experimental and Numerical Study. Metals 2018, 8, 16. [CrossRef]

37. Wang, R.; Chen, W.; Zhong, J.; Zhang, L. Experimental and numerical studies on the sluggish diffusion in face-centered cubic Co-Cr-Cu-Fe-Ni high-entropy alloys. J. Mater. Sci. Technol. 2018, 34, 1791-1798. [CrossRef]

38. Chen, S.; Li, Q.; Zhong, J.; Xing, F.; Zhang, L. On diffusion behaviors in face centered cubic phase of Al-Co-Cr-Fe-Ni-Ti high-entropy superalloys. J. Alloys Compd. 2019, 791, 255-264. [CrossRef]

39. Vaidya, M.; Pradeep, K.G.; Murty, B.S.; Wilde, G.; Divinski, S.V. Bulk tracer diffusion in CoCrFeNi and CoCrFeMnNi high entropy alloys. Acta Mater. 2018, 146, 211-224. [CrossRef]

40. Gaertner, D.; Kottke, J.; Wilde, G.; Divinski, S.V.; Chumlyakov, Y. Tracer diffusion in single crystalline CoCrFeNi and CoCrFeMnNi high entropy alloys. J. Mater. Res. 2018, 33, 3184-3191. [CrossRef]

41. Kottke, J.; Laurent-Brocq, M.; Fareed, A.; Gaertner, D.; Perriere, L.; Rogal, Ł.; Divinski, S.V.; Wilde, G. Tracer diffusion in the Ni-CoCrFeMn system: Transition from a dilute solid solution to a high entropy alloy. Scr. Mater. 2018, 159, 94-98. [CrossRef]

42. Vaidya, M.; Mohan Muralikrishna, G.; Divinski, S.V.; Murty, B.S. Experimental assessment of the thermodynamic factor for diffusion in CoCrFeNi and CoCrFeMnNi high entropy alloys. Scr. Mater. 2018, 157, 81-85. [CrossRef]

43. Gaertner, D.; Abrahams, K.; Kottke, J.; Esin, V.A.; Steinbach, I.; Wilde, G.; Divinski, S.V. Concentration-dependent atomic mobilities in FCC CoCrFeMnNi high-entropy alloys. Acta Mater. 2019, 166, 357-370. [CrossRef]

44. Kucza, W.; Dąbrowa, J.; Cieślak, G.; Berent, K.; Kulik, T.; Danielewski, M. Studies of “sluggish diffusion” effect in $\mathrm{Co}-\mathrm{Cr}-\mathrm{Fe}-\mathrm{Mn}-\mathrm{Ni}$, Co-Cr-Fe-Ni and $\mathrm{Co}-\mathrm{Fe}-\mathrm{Mn}-\mathrm{Ni}$ high entropy alloys; determination of tracer diffusivities by combinatorial approach. J. Alloys Compd. 2018, 731, 920-928. [CrossRef]

45. Dąbrowa, J.; Zajusz, M.; Kucza, W.; Cieślak, G.; Berent, K.; Czeppe, T.; Kulik, T.; Danielewski, M. Demystifying the sluggish diffusion effect in high entropy alloys. J. Alloys Compd. 2019, 783, 193-207. [CrossRef]

46. Paul, A. Comments on "Sluggish diffusion in Co-Cr-Fe-Mn-Ni high-entropy alloys" by Tsai, K.Y.; Tsai, M.H.; Yeh, J.W. Acta Mater. 2013, 61, 4887-4897, Scr. Mater. 2017, 135, 153-157.

47. Tsai, K.Y.; Tsai, M.H.; Yeh, J.W. Reply to comments on "Sluggish diffusion in Co-Cr-Fe-Mn-Ni high-entropy alloys" by Tsai, K.Y.; Tsai, M.H.; Yeh, J.W. Acta Mater. 2017, 61, 4887-4897. [CrossRef]

48. Beke, D.L.; Erdélyi, G. On the diffusion in high-entropy alloys. Mater. Lett. 2016, 164, 111-113. [CrossRef]

49. Allnatt, A.R.; Paul, T.R.; Belova, I.V. A high accuracy diffusion kinetics formalism for random multicomponent alloys: Application to high entropy alloys. Philos. Mag. 2016, 96, 2969-2985. [CrossRef]

50. Paul, T.R.; Belova, I.V.; Murch, G.E. Analysis of diffusion in high entropy alloys. Mater. Chem. Phys. 2018, 210, 301-308. [CrossRef]

51. Divinski, S.V.; Pokoev, A.V.; Esakkiraja, N.; Paul, A. A Mystery of “Sluggish Diffusion” in High-Entropy Alloys: The Truth or a Myth? Diff. Fund. 2018, 17, 69-104. [CrossRef] 
52. Huang, E.W.; Chou, H.S.; Tu, K.N.; Hung, W.S.; Lam, T.N.; Tsai, C.W.; Chiang, C.Y.; Lin, B.H.; Yeh, A.N.; Chang, S.H.; et al. Elements Effects on High-Entropy Alloy Vacancy and Heterogenous Lattice Distortion Subjected to Quasi-equilibrium Heating. Sci. Rep. 2019, 9, 14788. [CrossRef]

53. Pickering, E.J.; Munoz-Moreno, R.; Stone, H.J.; Jones, N.G. Precipitation in the equiatomic high-entropy alloy CrMnFeCoNi. Scr. Mater. 2016, 113, 106-109. [CrossRef]

54. Otto, F.; Dlouhý, A.; Pradeep, K.G.; Kubĕnová, M.; Raabe, D.; Egeler, G.; George, E.P. Decomposition of the single-phase high-entropy alloy $\mathrm{CrMnFeCoNi}$ after prolonged anneals at intermediate temperatures. Acta Mater. 2016, 112, 40-52. [CrossRef]

55. Takeuchi, A.; Inoue, A. Mixing enthalpy of liquid phase calculated by Miedema's scheme and approximated with sub-regular solution model for assessing forming ability of amorphous and glassy alloys. Intermetallics 2010, 18, 1779-1789. [CrossRef]

56. Kirkaldy, J.S. Diffusion in Multicomponent Metallic Systems. Can. J. Phys. 1957, 35, 435-440. [CrossRef]

57. Neumann, G.; Tuijn, C. Self-Diffusion and Impurity Diffusion in Pure Metals: Handbook of Experimental Data, 1st ed.; Elsevier: Oxford, UK, 2009.

58. Rothman, S.J.; Nowicki, L.J.; Murch, G.E. Self-diffusion in austenitic Fe-Cr-Ni alloys. J. Phys. F Met. Phys. 1980, 10, 383-398. [CrossRef]

59. Swalin, R.A. Thermodynamics of Solids, 2nd ed.; John Wiley \& Sons: New York, NY, USA, 1972.

60. Paul, A. A pseudobinary approach to study interdiffusion and the Kirkendall effect in multicomponent systems. Philos. Mag. 2013, 93, 2297-2315. [CrossRef]

61. Santra, S.; Paul, A. Estimation of intrinsic diffusion coefficients in a pseudo-binary diffusion couple. Scr. Mater. 2015, 103, 18-21. [CrossRef]

62. Manning, J.R. Cross Terms in the Thermodynamic Diffusion Equations for Multicomponent Alloys. Metall. Trans. 1970, 1, 499-505. [CrossRef]

63. Dayananda, M.A.; Sohn, Y.H. A new analysis for the determination of ternary interdiffusion coefficients from a single diffusion couple. Metall. Mater. Trans. A 1998, 30, 535-543. [CrossRef]

64. Kucza, W. A combinatorial approach for extracting thermo-kinetic parameters from diffusion profiles. Scr. Mater. 2012, 66, 151-154. [CrossRef]

65. Hultgren, R.; Desai, P.D.; Hawkins, D.T.; Gleiser, M.; Wagman, D.D. Selected Values of the Thermodynamic Properties of Binary Alloys, 1st ed.; ASM: Metals Park, OH, USA, 1973.

66. Dench, D.A. Adaibatic High-Temperature Calorimetr for the Measurement of Heats of Alloying. Trans. Faraday Soc. 1963, 59, 1279-1292. [CrossRef]

67. Colinet, C.; Pasturel, A.; Hictor, P. Trends in Cohesive Energy of Transition Metal Alloys. Calphad 1985, 9, 71-99. [CrossRef]

68. Mazandarany, F.N.; Pehelke, R.D. Thermodynamic Properties of Solid Alloys of Chromium with Nickel and Iron. Metall. Trans. 1973, 4, 2067-2076. [CrossRef]

69. Eremenko, V.N.; Lukaschenko, G.M. Thermodynamic Properties of Alloys of Manganese with Transition Metals of the Fourth Period- Chromium, Iron, Cobalt, Nickel and with Copper. Russ. J. Phys. Chem. 1968, 42, 343-346.

70. Boer, F.R.D.; Boom, R.; Miedema, A.R. Enthalpies of Formation of Liquid and Solid Binary Alloys Based on 3d Metals. Phys. B 1982, 113, 18-41. [CrossRef]

71. Ram-Mohan, L.R.; Dayananda, M.A. A Transfer Matrix Method for the Calculation of Concentrations and Fluxes in Multicomponent Diffusion Couples. Acta Mater. 2006, 54, 2325-2334. [CrossRef]

72. Redlich, O.; Kister, A.T. Algebraic Representation of Thermodynamic Properties and the Classification of Solutions. Ind. Eng. Chem. 1948, 40, 345-348. [CrossRef]

73. Chen, W.; Zhong, J.; Zhang, L. A Pragmatic Method to Determine the Composition-Dependent Interdiffusivities in Ternary Systems by Using a Single Diffusion Couple. Scr. Mater. 2014, 90-91, 53-56. [CrossRef]

74. Belova, I.V.; Murch, G.E. Comments on "Experimental assessment of the thermodynamic factor for diffusion in CoCrFeNi and CoCrFeMnNi high entropy alloys. " Scr. Mater. 2019, 172, 110-112. [CrossRef]

75. Belova, I.V.; Sohn, Y.H.; Murch, G.E. Measurement of tracer diffusion coefficients in an interdiffusion context for multicomponent alloys. Philos. Mag. Lett. 2015, 95, 416-424. [CrossRef] 
76. Darken, L.S. Diffusion, Mobility and Their Interrelation through Free Energy in Binary Systems. Trans. Am. Inst. Min. Metall. Eng. 1948, 175, 184-201.

77. Paul, T.R.; Belova, I.V.; Murch, G.E. Random alloy diffusion kinetics for the application to multicomponent alloy systems. Philos. Mag. 2016, 96, 1228-1244. [CrossRef]

(C) 2020 by the authors. Licensee MDPI, Basel, Switzerland. This article is an open access article distributed under the terms and conditions of the Creative Commons Attribution (CC BY) license (http://creativecommons.org/licenses/by/4.0/). 